Finite Element Glacier Dynamics Model Applied to Columbia Glacier, Alaska
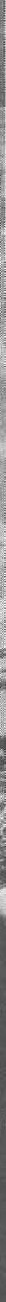



\section{Finite Element Glacier Dynamics Model Applied to Columbia Glacier, Alaska}

By W. G. SIKONIA

STUDIES OF COLUMBIA GLACIER, ALASKA

GEOLOGICAL SURVEY PROFESSIONAL PAPER 1258-B

Description of a computer model indicating

that Columbia Glacier will begin

a rapid, catastrophic retreat in 1983

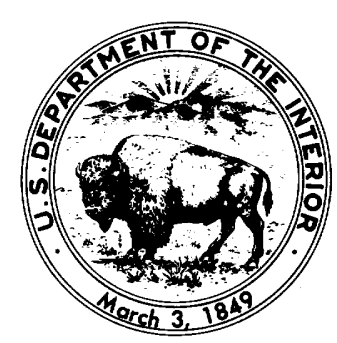

UNITED STATES GOVERNMENT PRINTING OFFICE, WASHINGTON:1982 


\section{UNITED STATES DEPARTMENT OF THE INTERIOR}

JAMES G. WATT, Secretary

GEOLOGICAL SURVEY

Dallas L. Peck, Director

Library of Congress catalog-card No. 81-607563

For sale by the Superintendent of Documents, U.S. Government Printing Office Washington, D.C. 20402 


\section{CONTENTS}

$\begin{array}{lr}\text { Symbols and abbreviations } & \text { Page } \\ \text { Abstract } & \text { BIV } \\ \text { Introduction } & 1 \\ \text { The finite element model } & 1 \\ \text { Calving law -- } & \\ \text { Modeling Columbia Glacier } & \\ \text { References cited }\end{array}$

\section{ILLUSTRATIONS}

Figure 1. Index map of Columbia Glacier, Alaska

2. Graph showing calving law

3. Contour map showing flow line used in modeling

4. Finite element grid

5. Flow-line profiles showing projected Columbia Glacier behavior

6-9. Graphs showing:

6. Terminus position in time

7. Unsupported height at the terminus, in time

8. Surface horizontal speed at flow line

9. Rate of iceberg production

Page

BIV

1

1

3

5

28

\section{TABLES}

TABLE 1. Calving law data

2. Flow-line data

\section{APPENDIXES}

APPEndix A. Mathematics

Tangent stiffness matrix

Upper free-surface dynamics

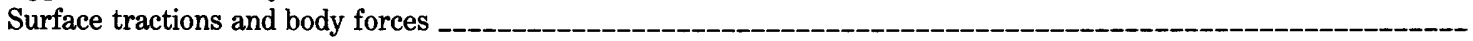

Updating the mesh

Future modification

B. User instructions for the computer program

Coordinate data

Material property data

Boundary restraint data

Nodal forced boundary data

Nodal temperature data

TANF macroinstruction

REST and SAVE macroinstructions

UPNO macroinstruction

PLOT macroinstruction

C. New subroutines

D. Modifications of the general purpose finite element program

E. Sample run 


\section{SYMBOLS AND ABBREVIATIONS}
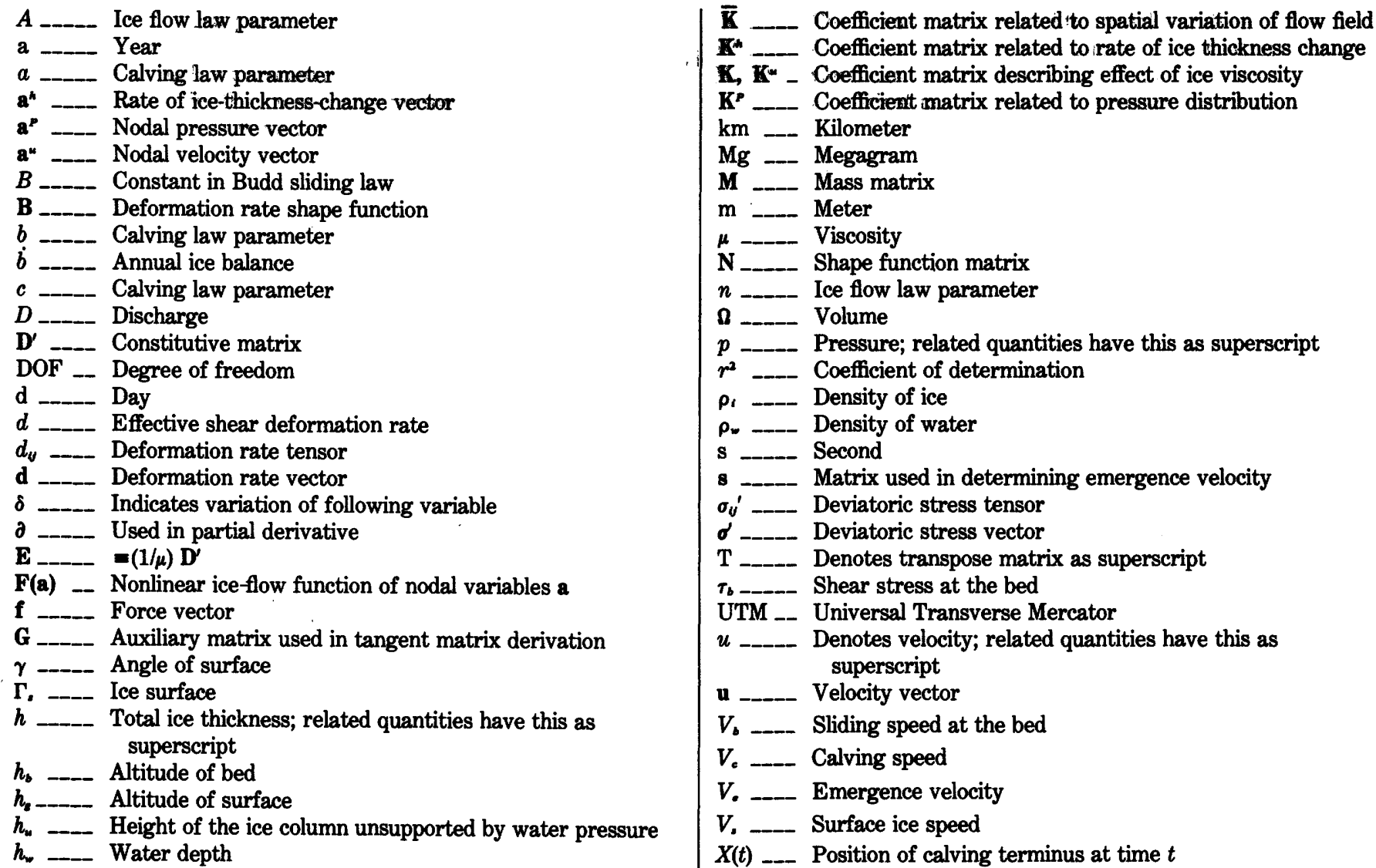


\title{
FINITE ELEMENT GLACIER DYNAMICS MODEL APPLIED TO COLUMBIA GLACIER, ALASKA
}

\author{
By W. G. SiKONIA
}

\begin{abstract}
A two-dimensional finite element computer model describes the dynamics of glacier flow and includes the flow of ice, sliding, calving, and surface balance. Surface profile and terminus position are followed in time. A calving law that relates calving speed to water discharge at the bed of the glacier and to the height of the ice column unsupported by water pressure is shown to fit observed calving at Columbia Glacier. Application of the flow model to Columbia Glacier indicates that catastrophic, rapid retreat from the terminal moraine will begin in 1983 . This will produce an increase in the production of icebergs that can drift into oil tanker lanes to and from Valdez, Alaska.
\end{abstract}

\section{INTRODUCTION}

Columbia Glacier, Alaska (fig. 1), is in a state precariously close to catastrophic retreat (Post, 1975; Meier and others, 1978; Sikonia and Post, 1980; Meier and others, 1980a, b). A dynamic model of glacier behavior was sought that could adequately represent at least the lowest $14 \mathrm{~km}$ of the glacier; the model must be capable of dealing with a large amount of sliding, with flow up a . terminal moraine, and with a moving calving face. Bindschadler applied a one-dimensional model (Bindschadler, 1978; Meier and others, 1980b), but it seems questionable whether the approximations of the model adequately represent reality near the calving face, especially with regard to surface-slope averaging schemes and longitudinal stresses.

\section{THE FINITE ELEMENT MODEL}

The two-dimensional finite element model described in this paper is an attempt to relate more adequately the motion of the ice mass to the physical processes involved. However, the two-dimensional nature of the model dictates that it also is an idealization of reality. The model represents a vertical cross section through a glacier along a central flow line, but no attempt has been made yet to include effects of lateral shear stresses or lateral deformation rates.
The ice flow law describing the deformational contribution to ice motion is

$$
d_{i j}=A \tau^{n-1} \sigma^{\prime}{ }_{i},
$$

where $d_{i j}$ is the deformation rate tensor; $\sigma_{i j}^{\prime}$, the deviatoric stress tensor; $\tau$, the effective shear stress defined by

$$
\tau=\left(1 / 2 \sigma^{\prime} \sigma^{\prime}{ }_{i j}\right)^{1 / 2}
$$

(summation convention on subscripts $i, j$ ); and $A$ and $n$ are constants, with approximate values of

$$
A=0.140 \text { bar }^{-n} a^{-1} \text { and } n=3 \text {. }
$$

Sliding is modeled as a layer of very soft ice (large valued $A$ ) along the bed. In the Columbia Glacier application, the layer is assumed to be a constant $10 \mathrm{~m}$ thick, with $n=3$ and $A$ ranging from 7 to $40 \mathrm{bar}^{-n} \mathrm{a}^{-1}$, fitted along the bed so that the correct sliding is obtained to match measured surface velocities. This is approximately equivalent to use of a sliding law suggested by Budd and others (1979) in the form

$$
V_{b}=B \tau_{b}{ }^{n} / h_{u} \text {. }
$$

Here $V_{b}$ is the sliding speed on the bed; $B$, a constant perhaps approximately $1,800 \mathrm{~m}^{2} \mathrm{a}^{-1} \mathrm{bar}^{-n}$ for $n=3 ; \tau_{b}$, the shear stress at the bed; and $h_{u}$, the ice-column height unsupported by water pressure

$$
h_{u}=h-h_{w} \rho_{w} / \rho_{i},
$$

where $h$ is total ice depth; $h_{w}$, water depth; and $\rho_{w}, \rho_{l}$, the densities of water and ice, respectively. Bindschadler (written commun., 1978) found that this sliding law fits Variegated Glacier, Alaska, data.

The solution proceeds in a sequence of time steps. At each step, equilibrium iterations using Newton's method are done first to produce consistent stress-velocity fields described by the nonlinear equation 1 . By using the velocity field, the surface and calving front then are projected to new positions, and the process stepped in time. 


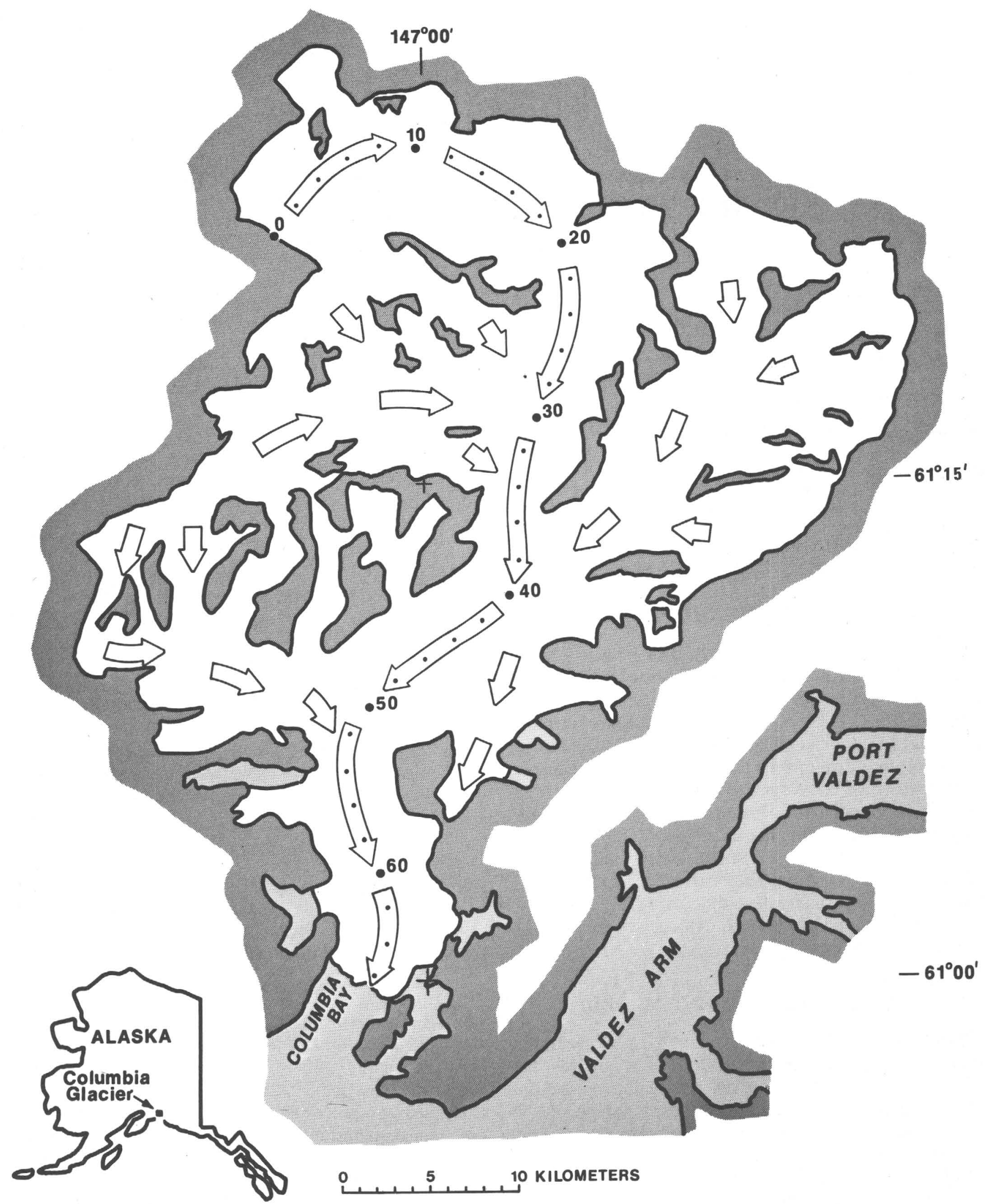

FIGURE 1.-Index map of Columbia Glacier, Alaska. Arrows show direction of flow. Main ice stream is indicated by longer arrows and dots at $2-\mathrm{km}$ intervals along the longitudinal coordinate system. 
The finite element framework for the computer program is a general purpose program (Taylor, 1980; Zienkiewicz, 1977, p. 733). Velocity and pressure are chosen as the variables, and the treatment follows that of Zienkiewicz (1977, p. 612) except that, for ice, the viscosity, $\mu$, is not constant but is rather a function of the effective shear stress,

$$
\mu=1 /\left(2 A \tau^{n-1}\right) \text {. }
$$

Also, kinetic effects can be ignored because of the slow creep of ice. Because the viscosity is nonconstant, the equations are nonlinear, and the tangent stiffness matrix for use in Newton-Raphson iteration takes the appropriate derivatives of viscosity into account. Other finite element programs with a similar approach are attributable to Schmidt (1977), Raymond (1978), and Hooke and others (1980), but these treat only geometrically static, purely creeping flow. The program described in this paper treats deformational motion, sliding, balance, and calving effects in a geometrically dynamic setting. It also starts with a good, readily available general purpose finite element framework; the advantage of this approach is that only the specific program modules directly concerned with the glacier dynamics need be considered, greatly simplifying programing, documentation, and orientation of new users.

To take into account the dynamics, the movement of the upper free surface must be followed. This surface is followed essentially as in Zienkiewicz (1977, p. 623); the free surface must be projected along the surface velocity vectors to its new position. The program makes this projection by defining an auxiliary variable-the vertical surface speed-decomposing the surface velocity into general nonorthogonal components along the surface and in the vertical direction. In addition to the movement of the upper free surface, the movement of the calving face is projected from one time step to the next by using the calving law described in the section on "Calving Law." Because of large changes in the configuration of the ice mass, the entire mesh must be reconstructed at each time step.

\section{CALVING LAW}

The position of the calving terminus, $X(t)$ (assumed vertical), in time is determined by the imbalance between the horizontal surface ice speed, $V_{s}$, at the terminus (positive downglacier) and the calving speed, $V_{c}$ (positive upglacier),

$$
X=V_{s}-V_{c} \text {. }
$$

Alternatively, equation 7 defines calving speed, $V_{c}$, as the rate of retreat of the calving terminus in the moving ice stream. A calving law relating calving speed linearly to water depth has been suggested (Meier and others, $1980 \mathrm{~b})$. The suggested water-depth law was restricted to yearly averaged data that was averaged also across the width of the glacier. It definitely does not apply for intervals of less than a year for calving at a single location on the terminus. When applied to the calving of Columbia Glacier at the head of the embayment, by using photogrammetrically determined terminus positions taken at approximately 2-month intervals from July 24, 1976 , to September 2,1980, the water-depth law yields a coefficient of determination, $r^{2}$, of only 0.08 . However, for Columbia Glacier, calving speed appears to be related to water discharge at the bed (Sikonia and Post, 1980). A law that does appear to fit the observed intrayearly calving at Columbia Glacier is (see also fig. 2 and table 1)

$$
V_{c}=a D^{b} h_{u}{ }^{c}
$$

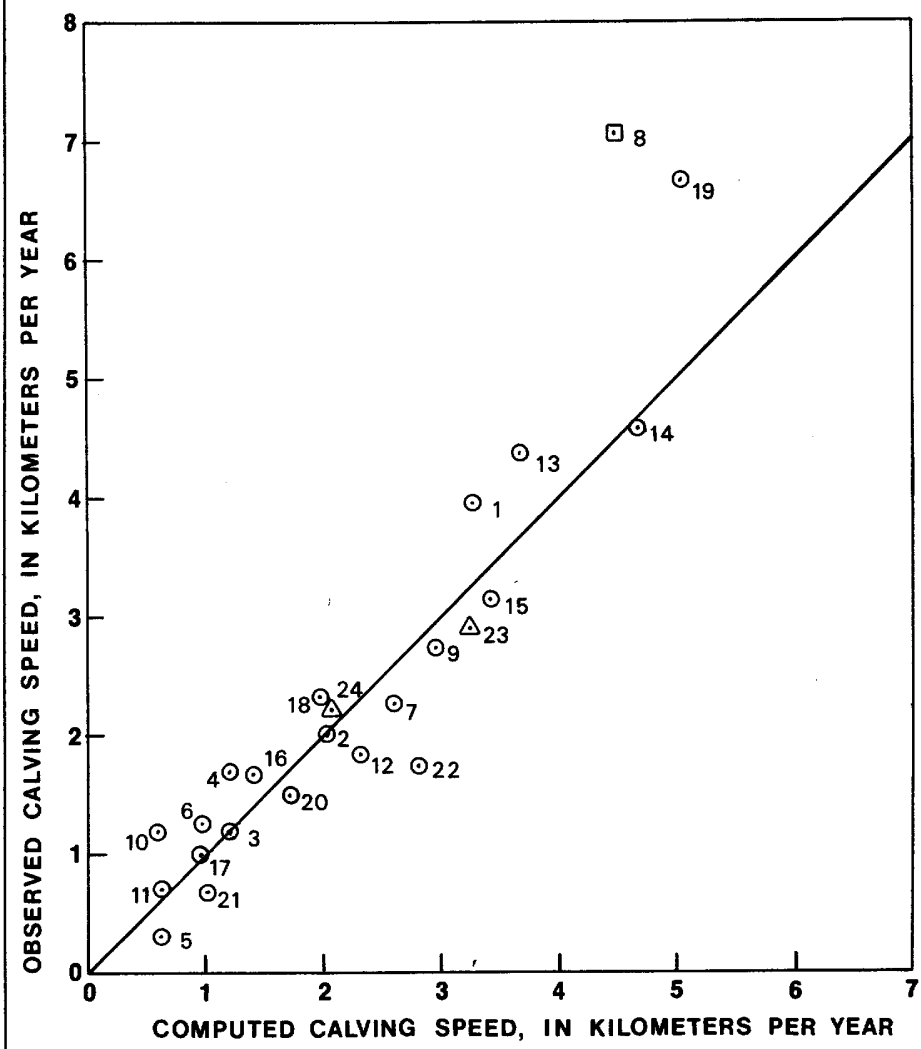

Figure 2.-Calving law $V_{c}=a D^{b} h_{n}{ }^{c}$, where $a=1.092 \times 10^{3}(\mathrm{~km} / \mathrm{a})$ $\left(\mathrm{m}^{3} / \mathrm{s}\right)^{-b} \mathrm{~m}^{-c}, b=0.5689$, and $c=-2.175 . V_{c}$ is speed of calving at the head of the embayment, $D$ is the discharge of the Knik River, and $h_{w}$ is the height of the unsupported ice column. The data points, as given in table 1 , were determined from analysis of aerial photographs. Point 8 corresponds to a time interval during which Kadin Lake suddenly released a large volume of water into the subglacial flow; in this interval, the Knik River discharge would not correlate well with this flow. Points 8,23 , and 24 were not used in the regression that fitted the constants $a, b$, and $c$. 
TABLE 1.-Calving law data

[ $N$, data interval number. $t_{1}$ and $t_{2}$, beginning and ending dates of interval. $\Delta t$, number of days in the interval. $h_{t 1}$ and $h_{t 2}$, ice-cliff heights at head of embayment at times $t_{1}$ and $t_{2}$, respectively. $h_{w 1}$ and $h_{w 2}$, water depths at head of embayment at times $t_{1}$ and $t_{2}$, respectively. $D$, average discharge of Knik River during interval. $h_{w 1}$ average unsupported height during interval. $\left(V_{c}\right)_{\circ}$ and $\left(V_{c}\right)_{c}$, observed and calculated calving speeds at head of embayment. $\Delta V_{c}$, difference between calculated and observed calving speed. Calculated speed is based on the calving law $\left.V_{c}=a D^{b} h^{c}\right]$

\begin{tabular}{|c|c|c|c|c|c|c|c|c|c|c|c|c|}
\hline$N$ & $t_{1}$ & $t_{2}$ & $\begin{array}{l}\Delta t \\
\text { (d) }\end{array}$ & $\begin{array}{l}h_{\mathrm{r} 1} \\
(\mathrm{~m})\end{array}$ & $\begin{array}{l}h_{y^{2}} \\
(\mathrm{~m})\end{array}$ & $\begin{array}{l}h_{m 1} \\
(\mathrm{~m})\end{array}$ & $\begin{array}{l}h_{w 2} \\
(\mathrm{~m})\end{array}$ & $\underset{\left(\mathrm{m}^{3 / \mathrm{s}}\right)}{D}$ & $\begin{array}{l}h_{m} \\
(\mathrm{~m})\end{array}$ & $\begin{array}{l}\left(V_{c}\right)_{0} \\
(\mathrm{~m} / \mathrm{a})\end{array}$ & $\begin{array}{l}\left(V_{c o}\right)_{c} \\
(\mathrm{~m} / \mathrm{a})\end{array}$ & $\begin{array}{c}\Delta V_{\mathrm{c}} \\
(\mathrm{m} / \mathrm{a})\end{array}$ \\
\hline 1 & $07 / 24 / 76$ & $10 / 01 / 76$ & 69 & 98 & 86 & 127 & 180 & 464.65 & 71.87 & 3,964 & 3,293 & -671 \\
\hline $2 \ldots$ & $10 / 01 / 76$ & $11 / 17 / 76$ & 47 & 86 & 86 & 180 & 175 & 119.82 & 62.73 & 2,008 & 2,047 & 39 \\
\hline 3 & $11 / 17 / 76$ & $01 / 19 / 77$ & 63 & 86 & 88 & 163 & 146 & 59.96 & 66.74 & 1,190 & 1,207 & 17 \\
\hline 4 & $01 / 19 / 77$ & $03 / 07 / 77$ & 47 & 85 & 89 & 155 & 142 & 63.45 & 67.53 & 1,697 & 1,215 & -482 \\
\hline 5 & $03 / 07 / 77$ & $04 / 23 / 77$ & 47 & 88 & 94 & 137 & 100 & 30.68 & 75.46 & 307 & 631 & 324 \\
\hline 6 & $04 / 23 / 77$ & $06 / 02 / 77$ & 40 & 94 & 100 & 100 & 80 & 110.07 & 85.20 & 1,259 & 1,002 & -257 \\
\hline 7 & $06 / 02 / 77$ & $07 / 07 / 77$ & 35 & 99 & 95 & 80 & 109 & 486.96 & 84.61 & 2,256 & 2,371 & 115 \\
\hline 8 & $07 / 07 / 77$ & $08 / 29 / 77$ & 53 & 93 & 99 & 102 & 278 & 765.94 & 71.09 & 7,059 & 4,481 & $-2,578$ \\
\hline 9 & $08 / 29 / 77$ & $11 / 08 / 77$ & 71 & 100 & 78 & 200 & 200 & 231.72 & 62.78 & 2,738 & 2,974 & 236 \\
\hline 10 & $11 / 08 / 77$ & $02 / 28 / 78$ & 112 & 81 & 97 & 170 & 125 & 21.12 & 69.66 & 1,175 & 607 & -568 \\
\hline 11 & $02 / 28 / 77$ & $04 / 19 / 78$ & 50 & 96 & 84 & 125 & 112 & 30.90 & 74.46 & 712 & 652 & -60 \\
\hline 12 & $04 / 19 / 78$ & $06 / 11 / 78$ & 53 & 68 & 81 & 110 & 113 & 126.76 & 59.88 & 1,832 & 2,339 & 509 \\
\hline $13 \ldots$ & $06 / 11 / 78$ & $07 / 30 / 78$ & 49 & 80 & 94 & 112 & 177 & 460.50 & 68.05 & 4,362 & 3,689 & -673 \\
\hline 14 & $07 / 30 / 78$ & $08 / 26 / 78$ & 27 & 90 & 90 & 160 & 182 & 684.48 & 67.58 & 4,588 & 4,692 & 104 \\
\hline 15 & $08 / 26 / 78$ & $11 / 08 / 78$ & 74 & 92 & 77 & 185 & 210 & 230.27 & 58.61 & 3,150 & 3,442 & 292 \\
\hline 16 & $11 / 08 / 78$ & $01 / 06 / 79$ & 59 & 72 & 76 & 215 & 182 & 22.46 & 47.97 & 1,657 & 1,415 & -242 \\
\hline 17 & $01 / 06 / 79$ & $04 / 12 / 79$ & 96 & 72 & 77 & 182 & 140 & 17.36 & 53.39 & 1,004 & 969 & -35 \\
\hline 18 & $04 / 12 / 79$ & 08/18/79 & 128 & 93 & 111 & 85 & 135 & 412.75 & 87.58 & 2,318 & 2,002 & -316 \\
\hline 19 & $08 / 18 / 79$ & $10 / 20 / 79$ & 63 & 70 & 76 & 82 & 195 & 350.34 & 54.84 & 6,669 & 5,049 & $-1,620$ \\
\hline 20 & $10 / 20 / 79$ & $02 / 29 / 80$ & 132 & 77 & 75 & 195 & 167 & 44.71 & 52.27 & 1,478 & 1,737 & 259 \\
\hline 21 & $02 / 29 / 80$ & $05 / 12 / 80$ & 73 & 74 & 90 & 167 & 130 & 35.61 & 62.53 & 683 & 1,034 & 351 \\
\hline 22 & $05 / 12 / 80$ & $07 / 22 / 80$ & 71 & 80 & 101 & 110 & 137 & 390.94 & 74.31 & 1,748 & 2,775 & 1,027 \\
\hline $23 \ldots$ & $07 / 22 / 80$ & $09 / 02 / 80$ & 42 & 92 & 89 & 90 & 118 & 587.54 & 76.86 & 2,880 & 3,252 & 372 \\
\hline 24 & $09 / 02 / 80$ & $10 / 30 / 80$ & 58 & 91 & 85 & 110 & 133 & 207.33 & 72.07 & 2,205 & 2,068 & -137 \\
\hline
\end{tabular}

$V_{c}$ is the calving speed at the head of the embayment, and $h_{u}$ is the ice column height unsupported by water pressure, as defined in equation 5 . The variable $D$ would most appropriately be the actual discharge at the bed of the Columbia Glacier, but because actual discharge would be almost impossible to measure, a related discharge, that of nearby Knik River, was used instead (see Sikonia and Post, 1980). Constants $a, b$, and $c$ have fitted values as follows:

$$
\begin{aligned}
& a=1.092 \times 10^{6}(\mathrm{~m} / \mathrm{a})\left(\mathrm{m}^{3} / \mathrm{s}\right)^{-b} \mathrm{~m}^{-c}, \\
& b=0.5689, \\
& c=-2.175, \\
& \quad \rho_{w}=1.018 \mathrm{Mg} / \mathrm{m}^{3}, \\
& \rho_{i}=0.900 \mathrm{Mg} / \mathrm{m}^{3} .
\end{aligned}
$$

The standard error for the Columbia data is $529 \mathrm{~m} / \mathrm{a}$ (in calving speeds ranging from 307 to $4,588 \mathrm{~m} / \mathrm{a}$ ), with a coefficient of determination of the logarithmically derived corresponding linear regression problem of $r^{2}=0.83$. (Although $1.018 \mathrm{Mg} / \mathrm{m}^{3}$ is the measured density of seawater in front of Columbia Glacier, the modeling computer runs (see section entitled "Modeling Columbia Glacier") actually were made by using $\rho_{w}=1.000 \mathrm{Mg} / \mathrm{m}^{3}$ and $\rho_{i}=0.900 \mathrm{Mg} / \mathrm{m}^{3}$. In this case, $a=1.798 \times 10^{6}$ $(\mathrm{m} / \mathrm{a})\left(\mathrm{m}^{3} / \mathrm{s}\right)^{-b} \mathrm{~m}^{-c}, b=0.5510, c=-2.239, r^{2}=0.83$, and the standard error was $369 \mathrm{~m} / \mathrm{a}$, based on fewer data points than the constants in equation 9 because of limited data availability at the time. It was not considered worth rerunning the program for these minor changes in constants.) 
It is uncertain exactly what the relation between the discharge-unsupported height calving law and the water-depth law is, but there appear to be at least three possibilities:

1. One or the other law is wrong.

2. Some, as yet, not understood process averages the above law into the water-depth law for time periods of a year or longer.

3. The two laws are describing two, as yet, undistinguished distinct calving processes.

The discharge-unsupported height law is used in this study for reasons discussed in this section. This law also accommodates the observation that embayments form at the location of the main water discharge from the terminus and supports the physical idea that the closer the terminus is to floating, the more easily this discharge can bring about calving and ice removal from the face.

\section{MODELING COLUMBIA GLACIER}

The finite element model was applied to the lowest 14 $\mathrm{km}$ of Columbia Glacier to gain a better understanding of its possible future behavior (see also figs. 3 and 4 and table 2). The constant $a$ in the calving law is too large for an idealized two-dimensional glacier; it produces an immediate catastrophic retreat, from the starting modeling date 1978.150, that has not occurred on the real glacier. This is understandable because embayments and related surface lowering are filled partly by flow from the sides, a factor which the two-dimensional model does not take into account. Also there is an "archbridging" stress effect within the ice around an embayment that could partly support the ice cliff at the head of the embayment, thus providing a larger unsupported height, $h_{u}$, and a smaller calving speed, $V_{c}$. This effect also is not taken into account in the two-dimensional model. An a corresponding to width-averaged calving is needed. Rather than trying to derive the averaging effect, the exponents $b$ and $c$ were fixed, and the $a$ parameter adjusted for the two-dimensional glacier to produce future behavior that seems reasonable in view of the actual configuration of the glacier from early 1978 to the present.

Future behavior is extremely sensitive to changes in the $a$ parameter. For example, $a=1168750$ produced a collapse that could not be followed with a time step of 0.025 year by 1982.075 ; the terminus had retreated $2,285 \mathrm{~m}$ by 1982.025 . Decreasing $a$ by only 0.27 percent to $a=1165625$ extended extremely rapid collapse to 1984.600 , the terminus retreating $3,031 \mathrm{~m}$ by 1984.525 . Decreasing $a$ by another 0.27 percent to $a=1162500$ produced a gradual advance to the crest of the terminal moraine by 1982.400 (see also figs. 5, 6, 7, 8, and 9). The modeling also showed that a collapse is preceded by thinning of the glacier to the point that the unsupported height factor, $h_{u}$, of the calving law is small enough to produce a large calving speed when applied in equation 8 ; for example, $h_{x}=7 \mathrm{~m}$ at the terminus, time 1982.250 and $a=1168750$.

The sensitivity of the glacier's behavior to the $a$ parameter may be overstated or at least compressed in time scale because of the two-dimensional idealization, but, nevertheless, the behavior of the real glacier is probably still quite dependent on relatively small changes in the calving. As indicated by the calving law, for the real glacier, decreased calving that would stall collapse could be brought about by low runoff or by outlet of the major discharge at a location having a relatively high ice cliff and shallow water depth. Reference to figure 7 shows that $h_{u}$ was relatively large in 1980 , and, as indicated on figure 6 , the retreat was, indeed, slowed that year. However, heavy rains in July and August 1981, together with a partial outburst of Kadin Lake, produced a large discharge that caused a large embayment to form. The data presented in figure 6 show that the observed terminus position is following again the retreat predicted by the model using $a=1165625$ and that the indicated collapse of Columbia Glacier is imminent. 
TABLE 2. -Flow-line data

[Col., column number. Easting and Northing, UTM coordinates. $h_{t}$, ice surface altitude. $h_{b}$, bed altitude. $b$, annual balance. $V_{n}$, surface speed. $h$, annual surface altitude change]

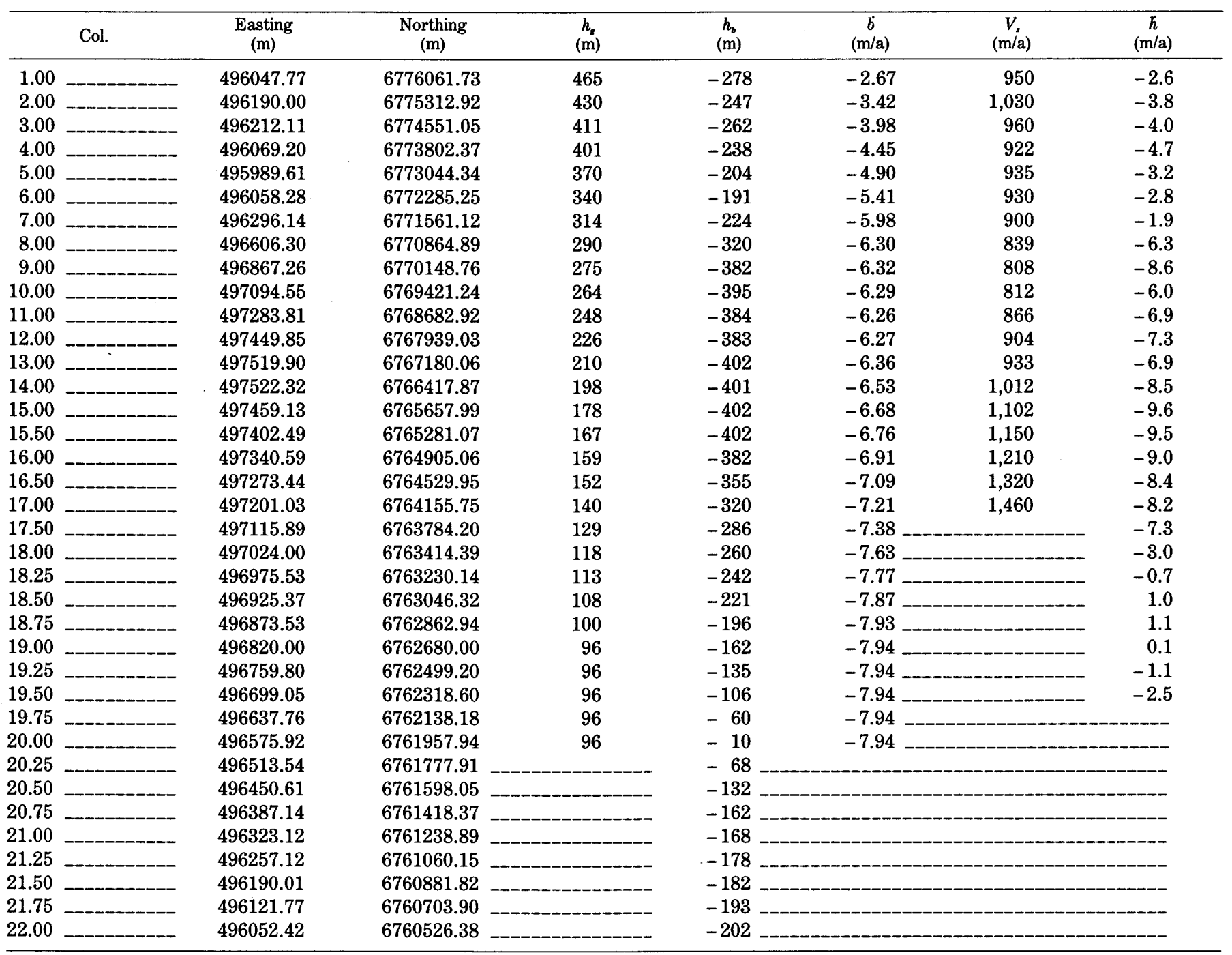



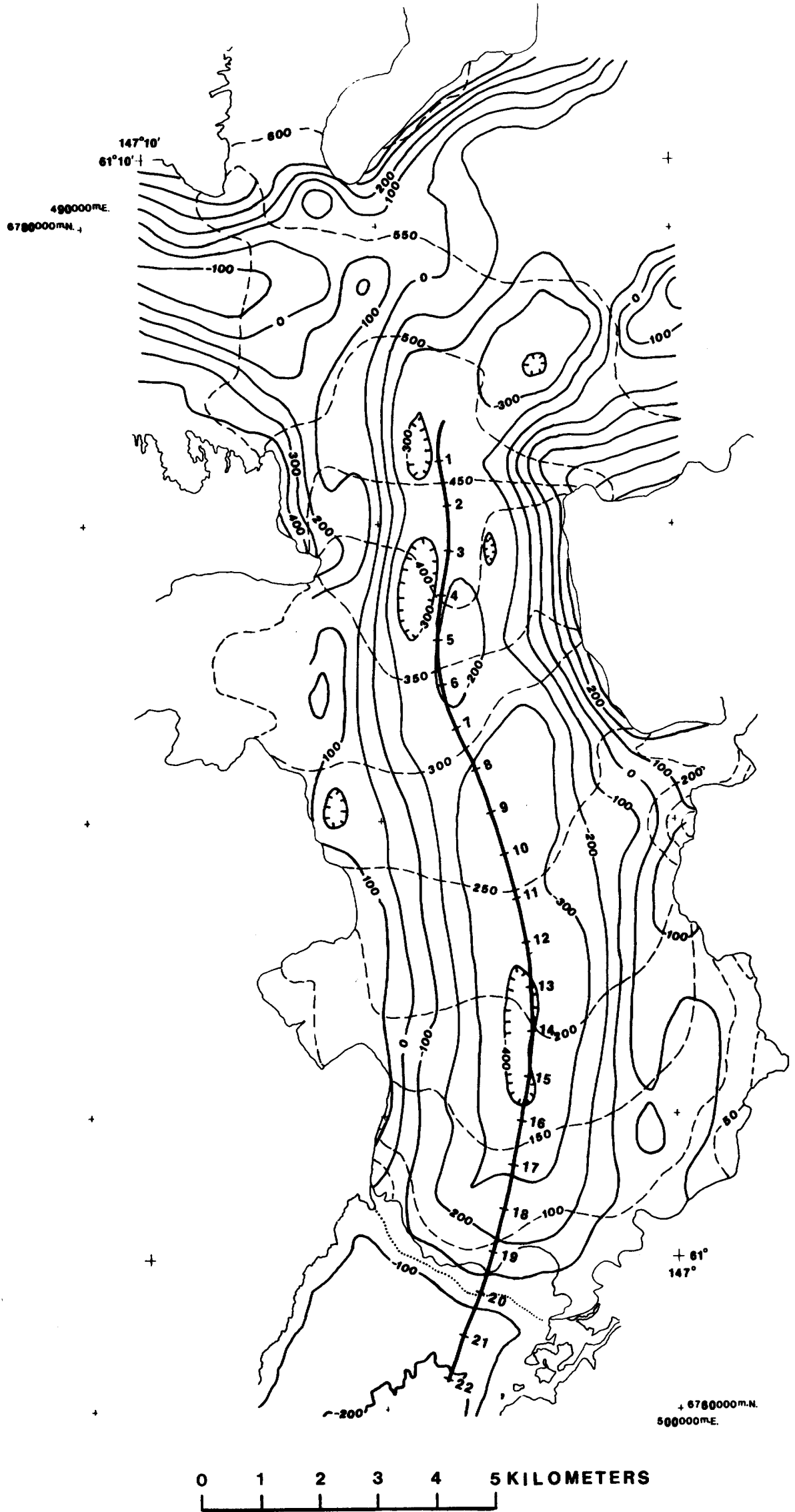

Figure 3.-Flow line used in the modeling. The numbers along the flow line are the column numbers, and UTM locations and data correspond to those given in table 2 . Bed contours are solid, surface contours are dashed, and the terminal moraine is dotted (column locations 21 and 22 are in Columbia Bay). Kadin Lake is at UTM coordinates 490000 m.E., 6774000 m.N. 

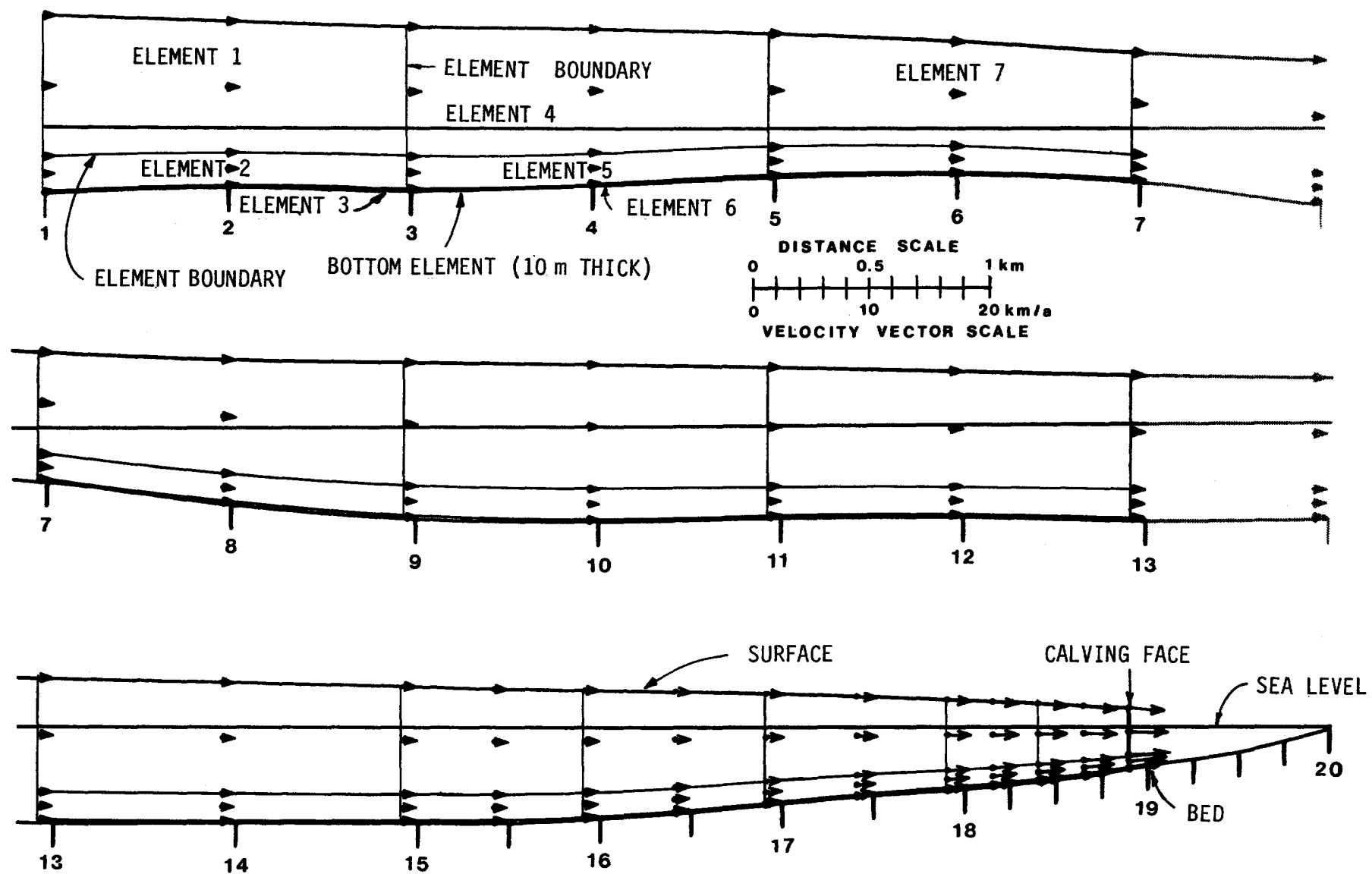

FIGURE 4. - Finite element grid. There are three elements through the thickness, with the bottom element a uniform $10 \mathrm{~m}$ in thickness. The ice velocity vectors are scaled to represent 0.05 year of displacement (if the ice continued beyond the velocity sampling points in straight lines, which, in general, it does not do). 


\section{DISTANCE SCALE}

0

$\mathrm{HHH}+\mathrm{HH}$

VELOCITY VECTOR SCALE
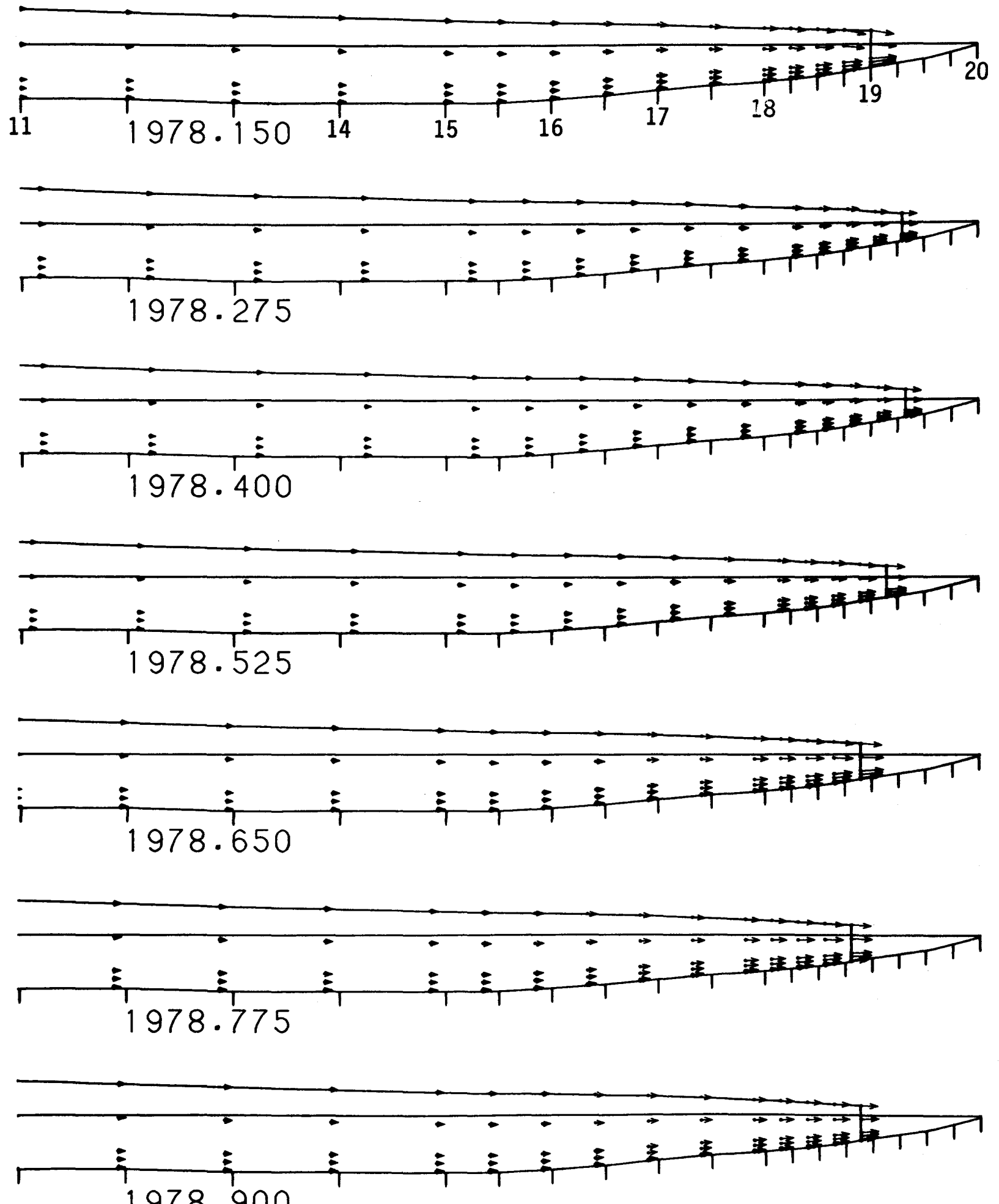

Figure 5. - Future Columbia glacier behavior, projected by using modeling constant $a=1165625$. The individual illustrations show the flow-line profile from column locations 11 through 20 as a function of time. 

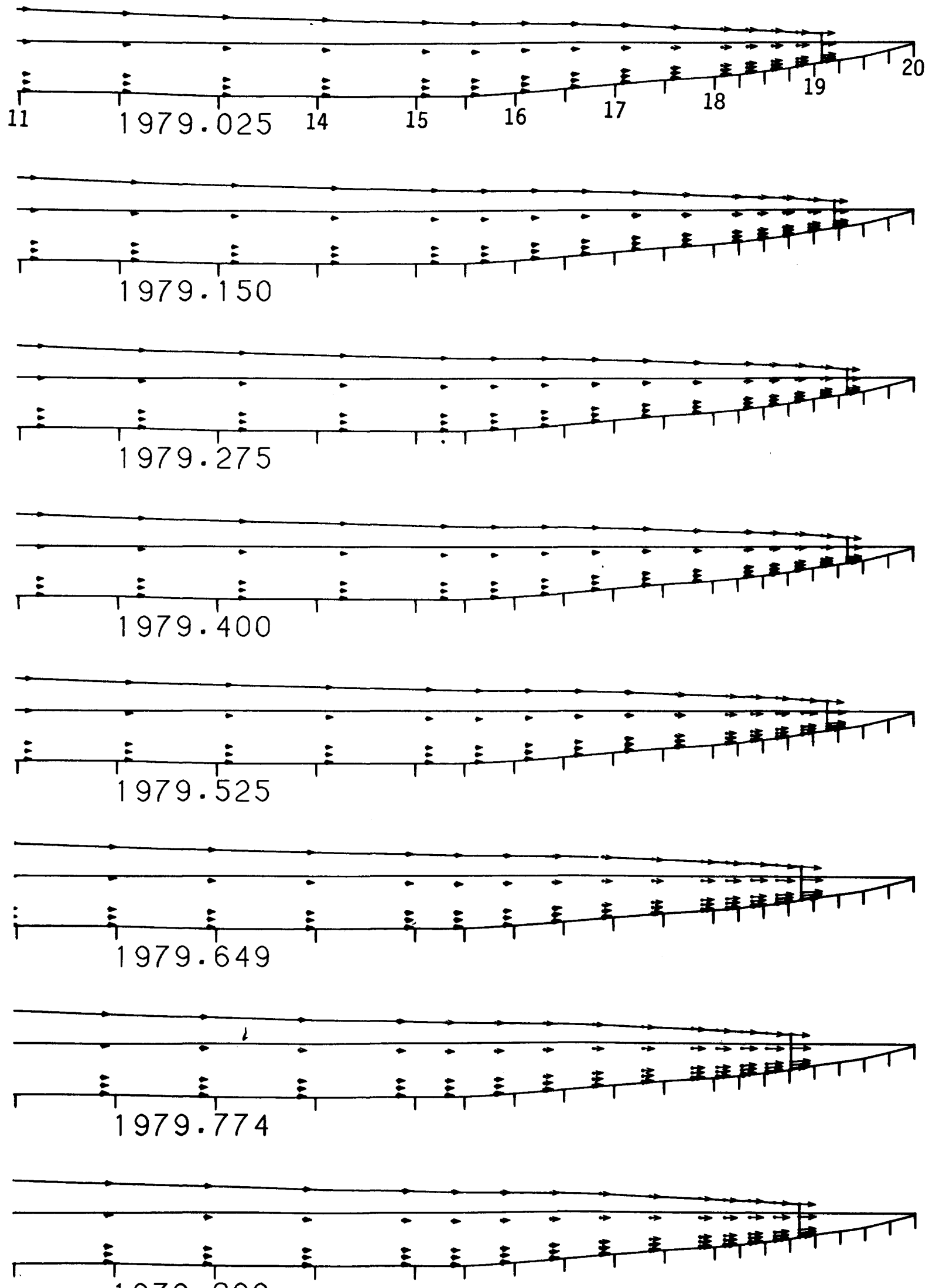

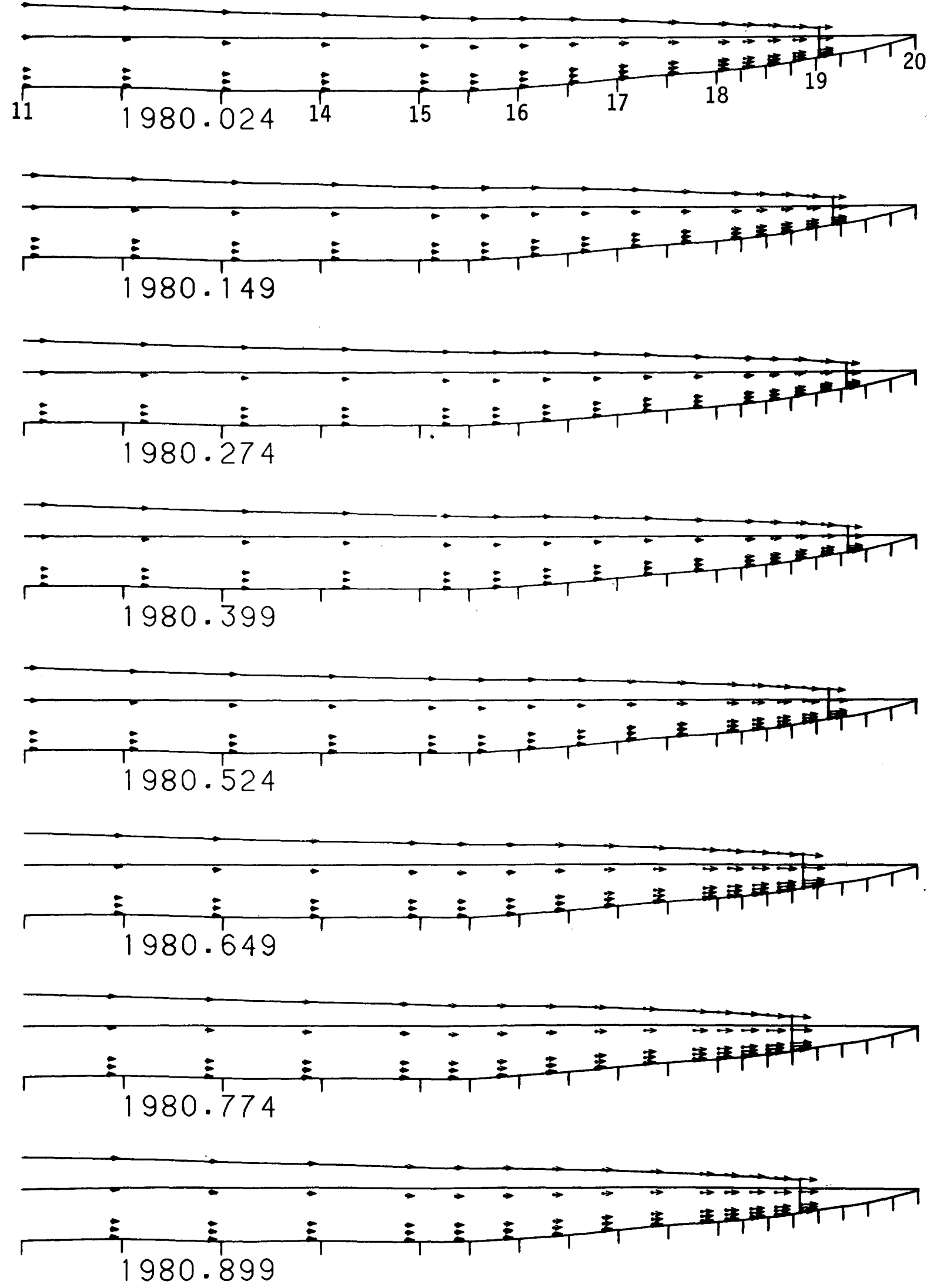

FIGURE 5 (Continued). - Future Columbia glacier behavior, projected by using modeling constant $a=1165625$. The individual illustrations show the flow-line profile from column locations 11 through 20 as a function of time. 

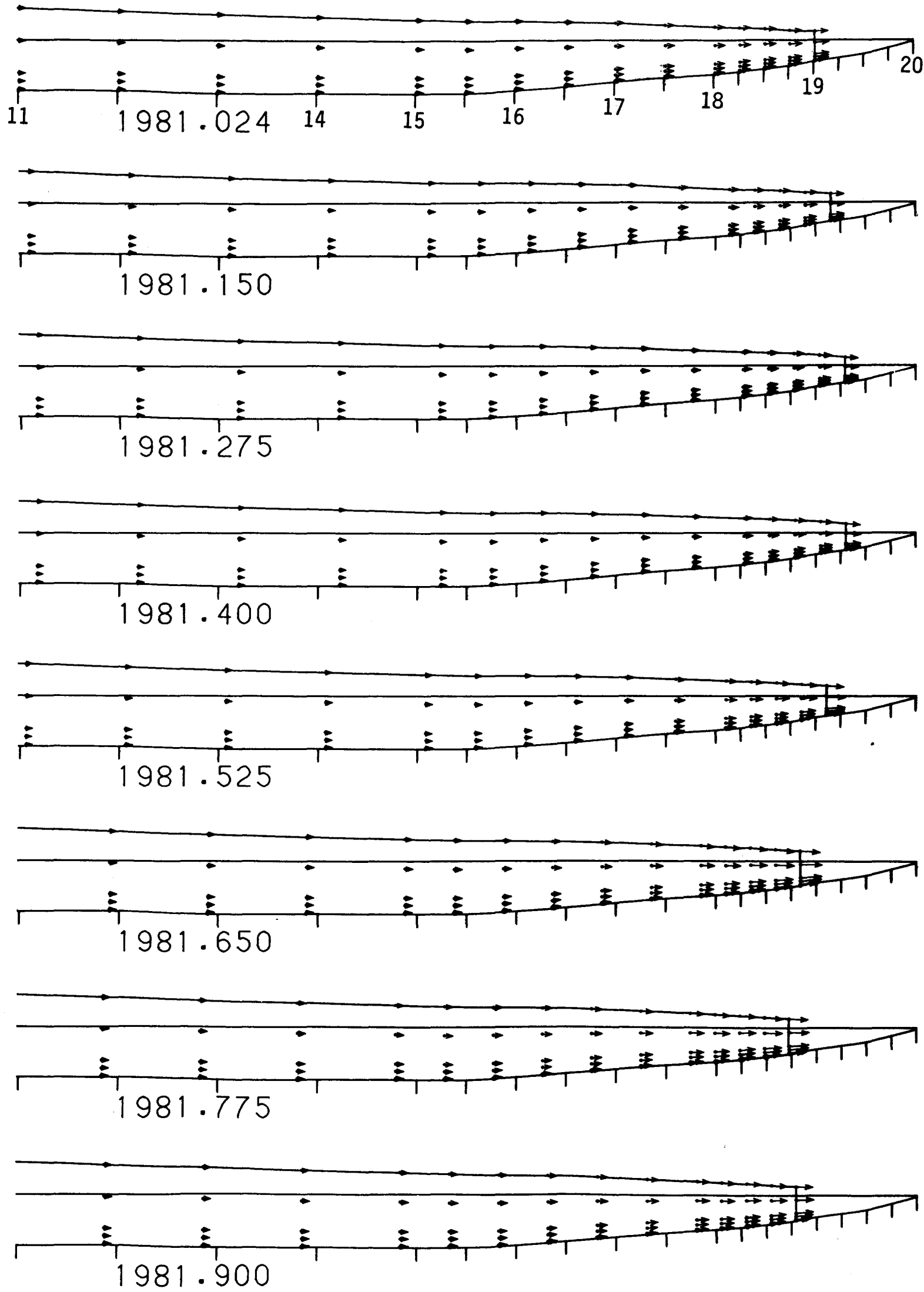

FIGURE 5 (Continued). - Future Columbia glacier behavior, projected by using modeling constant $a=1165625$. The individual illustrations show the flow-line profile from column locations 11 through 20 as a function of time. 

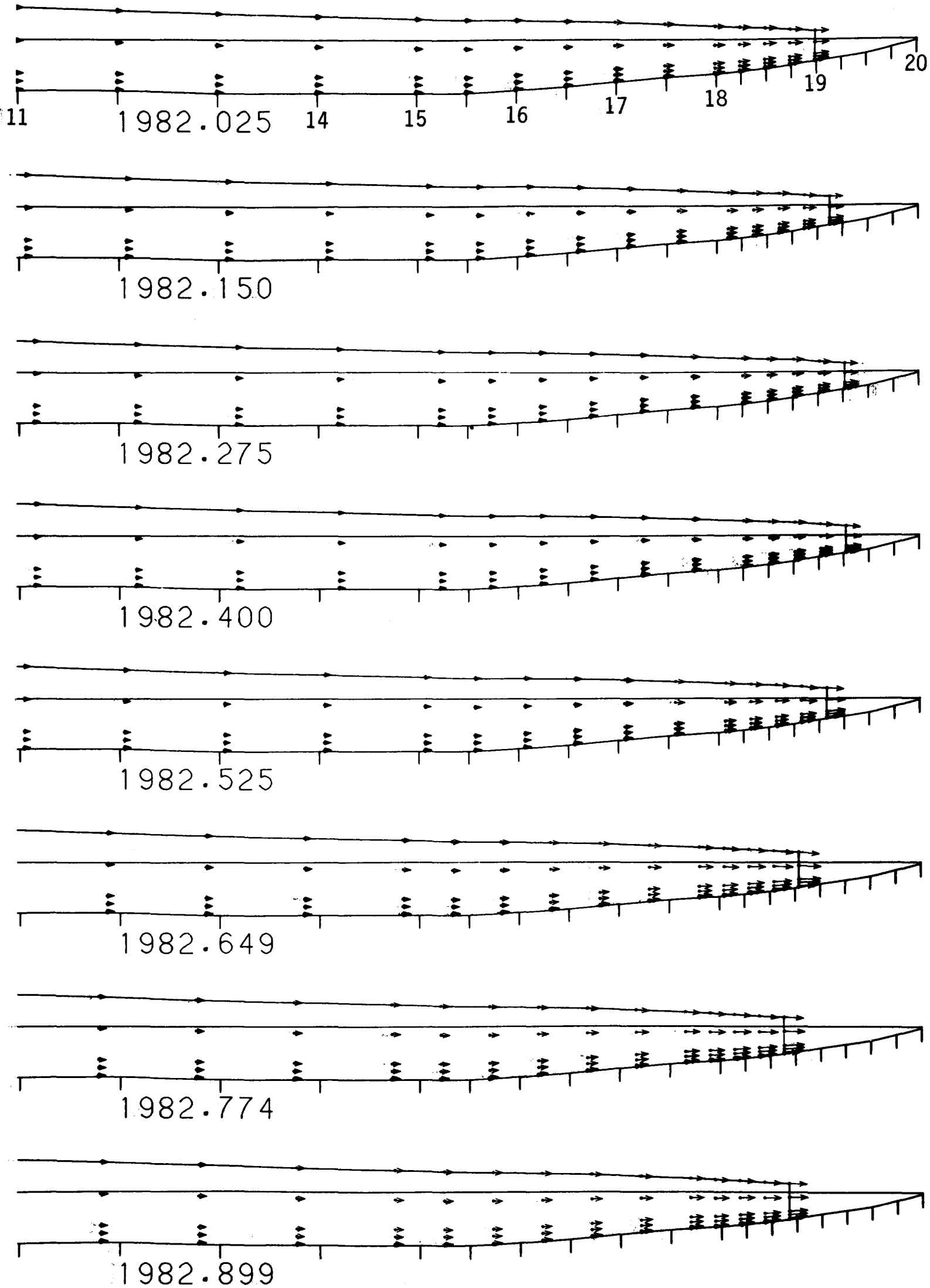

FiguRE 5 (Continued). - Future Columbia glacier behavior, projected by using modeling constant $a=1165625$. The individual illustrations show the flow-line profile from column locations 11 through 20 as a function of time. 

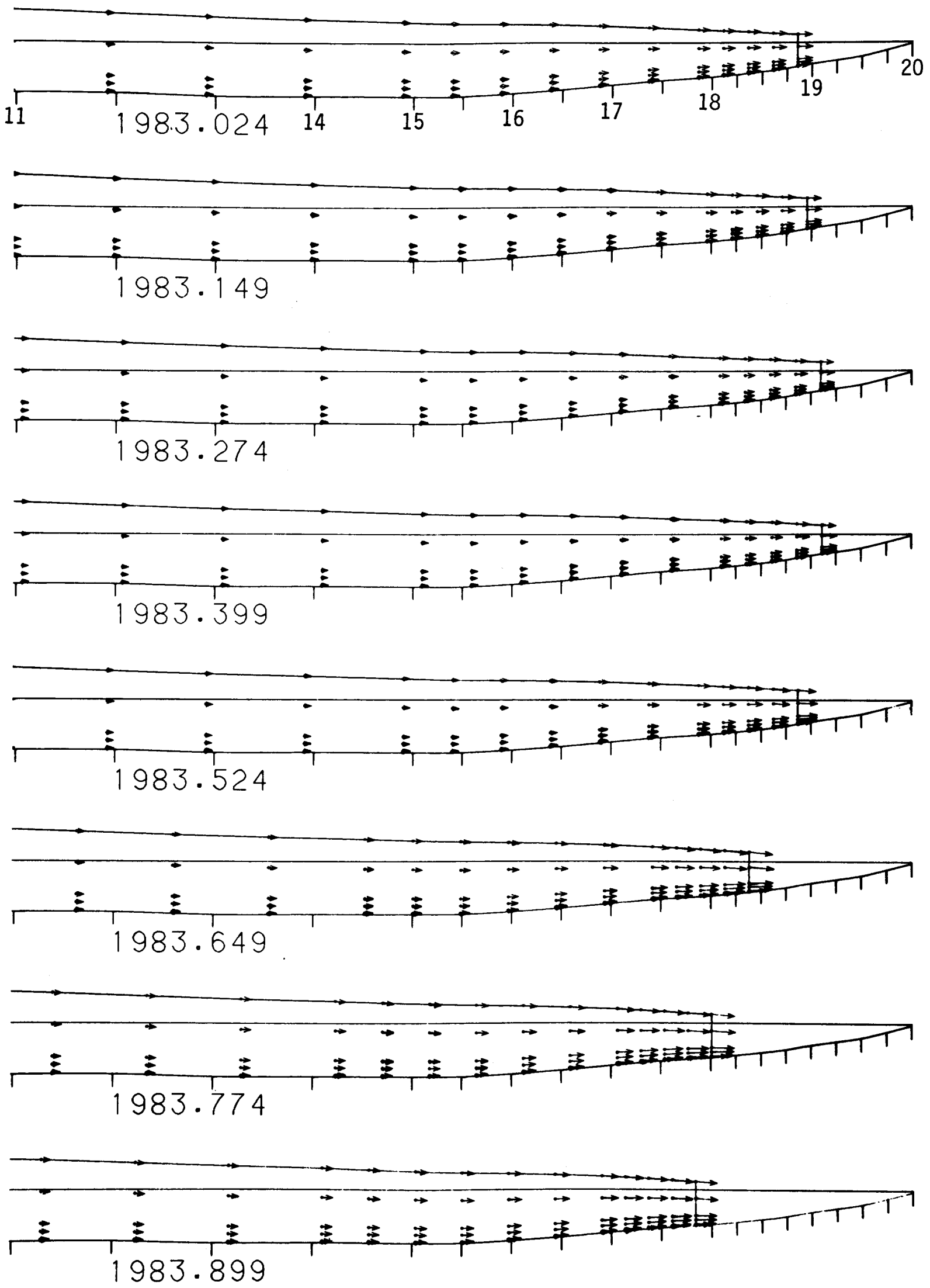

FIGURE 5 (Continued). - Future Columbia glacier behavior, projected by using modeling constant $a=1165625$. The individual illustrations show the flow-line profile from column locations 11 through 20 as a function of time. 

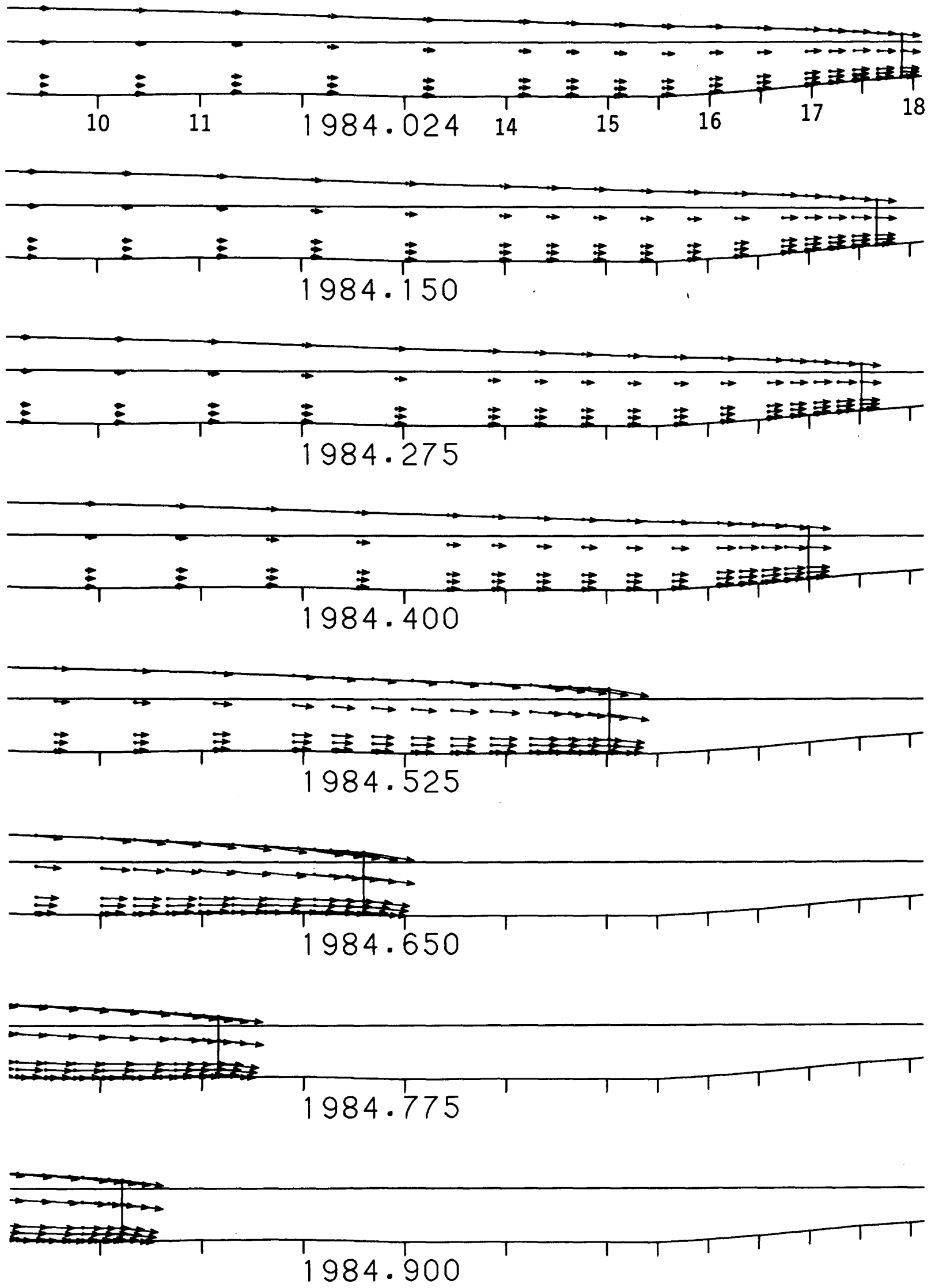

FiguRE 5 (Continued). - Future Columbia glacier behavior, projected by using modeling constant $a=1165625$. The individual illustrations show the flow-line profile from column locations 10 through 18 as a function of time. 


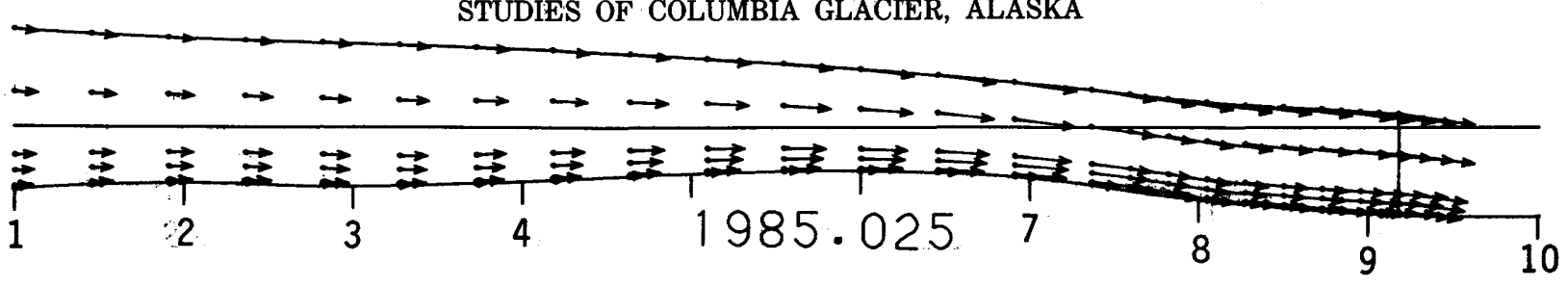

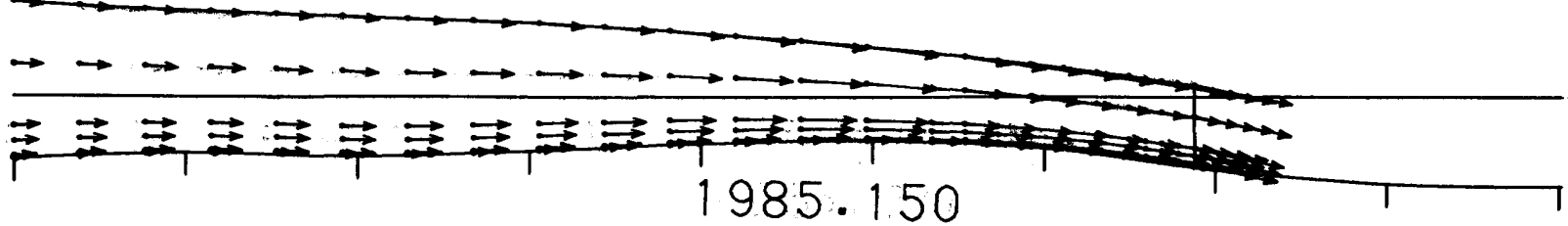

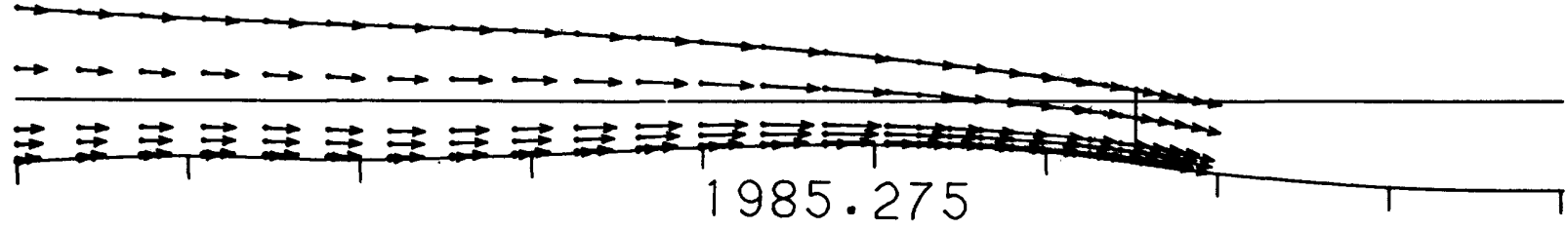

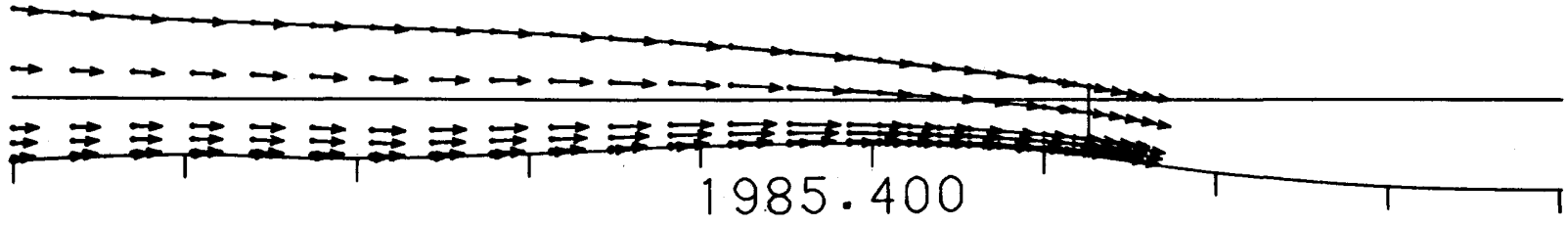
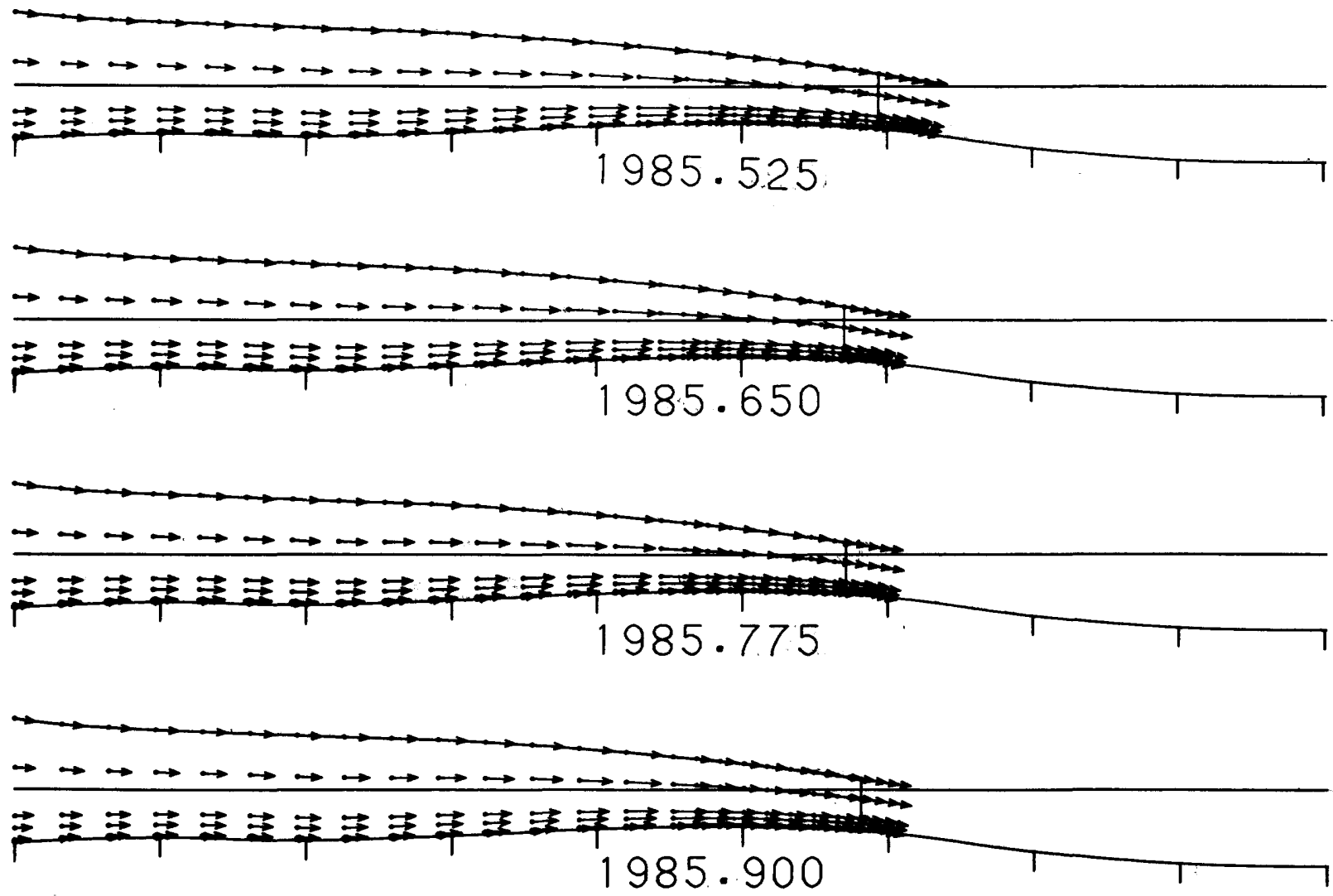

FIgURE 5 (Continued). - Future Columbia glacier behavior, projected by using modeling constant $a=1165625$. The individual illustrations show the flow-line profile from column locations 1 through 10 as a function of time. 

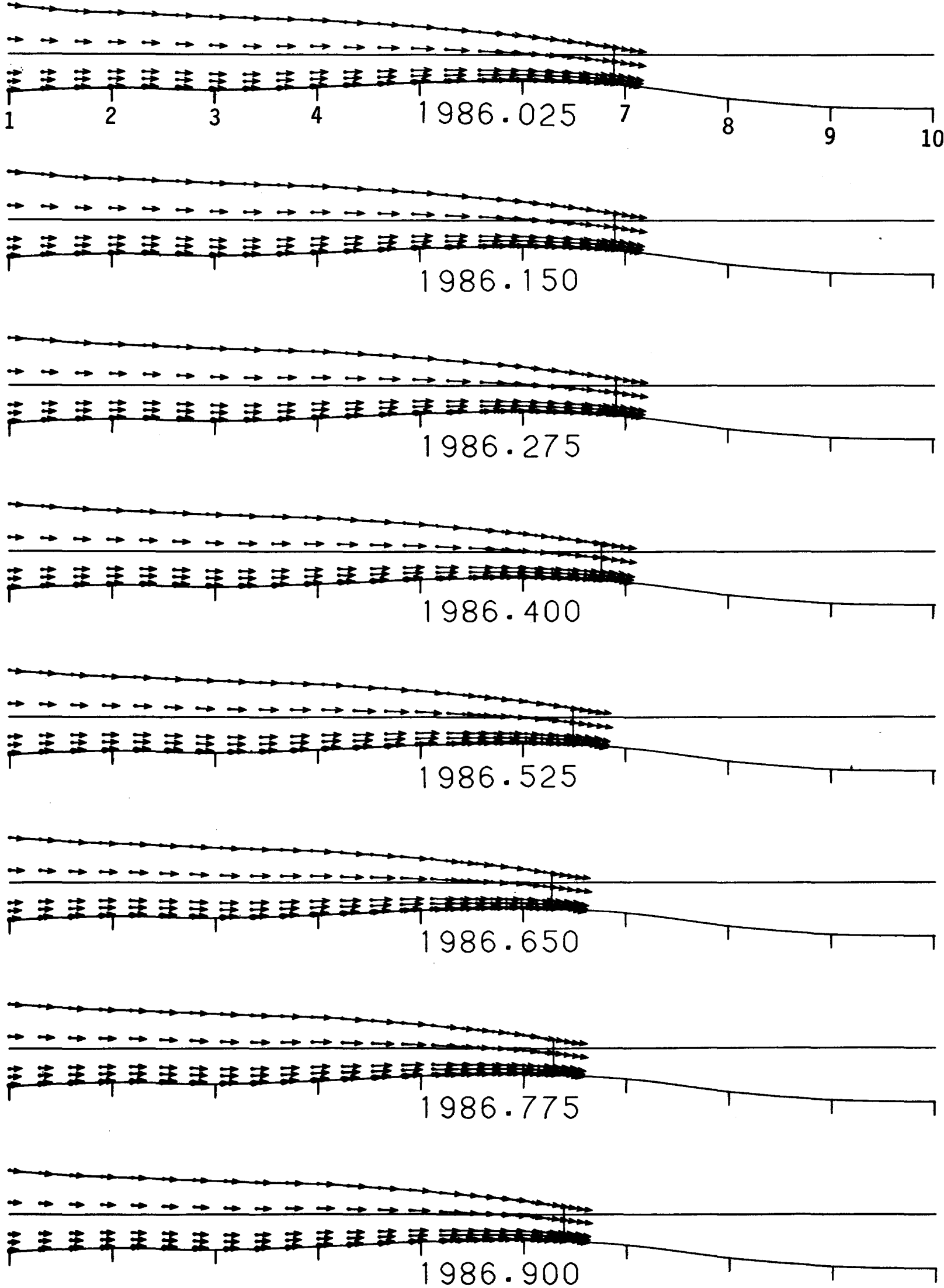

FiguRE 5 (Continued). - Future Columbia glacier behavior, projected by using modeling constant $a=1165625$. The individual illustrations show the flow-line profile from column locations 1 through 10 as a function of time. 

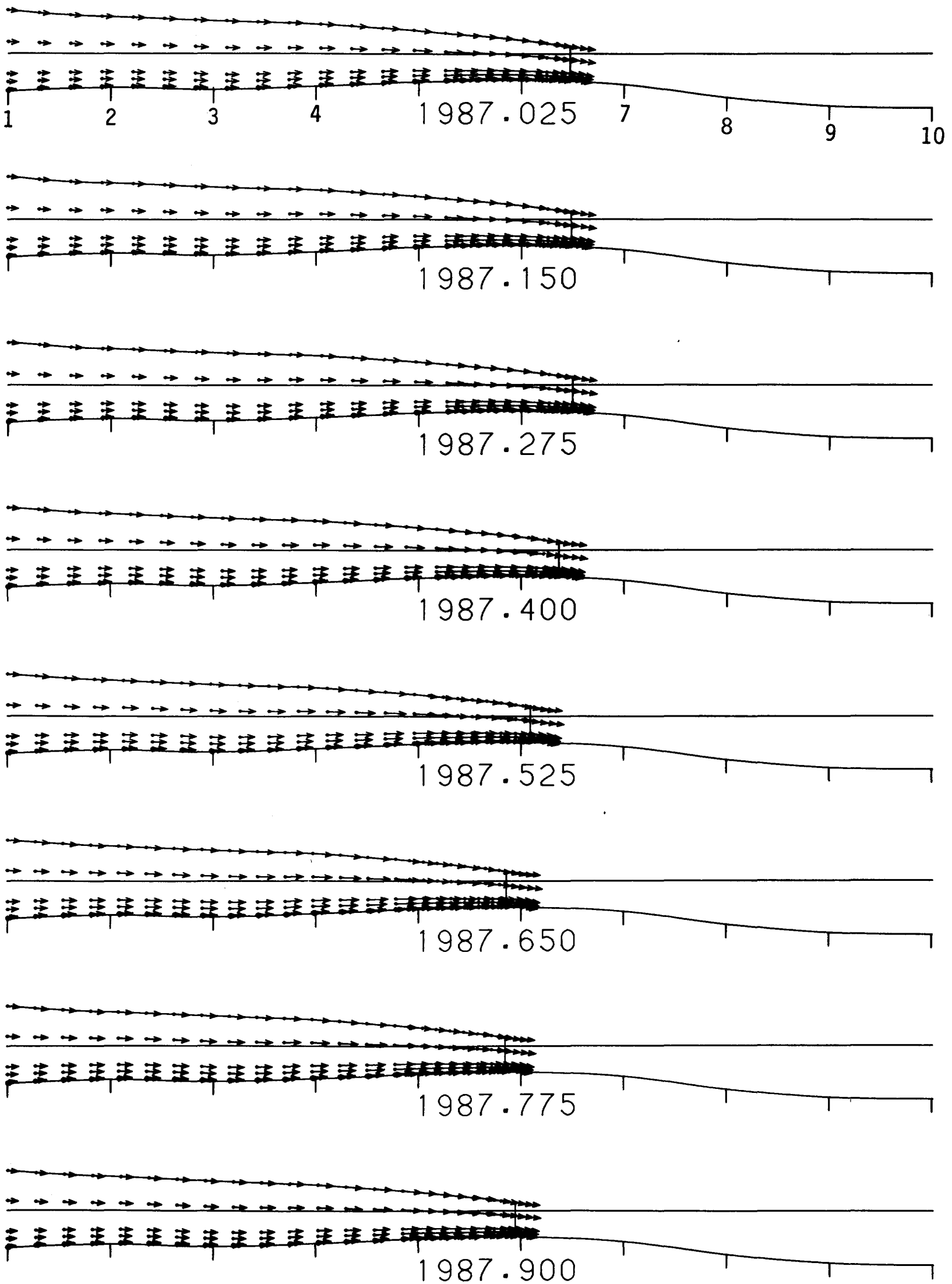

FIGURE 5 (Continued). - Future Columbia glacier behavior, projected by using modeling constant $a=1165625$. The individual illustrations show the flow-line profile from column locations 1 through 10 as a function of time. 

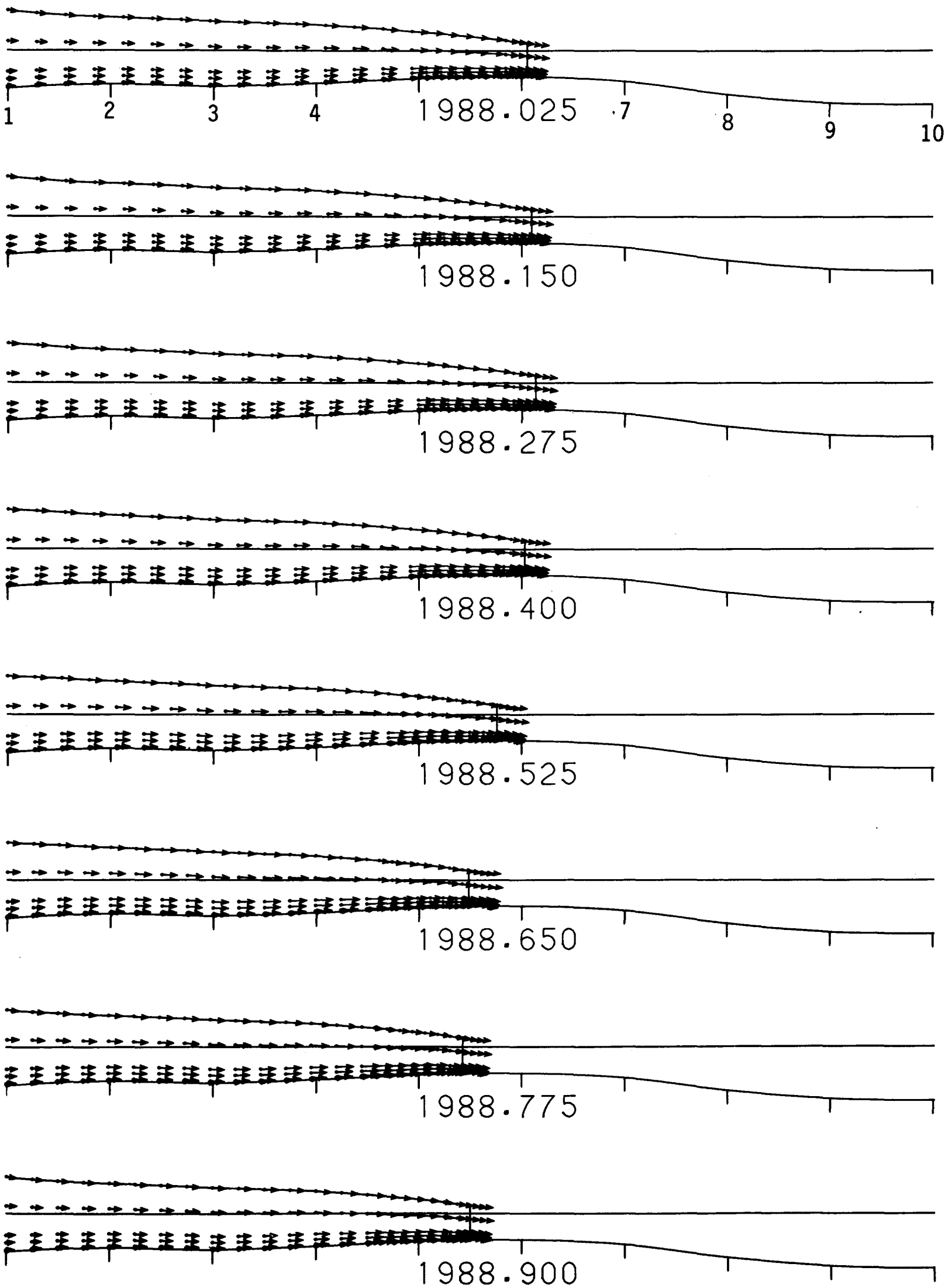

FIgURE 5 (Continued).-Future Columbia glacier behavior, projected by using modeling constant $a=1165625$. The individual illustrations show the flow-line profile from column locations 1 through 10 as a function of time. 

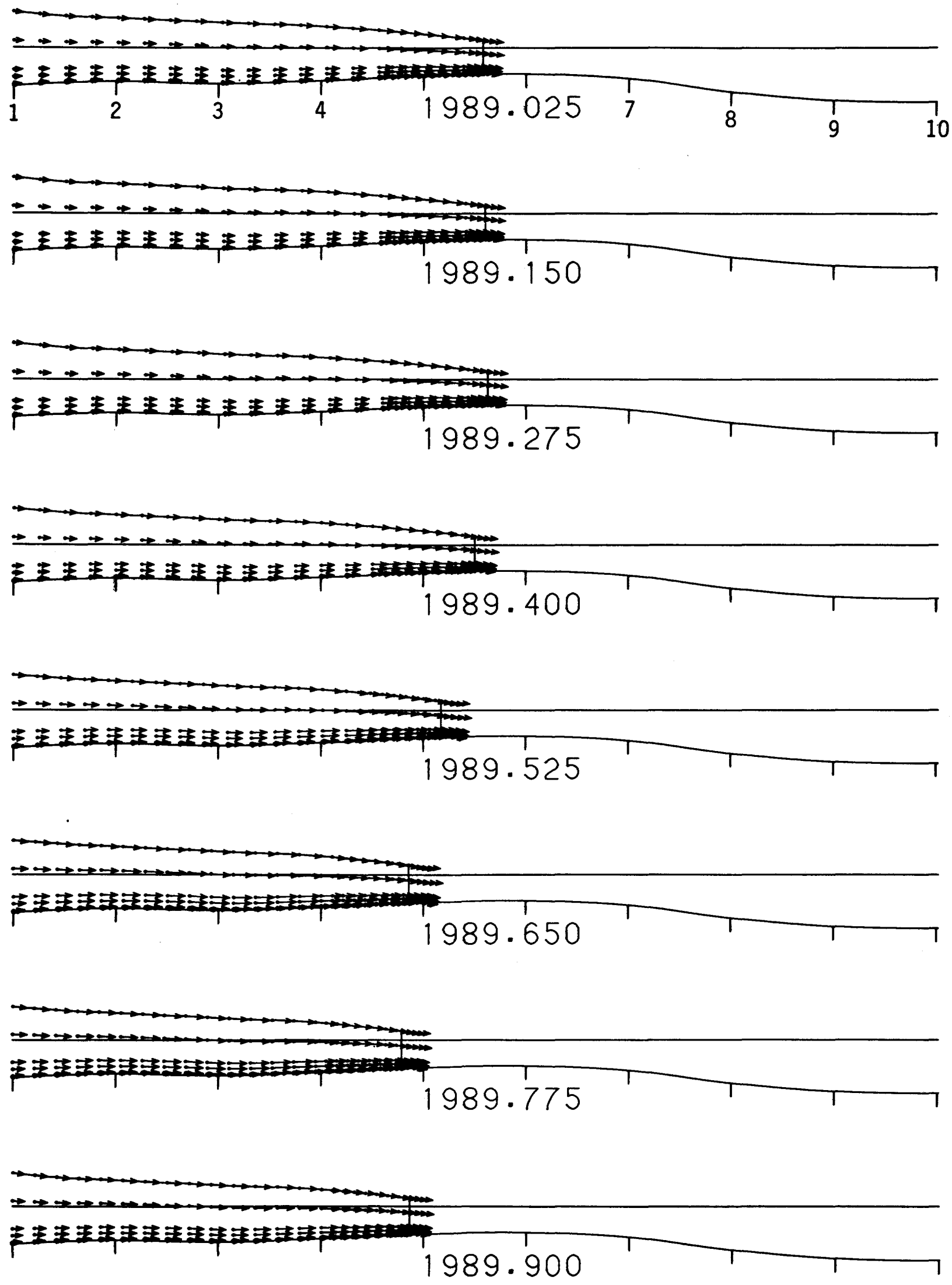

FIgURE 5 (Continued). - Future Columbia glacier behavior, projected by using modeling constant $a=1165625$. The individual illustrations show the flow-line profile from column locations 1 through 10 as a function of time. 

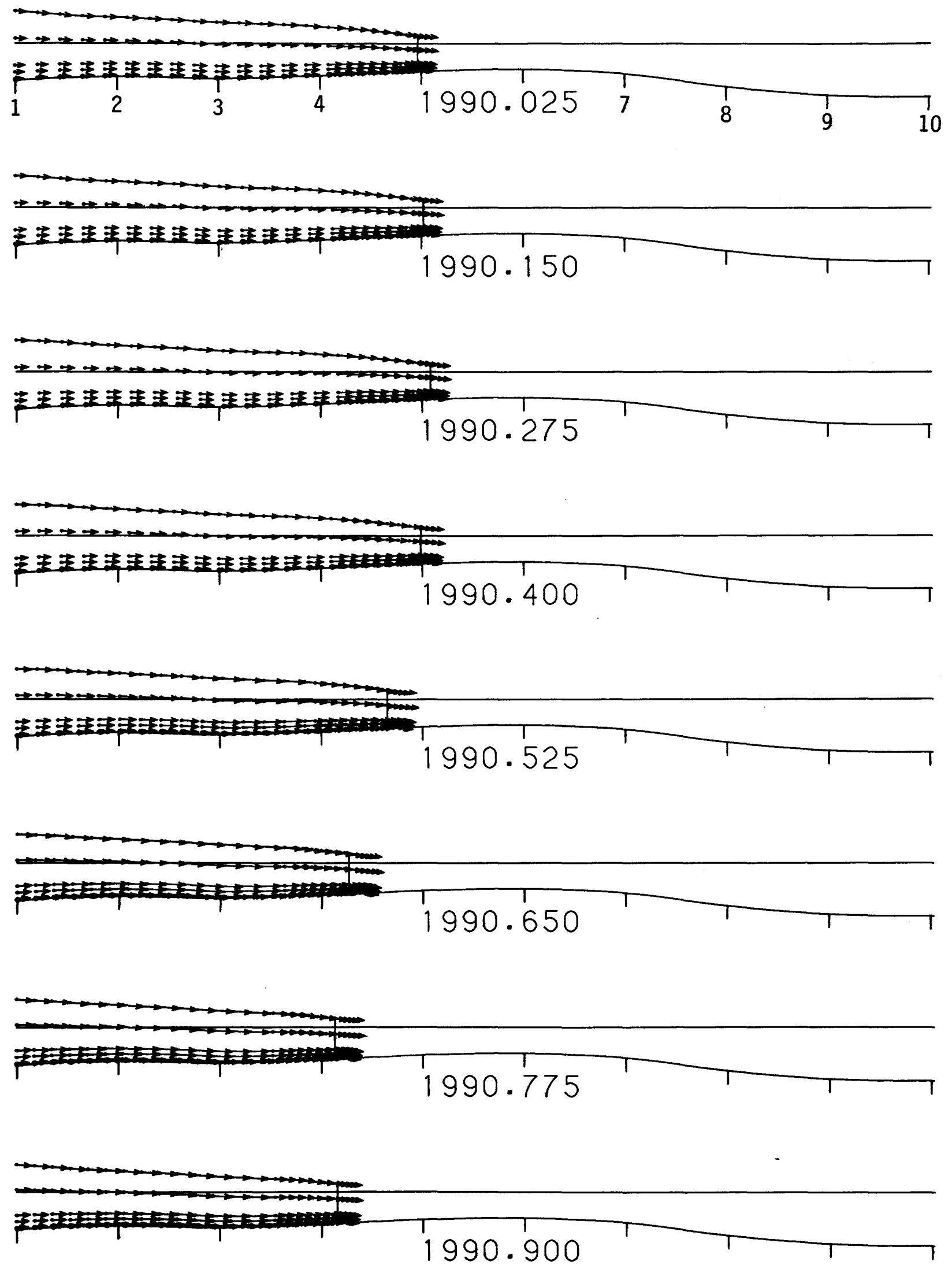

FIgURE 5 (Continued). - Future Columbia glacier behavior, projected by using modeling constant $a=1165625$. The individual illustrations show the flow-line profile from column locations 1 through 10 as a funetion of time. 

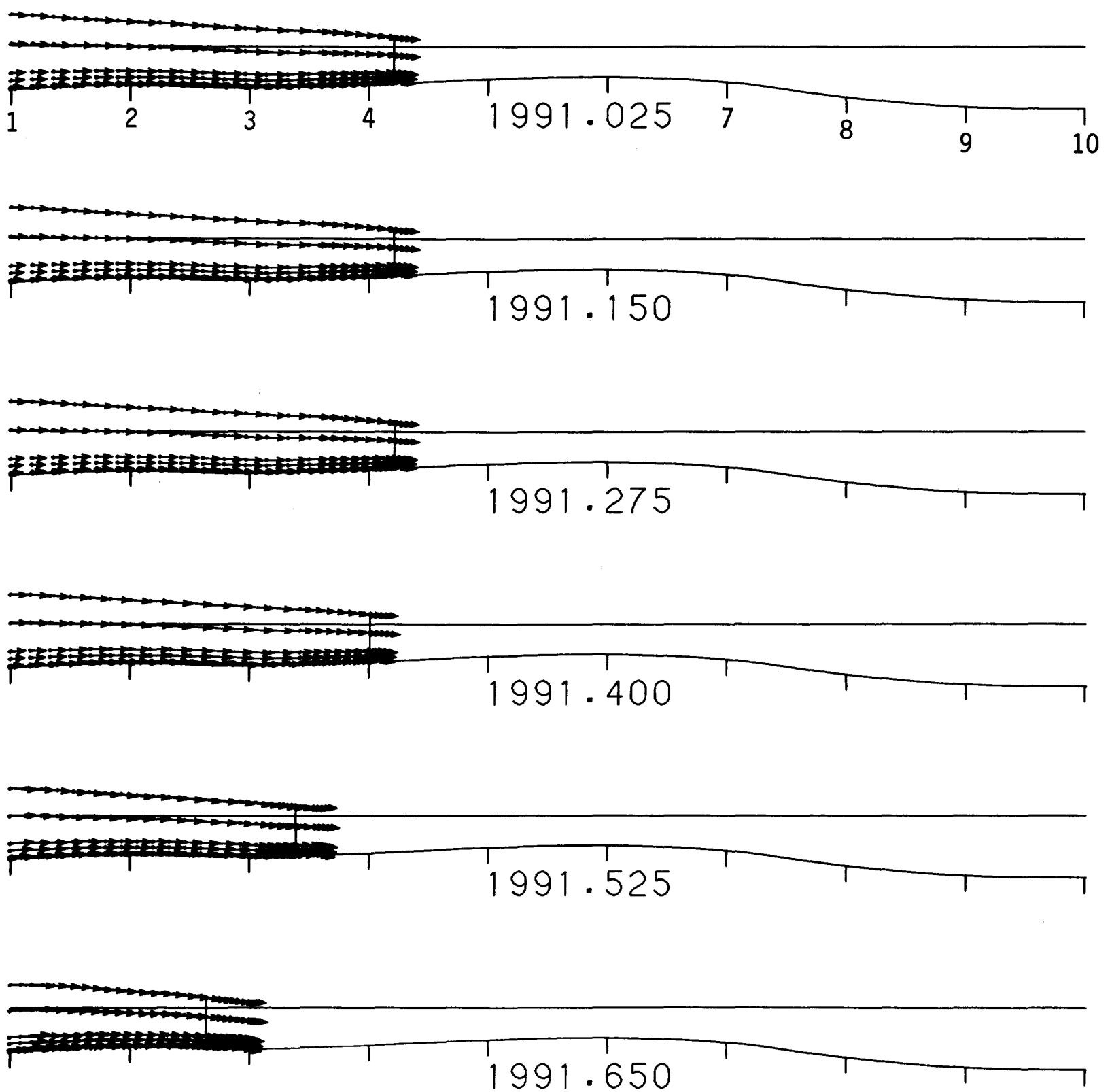

FIgURE 5 (Continued). - Future Columbia glacier behavior, projected by using modeling constant $a=1165625$. The individual illustrations show the flow-line profile from column locations 1 through 10 as a function of time. 


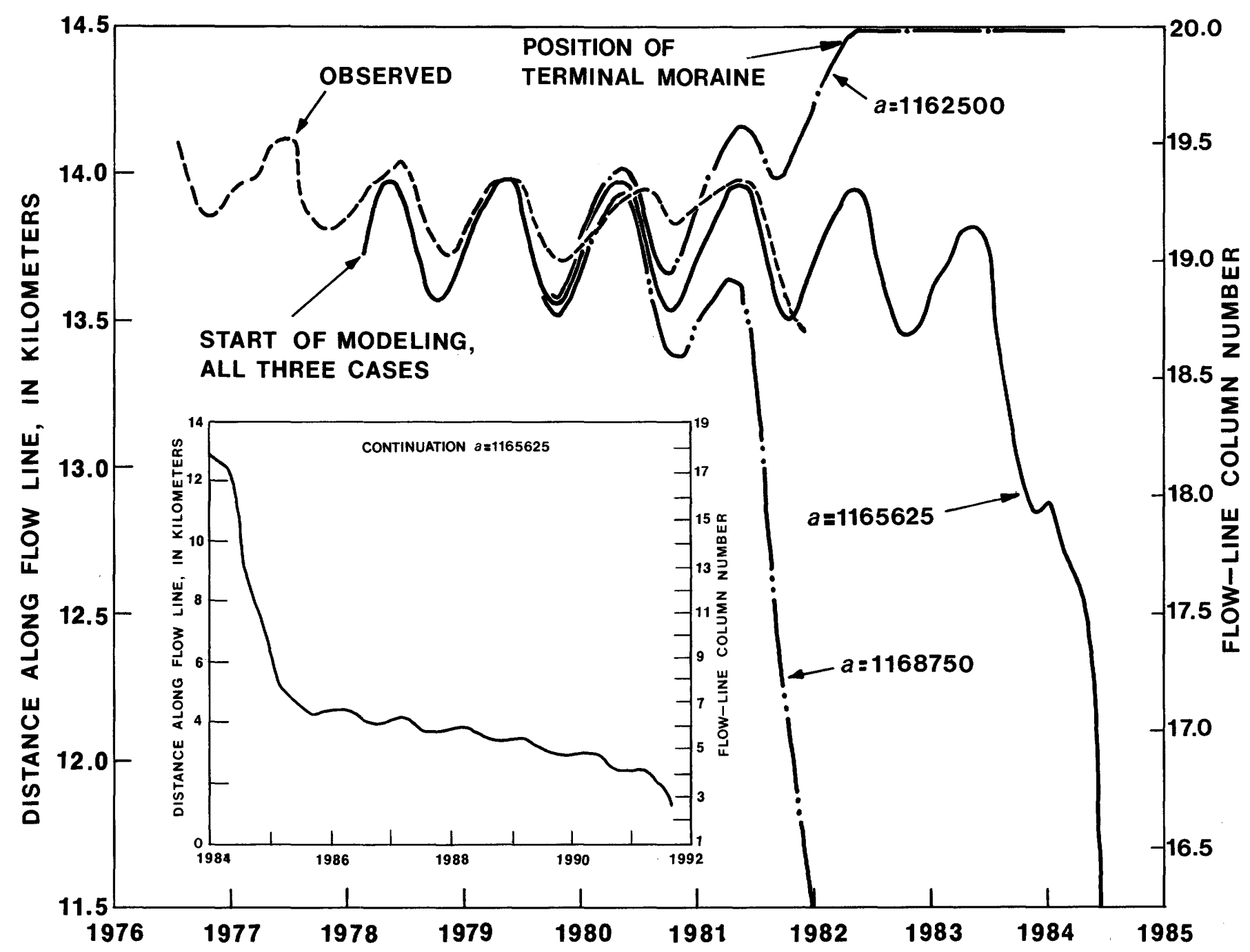

FigurE 6. - Terminus position in time, for three values of the modeling constant $a$ of the calving law. The observed position represents an average across the width of the terminus. 


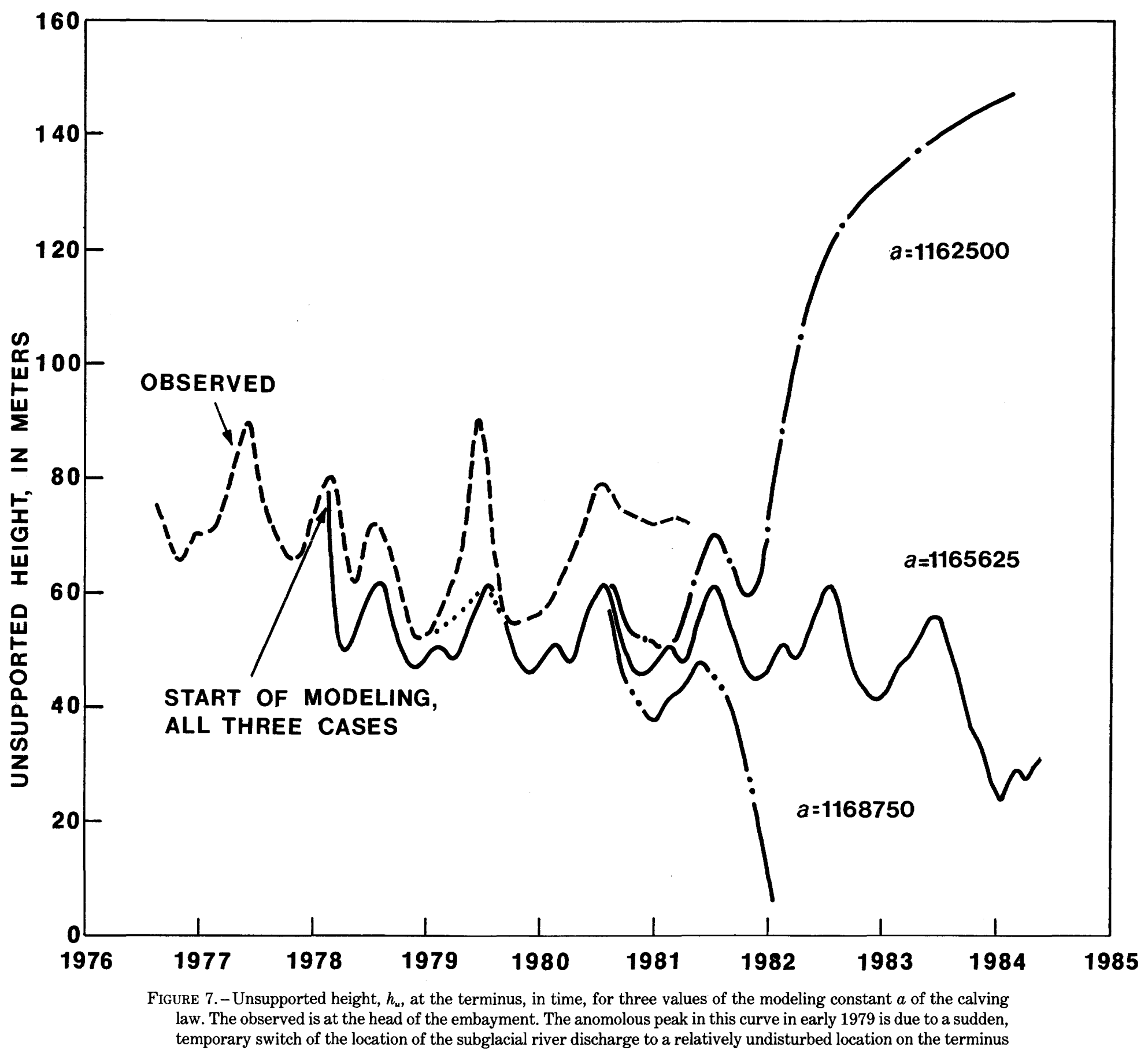




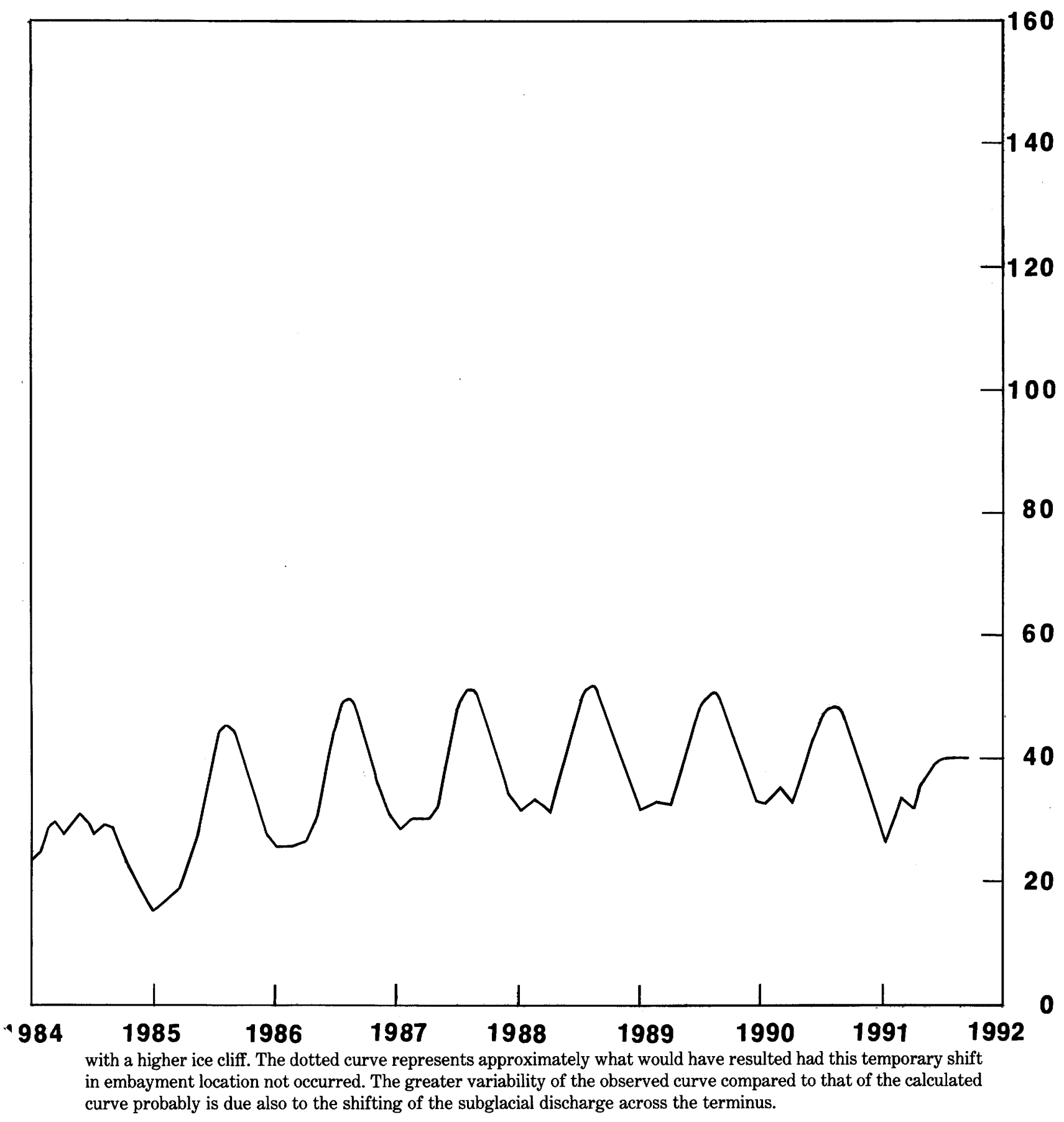




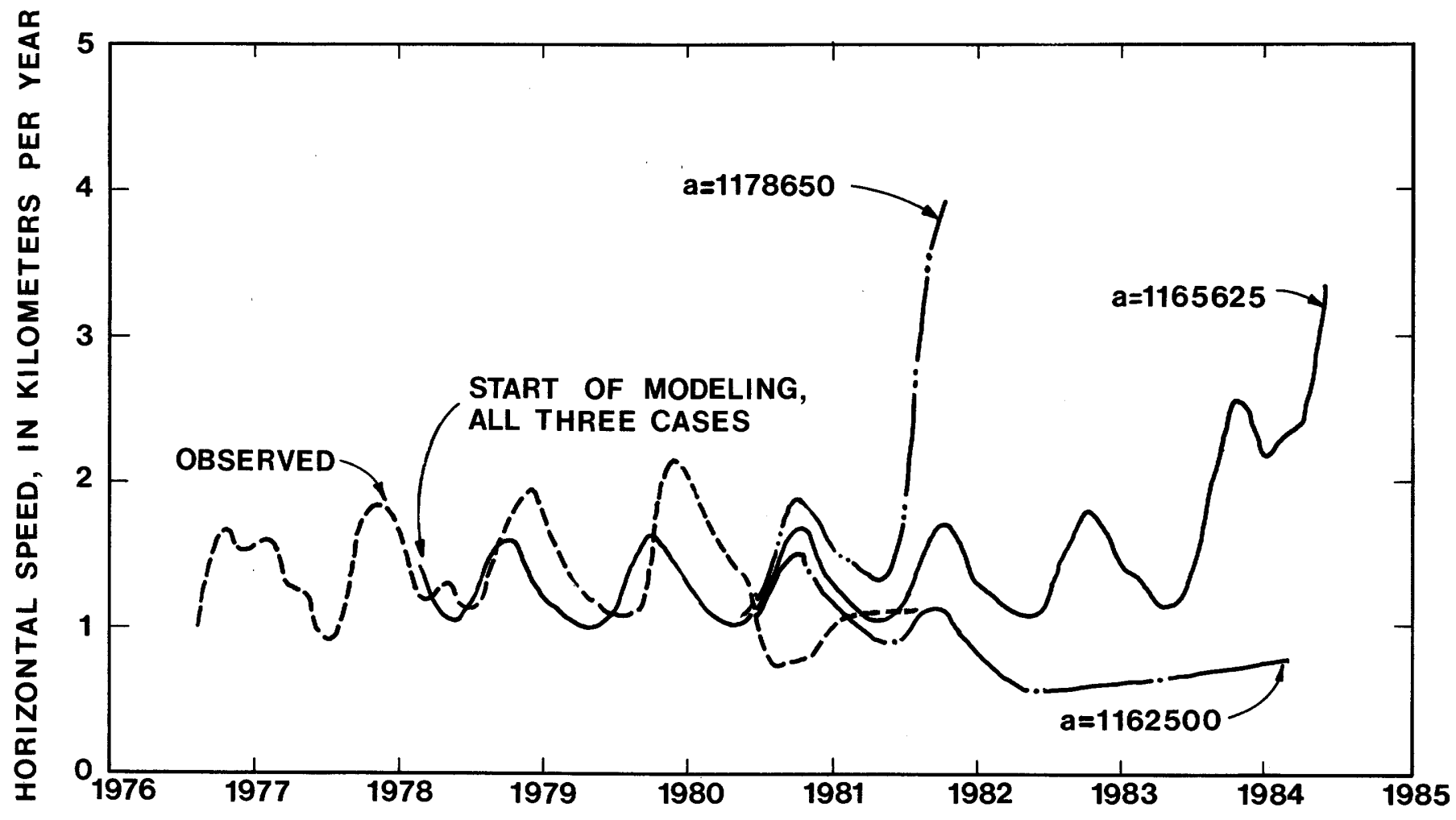

FIGURE 8. - Surface horizontal speed at flow-line-column number 16.9, in time. A phase shift of unknown origin (a three-dimensional effect?) between computed speed and observed speed indicates computed speed leading the observed speed, $\left(V_{s}\right)_{o}$, by about $1 / 8$ year. Note the low speeds in 1980 , when the retreat was interrupted. 


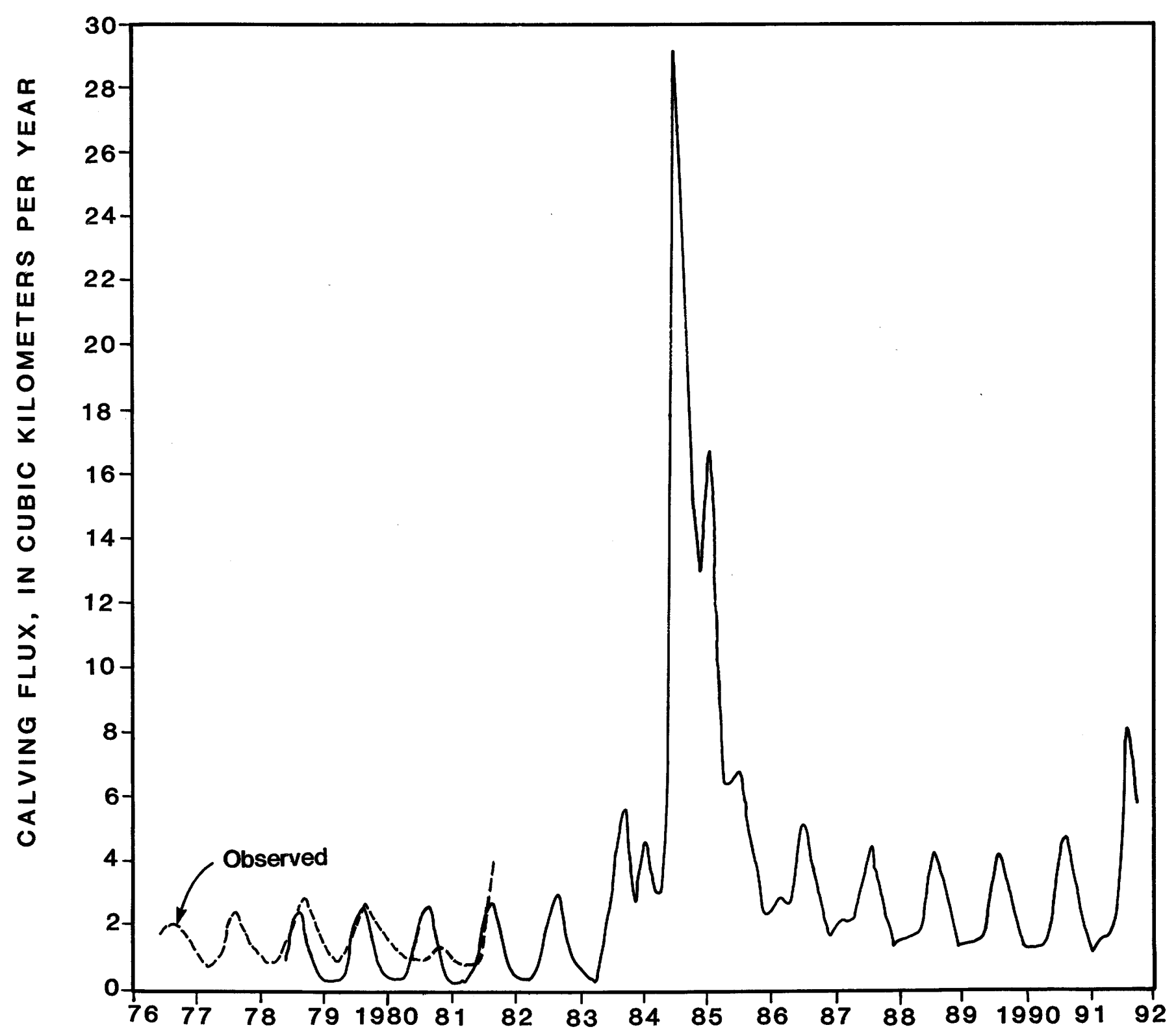

FIGURE 9. - Rate of iceberg production, in volume, projected by using modeling constant $a=1165625$. This graph was derived by converting the two-dimensional flux of the model to three dimensions, using bed configuration and spatial velocity distributions for the real glacier. 


\section{REFERENCES CITED}

Bindschadler, R. A., 1978, A time-dependent model of temperate glacier flow and its application to predict changes in the surge-type Variegated Glacier during its quiescent phase: Seattle, University of Washington Geophysics Program, unpublished thesis, $244 \mathrm{p}$.

Budd, W. F., Keage, P. L., and Blundy, N. A., 1979, Empirical studies of ice sliding: Journal of Glaciology, v. 23, no. 89, p. 157-170.

Hooke, R. L., Gustafson, R. J., Raymond, C. F., and Hotchkiss, R. L., 1980, Computer programs for calculating temperatures and velocities in polar glaciers using the finite element method: Minneapolis, University of Minnesota, Report UM-GMPH-2, $95 \mathrm{p}$.

Meier, M. F., Post, Austin, Brown, C. S., Frank, David, Hodge, S. M., Mayo, L. R., Rasmussen, L. A., Senear, E. A., Sikonia, W. G., Trabant, D. C., and Watts, R. D., 1978, Columbia Glacier progress report-December 1977: U.S. Geological Survey Open-File Report 78-264, 56 p.

Meier, M. F., Post, Austin, Rasmussen, L. A., Sikonia, W. G., and Mayo, L. R., 1980a, Retreat of Columbia Glacier-A preliminary prediction: U.S. Geological Survey Open-File Report 80-10, 12 p.

Meier, M. F., Rasmussen, L. A., Post, Austin, Brown, C. S., Sikonia, W. G., Bindschadler, R. A., Mayo, L. R., and Trabant, D. C., $1980 \mathrm{~b}$, Predicted timing of the disintegration of the lower reach of
Columbia Glacier, Alaska: U.S. Geological Survey Open-File Report 80-582, 58 p.

Post, Austin, 1975 [1976], Preliminary hydrography and historic terminal changes of Columbia Glacier, Alaska: U.S. Geological Survey Hydrologic Investigations Atlas 559, 3 sheets.

Raymond, C. J., 1978, Numerical calculation of glacier flow by finite element methods: Seattle, University of Washington, final technical report for National Science Foundation grant no. DPP74-19075, geophysics program AK50, $201 \mathrm{p}$.

Schmidt, W. F., 1977, Finite element analysis of planar creeping viscous ice flow: Orono, University of Maine, Department of Meehanical Engineering, Report No. 77-1, 36 p.

Sikonia, W. G., and Post, Austin, 1980, Columbia Glacier, Alaska: Recent ice loss and its relationship to seasonal terminal embayment, thinning, and glacier flow: U.S. Geological Survey Hydrologic Investigations Atlas 619, 3 sheets.

Taylor, R. L., 1980, Finite element analysis program, in Zienkiewicz, O. C., The finite element method (3d ed.): Berkeley, University of California, Department of Civil Engineering. [Available on cards (for $\$ 100$ as of 1980 ) from R. L. Taylor at the university.]

Zienkiewicz, O: C., 1977, The finite element method (3d ed.): McGraw-Hill, 787 p: 


\section{APPENDIX A: MATHEMATICS}

The formulation used is that of Zienkiewicz (1977, p. 612 , sec. 22.3.1). The $\bar{K}$ and $M$ matrices can be omitted as they represent contributions from kinetic effects that can be ignored in the slow movement of glaciers. Quadratic Lagrange shape functions were used for velocities, and so each element is three nodes by three nodes. Pressure shape functions were chosen to be linear in the vertical direction and quadratic in the horizontal direction, and so pressure unknowns are associated with only the top and bottom nodes of each element; that is, with nodes number $4,7,3,1,5$, and 2 in figure 24.25 of Zienkiewicz (1977, p. 748). Three-bythree Gaussian intregration is used. The starting point for the element subroutine is Taylor's fluid element (Zienkiewicz, 1977, p. 755). The viscosity, $\mu$, for ice is nonconstant, and so the resultant system of equations is solved iteratively and has a contribution to the tangent stiffness matrix (Zienkiewicz, p. 699, equation 24.2) arising from appropriate partial derivatives of $\mu$.

\section{TANGENT STIFFNESS MATRIX}

Assume for simplicity that $\mathbf{a}^{u}, \mathbf{a}^{p}$ are partitioned within an element as in section 22.3.1 of Zienkiewicz (1977, p. 612). (Actually, in the program, the velocities and pressures alternate, grouped according to node number.) In Zienkiewicz' notation, the equation for ice is (see equation 22.17)

$$
F(a) \equiv K^{u}+K^{p} a^{p}+f^{u}=0,
$$

where

$$
\mathbf{a}^{T}=\left(\left(\mathbf{a}^{u}\right)^{T},\left(\mathbf{a}^{p}\right)^{T}\right) .
$$

This equation is nonlinear because $\mu$ (in $\mathbf{K}$ ) is a function of the effective shear stress, and so of $a^{u}$. To solve iteratively by Newton's method, expand to the linear term in Taylor's series:

$$
F(a)+F^{\prime}(a) \delta a \cong 0
$$

or

$$
\left[\frac{\partial}{\partial \mathbf{a}^{u}}\left(\mathbf{K} \mathbf{a}^{u}\right)\right] \delta \mathbf{a}^{u}+\mathbf{K}^{p} \delta \mathbf{a}^{p} \cong-\mathbf{F}(\mathbf{a}) .
$$

Here a is the trial, or "current," approximation of the solution of equation $\mathrm{A} 1$, and $\delta \mathrm{a}$ represents a correction to be applied to improve this approximation. Considering the first term in which

$$
K \mathbf{a}^{u}=\left[\int_{\mathbf{a}} \mathbf{B}^{\mathrm{T}} \mathbf{D}^{\prime} \mathbf{B} \mathrm{d} \mathbf{\Omega}\right] \mathbf{a}^{u},
$$

define

$$
\mathbf{G}=\frac{1}{\mu} \mathbf{B}^{\mathbf{T}} \mathbf{D} \mathbf{B}
$$

Differentiating,

$$
\left[\frac{\partial}{\partial \mathbf{a}^{\mu}}\left(\mu \mathrm{Ga}^{u}\right)\right] \delta \mathbf{a}^{\mu}=\left[\frac{\partial \mu}{\partial \mathbf{a}^{u}} \delta \mathbf{a}^{u}\right] \mathrm{Ga}^{\mu}+\mu \mathrm{G} \delta \mathbf{a}^{\mu} .
$$

Note that $\frac{\partial \mu}{\partial \mathbf{a}^{u}}$ is a row matrix, while $\partial \mathbf{a}^{u}$ and $\mathbf{G a}^{u}$ are column matrices. Because of the special nature of these matrices, the order of operations in the first term on the right can be rearranged to give

$$
\left[\frac{\partial}{\partial \mathbf{a}^{u}}\left(\mu \mathbf{G a}^{u}\right)\right] \delta \mathbf{a}^{\mu}=\left[\mathbf{G a}^{u} \frac{\partial \mu}{\partial \mathbf{a}^{\mu}}+\mu \mathbf{G}\right] \delta \mathbf{a}^{\mu}
$$

Thus equation A4 becomes

$$
\left[\int_{\mathbf{a}} \mathbf{G} \mathbf{a}^{u} \frac{\partial \mu}{\partial \mathbf{a}^{u}} \mathrm{~d} \mathbf{\Omega}+K \mathbf{a}^{u}\right] \delta \mathbf{a}^{u}+K^{p} \delta \mathbf{a}^{p} \cong-\mathbf{F}(\mathbf{a}) .
$$

The integral represents the contribution due to the nonconstant viscosity, $\mu$. To express it in workable form, note that

$$
\frac{\partial \mu}{\partial \mathbf{a}^{\alpha}}=\frac{\partial \mu}{\partial d^{2}} \frac{\partial d^{2}}{\partial \mathbf{a}^{\mu}}
$$

where

$$
d=\left(1 / 2 d_{t} d_{t}\right)^{1 / 2}
$$

(summation convention on subscripts) is the effective shear deformation rate. Using the notation of Zienkiewicz, section 22.3.1, and writing column matrix $\mathrm{d}$ in place of $d_{i}$,

$$
\mathbf{d}=\mathbf{B} \mathbf{a}^{u} \text {, }
$$

we have

$$
d^{2}={ }^{1 / 4}\left(\mathbf{B} \mathbf{a}^{u}\right)^{T} \mathbf{E}\left(\mathbf{B} \mathbf{a}^{u}\right),
$$

where

$$
\mathbf{E}=\frac{1}{\mu} \mathbf{D} .
$$


Taking the derivative,

$$
\frac{\partial d^{2}}{\partial \mathbf{a}^{u}} \delta \mathbf{a}^{u}=1 / 4\left[\left(\delta \mathbf{a}^{u}\right)^{T} \mathbf{B}^{T} \mathbf{E B} \mathbf{a}^{u}+\mathbf{a}^{u T} \mathbf{B}^{T} \mathbf{E B} \delta \mathbf{a}^{u}\right],
$$

or rearranging,

$$
\frac{\partial d^{2}}{\partial \mathbf{a}^{u}} \delta \mathbf{a}^{u}=\left[1 / 2 \mathbf{a}^{\mu} \mathbf{B} \mathbf{B}^{x} \mathbf{E B}\right] \delta \mathbf{a}^{u}
$$

that is,

$$
\frac{\partial d^{2}}{\partial \mathbf{a}^{u}}=1 / 2 \mathbf{a}^{u} \mathbf{B}^{T} \mathbf{E B}=1 / 2\left(\mathbf{G a}^{u}\right)^{T} .
$$

From equations 1,6 , and $\mathrm{A} 11$, the ice viscosity, $\mu$, can be written in terms of the effective deformation rate, $d$, as

$$
\mu=\frac{\left(d^{2}\right)^{((1-n) / 2 n)}}{2 A^{1 / n}} .
$$

This yields

$$
\frac{\partial \mu}{\partial d^{2}}=\frac{(1-n) d^{((1 / n)-3)}}{4 n A^{1 / n}}
$$

Thus, the integral term in equation A9 - the contribution in Newton's method due to nonconstant $\mu$-is

$$
\left[\int_{\mathbf{a}} 1 / 2 \frac{\partial \mu}{\partial d^{2}}\left(\mathbf{G a}^{u}\right)\left(\mathbf{G a}^{u}\right)^{T} \mathrm{~d} \mathbf{\Omega}\right] \delta \mathbf{a}^{u}
$$

The column matrix

$$
\mathbf{Q} \equiv \mathbf{G a}^{u}=\mathbf{B}^{T} \sigma^{\prime}
$$

(defining $\mathbf{Q}$ as found in the element subroutine, not the $\mathbf{Q}$ of equation 24.10 of Zienkiewicz (1977, p. 710)) is evaluated by using the "current" velocities, $\mathbf{a}^{u}$, of the iterative Newton's method process. $Q$ must be calculated as part of accounting for "current" internal forces (Zienkiewicz, equation 24.2 , p. 699), so the dependence of the tangential matrix on $\mu$ can be obtained with little additional effort.

Some distribution of $\mu$ must be chosen initially to start the iterative process. In the program, this initial $\mu$ is assumed to be given by equation 6 with effective shear stress, $\tau$, identically 1 bar throughout the ice mass.

\section{UPPER FREE-SURFACE DYNAMICS}

To follow the motion of the glacier surface in time, the ice velocity along the surface, $\Gamma_{s}$, is resolved into generally nonorthogonal components along the surface and in the vertical direction; this vertical component is called the emergence velocity, $V_{\text {. }}$. If $\gamma$ is the angle between horizontal and an upward normal to the surface, define

$$
\mathbf{s}^{T}=(\operatorname{ctn} \gamma, 1),
$$

then

$$
V_{\mathbf{s}}=\mathbf{s}^{\mathrm{T}} \mathbf{u}=\mathbf{s}^{\mathrm{T}} \mathbf{N}^{u} \mathbf{a}^{\mathbf{u}} .
$$

For $V$. evaluated on the surface, the only nonzero elements in $\mathrm{N}^{\mu}$ are those which correspond to surface nodes. Let $\dot{h}$ represent the (unknown) rate of thickness change and suppose that

$$
\dot{h}=\mathbf{N}^{h} \mathbf{a}^{n},
$$

where the scalar shape function elements in $\mathbf{N}^{h}$ correspond to scalar velocity shape function elements for the surface nodes, for evaluation on the surface only; that is, they correspond to the nonzero elements of $\mathrm{N}^{*}$ in equation A23. If $\dot{b}$ is the balance rate, then at any point on the surface,

$$
\dot{h}-V_{\bullet}-\dot{b}=0 \text {. }
$$

To obtain a suitable numerical equation, use the Galerkin process and premultiply equation A25 by $(\delta \dot{h})^{T}$, then integrate over the surface:

$$
\left(\delta \mathbf{a}^{h}\right)^{T} \int_{\Gamma_{\iota}} \mathrm{N}^{h T}\left(\dot{h}-V_{\bullet}-\dot{b}\right) \mathrm{d} \Gamma_{s}=0
$$

Define

$$
\begin{gathered}
\mathbf{K}_{i j}{ }^{h}=\alpha \int_{\Gamma_{s}}\left(\mathbf{N}_{i}{ }^{h}\right)^{T} \mathbf{N}_{j}{ }^{h} \mathrm{~d} \Gamma_{a}, \\
\mathbf{K}_{i j}{ }^{u}=-\alpha \int_{\Gamma_{s}}\left(\mathbf{N}_{i}\right)^{T} \mathbf{s}^{T} \mathbf{N}_{j}{ }^{u} \mathrm{~d} \Gamma_{s}, \\
\mathbf{f}_{i}^{h}=-\alpha \int_{\Gamma_{d}}\left(\mathbf{N}_{i}{ }^{h}\right)^{T} \dot{b} \Gamma_{s},
\end{gathered}
$$

where $\dot{b}$ is actually stored for the surface nodes and interpolated along the surface as $\dot{h}$ is in equation A24 and where $\alpha$ is a constant to be explained in the next paragraph. Thus, equation A26 is

$$
K^{\boldsymbol{k}} \mathbf{a}^{\boldsymbol{h}}+K^{\boldsymbol{u}} \mathbf{a}^{\boldsymbol{u}}+\mathbf{f}^{\boldsymbol{u}}=\mathbf{0} .
$$

The equation which replaces equation 22.22 of Zienkiewicz $(1977$, p. 613$)$ is as follows:

$$
\left[\begin{array}{lrr}
\mathbf{K}^{h} & \mathbf{K}^{u} & \mathbf{0} \\
\mathbf{K}^{u T} & \mathbf{K} & \mathbf{K}^{p} \\
\mathbf{0} & \mathbf{K}^{p T} & \mathbf{0}
\end{array}\right]\left\{\begin{array}{l}
\mathbf{a}^{h} \\
\mathbf{a}^{u} \\
\mathbf{a}^{p}
\end{array}\right\}+\left\{\begin{array}{l}
\mathbf{f}^{h} \\
\mathbf{f} \\
0
\end{array}\right\}=\mathbf{0}
$$

$\mathrm{K}^{\boldsymbol{}} \boldsymbol{T}$ was added to the stiffness matrix to preserve symmetry, and the value assigned to constant $\alpha$ of equations A27 was chosen to be a very small number $\left(10^{-16}\right)$ so that the $\mathbf{K}^{\boldsymbol{\mu} T}$ would not significantly alter the second (set of) rows of equation A29.

Here the unknowns $\mathbf{a}^{h}, \mathbf{a}^{u}$, and $\mathbf{a}^{p}$ have been partitioned into groups for simplicity, but, in the program, 
they alternate, grouped by node number. The unknowns $\mathbf{a}^{h}$ occupy some of the third nodal degree of freedom (DOF) not needed for pressure unknowns $a^{p}$ (since pressure is only linear in the vertical direction). The third DOF of the second node from the surface in a column, thus, is assigned the unknown $\mathbf{a}_{i}{ }^{h}$, which then represents the rate of surface altitude change at the current column location.

The tangent stiffness matrix has $\mathbf{K}^{h}, \mathbf{K}^{u}$, and $\mathbf{K}^{\boldsymbol{}} \boldsymbol{T}$ added in the same locations as in equation A29. The right side of the Newton's method equation must include the contribution arising from "current" $V_{e}, \dot{b}$, and $\dot{h}$,

$$
\mathbf{P}_{i}^{h}=\alpha \int_{\Gamma_{s}}\left(\mathbf{N}_{i}^{h}\right)^{T}\left(V_{e}+\dot{b}-\dot{h}\right) \mathrm{d} \Gamma_{s} .
$$

(Caution: $\mathbf{P}$ as defined by Taylor in the element routines is the entire right side of the Newton's method equation; that is, it is $-\mathbf{f}-\mathbf{P}$ of equation 24.2 or equation 18.10 (Zienkiewicz, 1977, p. 699, 453).)

\section{SURFACE TRACTIONS AND BODY FORCES}

Water and atmospheric pressure (surface tractions) and gravity (a body force) are added to the equations, as in equation 22.16 of Zienkiewicz (1977, p. 612).

\section{UPDATING THE MESH}

If $h_{g}$ denotes the ice surface altitude and $h_{b}$ is the bed altitude and

$$
h=h_{g}-h_{b} \text { meters, }
$$

the eight nodes within a vertical column have been chosen to be at locations $h_{g}, h_{g}-0.4(h-10), h_{g}-0.8$ $(h-10), h_{g}-0.9(h-10), h_{b}+10, h_{b}+10, h_{b}+5$ and $h_{b}$, with a greater concentration of nodes near the bed where deformation rates are higher. (In an infinitely wide slab glacier with $n=3$, deformational velocity varies through the thickness as a quartic; the program would approximate this quartic with two quadratics.)

The upper free surface and calving face are updated as in section 22.6 of Zienkiewicz $\left(1977\right.$, p. 623), using $\mathbf{a}^{h}$ calculated as described in the section of Appendix A entitled "Upper Free-Surface Dynamics" and the calving speed from the calving law of equation 8 . Because of large deformations, the entire mesh is updated at each step. The updating is done by calculating glacier length at each time step and then by requiring that each column of nodes be at the same fractional location within this new length as it was initially. Nodes are then distributed within each column as a fraction of the new thickness, as described in the preceding paragraph.

\section{FUTURE MODIFICATION}

The program was written to allow easy future modification to three space dimensions; a large part of this change can be done by simply replacing twodimensional shape functions by three-dimensional ones. 


\section{APPENDIX B: USER INSTRUCTIONS FOR THE COMPUTER PROGRAM}

The general purpose finite element program resembles closely that described by Taylor in chapter 24 of Zienkiewicz (1977); only relevant changes and specialized modules are described in this appendix. The program now (1980) available from Taylor contains a data prerocessor that converts free format input to fields always of length 10 -if an integer is expected, the field is I10; if a FORTRAN real is expected, the field is F10.0.

\section{COORDINATE DATA}

The program assumes that nodes are specified in vertical columns. Each column is, to some extent, considered a unit. The sample run of Appendix C ( $p$. B34-B46) uses columns of 8 nodes (the user can select more elements per column if he chooses). The third and fourth nodes from the bottom in a column are at the same location on the column and have the velocity DOF tied together, allowing only a pressure discontinuity to accommodate the discontinuity in the $A$ flow law parameter at that point. Extra "dummy" columns can be specified beyond the initial terminus position to accommodate an advancing glacier. The NUMNP on the control card should be the total number of nodes including these extras. The true terminus position is as specified on the material property data card.

\section{MATERIAL PROPERTY DATA}

\begin{tabular}{|c|c|c|}
\hline Columns & Description & Variable \\
\hline 01 to 10 & $A$ of ice-flow law _- & $\mathrm{D}(1,1)$ \\
\hline 11 to 20 & $n$ of ice-flow law & $\mathrm{D}(2,1)$ \\
\hline 21 to 30 & Uppermost element in terminal face & $\mathrm{D}(3,1)$ \\
\hline 31 to 40 & Number of nodes in each column & $\mathrm{D}(4,1)$ \\
\hline
\end{tabular}

\section{BOUNDARY RESTRAINT DATA}

Boundary Condition Cards-FORMAT(8I10). - Use only $0,+1$, and -1 for the constraint conditions that Taylor describes. A boundary code describing tieing is the node number of a preceding like-numbered DOF. For example, to tie DOF 1 and DOF 2 of node 14 to DOF 1 and DOF 2 of node 13 , specify the following boundary condition codes:

$\begin{array}{rrrr}14 & 8 & 13 & 13 \\ 198 & 0 & 197 & 197\end{array}$

B32
The tieing uses the generation increment also to tie the first two degrees of freedom for node 22 to 21 , node 30 to $29, \ldots$, node 198 to 197 . When tieing is specified, only the DOF of the node tied to is retained in the system of equations. Do not tie degrees of freedom that have specified displacements.

Unused degrees of freedom should have displacements specified. Thus, the middle row of nodes in each element, except for the surface elements, should have specified displacements for the third DOF, because pressure is only modeled linearly in the vertical direction. (The middle row of nodes of the surface elements have the $\dot{h}$ unknown as the third DOF.) Also, the extra "dummy" nodes beyond the initial terminus position should have all degrees of freedom with displacements specified.

\section{NODAL FORCED BOUNDARY DATA}

Boundary forces $F\left(3,,^{\circ}\right)$ corresponding to unused degrees of freedom in a column are used to store the balance rate, $\dot{b}$, and sliding flow law parameter, $A_{b}$. These are considered to be at the location of the column when dynamic modeling changes the column position. Within a column, storage is as follows:

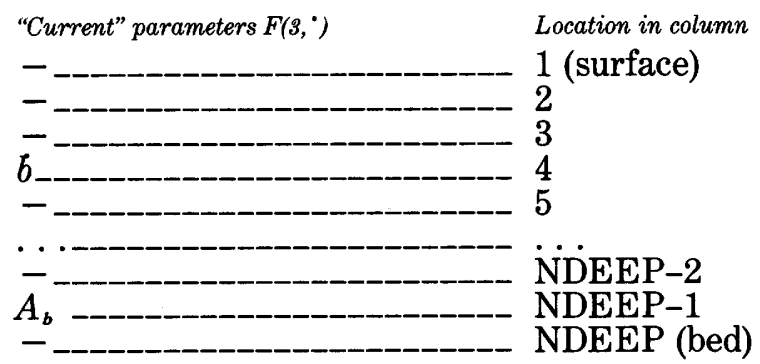

For example, if the second node from the bottom in a column is node number 55, the sliding flow law parameter, $A_{b}$, for the current position of the column is stored in $F(3,55)$.

\section{NODAL TEMPERATURE DATA}

In a manner similar to column storage of parameters in $\mathrm{F}\left(3,^{\circ}\right)$, nodal "temperatures," $\mathrm{T}\left({ }^{\bullet}\right)$, are used to store information corresponding to the initial configuration of the ice mass. Note the distinction that the $T\left({ }^{\circ}\right)$ refer to fixed initial column coordinates, while the $F\left(3,{ }^{\circ}\right)$ refer to 


\section{APPENDIX C: NEW SUBROUTINES}

The following subroutines were written by the author specifically to treat the modeling of glaciers.

\begin{tabular}{|c|c|c|c|}
\hline & SUBROUTINE ELMTO4 (D, UL, XL, IX,TL , S , P,NDF , NDM, NST, ISW) & ELM & \\
\hline C & & ELM & 002 \\
\hline & TWO DIMENSIONAL ELEMENT FOR ICE FLOW & ELM & 003 \\
\hline & & ELM & 004 \\
\hline & COMMON /CDATA/ O,HEAD (20), NUMNP, NUMEL , NUMMAT, NEN , NEQ, IPR & ELM & 005 \\
\hline & COMMON /ELDATA/ DM, N, MA, MCT, IEL, NEL & ELM & 006 \\
\hline & COMMON /RSTART/ ISTART & ELM & 007 \\
\hline & COMMON /JACOBI/ XS $(2,2), \mathrm{SX}(2,2)$ & ELM & 008 \\
\hline & COMMON M(1) & ELM & 009 \\
\hline & 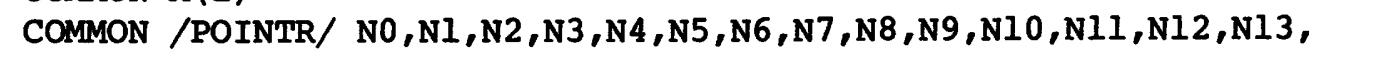 & ELM & 010 \\
\hline & $\star \mathrm{N} 14, \mathrm{NE}$ & ELM & 011 \\
\hline & LOGICAL SFLAG & ELM & 012 \\
\hline & DIMENSION XL (NDM, 1), UL (NDF, 1$), P(N D F, 1), S(N S T, 1), D(1), V(3), D V(2,2)$ & ELM & 013 \\
\hline & $1, \operatorname{SHP}(3,9), \operatorname{IX}(1), \operatorname{SG}(9), \operatorname{TG}(9), \operatorname{WG}(9), \operatorname{SHPP}(3,9), \operatorname{TL}(1)$ & ELM & 014 \\
\hline & DIMENSION SGID (3), TGID (3), WGID (3), IANODE (9), IXP (9), INTERP (9) & ELM & 015 \\
\hline & DIMENSION ITOP (3), MID (3), Q (27), ANODE (3) & ELM & 016 \\
\hline & IANODE GIVES VISCOSITY "A" INTERPOLATION (REDEFINITION OF NODES). & ELM & 017 \\
\hline & INTERP YIELDS PRESSURE INTERPOLATION ( $I=$ NODE USED, $0=$ NOT) & ELM & 018 \\
\hline & DATA IANODE $/ 1,2,2,1,3,2,3,1,3 /$, INTERP $/ 1,1,1,1,1,0,1,0,0 /$ & ELM & 019 \\
\hline & DATA ITOP $/ 3,4,7 /, \mathrm{MID} / 6,8,9 /, Q / 27 * 0 . /$ & ELM & 020 \\
\hline & Go To $(1,2,3,4,5,3)$, ISW & ELM & 021 \\
\hline & INPUT/OUTPUT FLUID PROPERTIES & ELM & 022 \\
\hline & LINTID IS THE NUMBER OF INTEGRATION POINTS IN EACH DIRECTION & ELM & 023 \\
\hline & $D(1)=A(I C E), D(2)=N$ & ELM & 024 \\
\hline & D(3) IS THE LOWEST NUMBERED NODE IN THE CALVING FACE - & ELM & 025 \\
\hline & ALL NODES FROM D(3) TO NUMNP ARE ASSUMED TO BE IN THE FACE. & ELM & 026 \\
\hline & D (4) IS THE NUMBER OF NODES IN A VERTICAL COLUMN THROUGH DEPTH. & ELM & 027 \\
\hline 1 & $\operatorname{READ}(5,1000) \quad(D(I), I=1,4)$ & ELM & 028 \\
\hline & $\operatorname{WRITE}(6,2000) \quad(D(I), I=1,4)$ & ELM & 029 \\
\hline & LINTID $=3$ & ELM & 030 \\
\hline & LINT $=0$ & ELM & 031 \\
\hline & ISTART $=0$ & ELM & 032 \\
\hline & FlEPS $=1 . / D(2)$ & ELM & 033 \\
\hline & F2EPS $=1 . / D(2)-1$ & ELM & 034 \\
\hline & RHOG $=0.0882$ & ELM & 035 \\
\hline & RHOGW $=0.0980$ & ELM & 036 \\
\hline & ATMOSP $=1.013$ & ELM & 037 \\
\hline & ALPHA $=1 . \mathrm{E}-16$ & ELM & 038 \\
\hline & NFACE $=D(3)+0.1$ & ELM & 039 \\
\hline & NDEEP $=D(4)+0.1$ & ELM & 040 \\
\hline
\end{tabular}


DO $20 I=1,9$

ELM 041

$\operatorname{IXP}(I)=0$

IF (INTERP (I) .EQ.1) NELPC $=I$

ELM 042

$20 \operatorname{SHPP}(3, I)=0$.

RETURN

2 RETURN

C.... COMPUTE SYMMETRIC TANGENT STIFFNESS AND OUT OF BALANCE FORCES.

C.... USE TANF, NOT TANG AND FORM -- ONLY ONE PASS PER ELEMENT.

3 ISTART = ISTART + 1

C.... REDEFINE NUMNP TO EXCLUDE "EXTRA" NODES BEYOND CALVING FACE. NUMNP = NFACE + NDEEP - 1

$L=$ LINTID

IF ( $L *$ L.NE. LINT) CALL PGAUSS (L,LINT,SG,TG,WG)

DO $65 \mathrm{~L}=1$, LINT

CALL SHAPE (SG (L) ,TG (L) ,XL , SHP , XSJ ,NDM, NEL, IX, . FALSE. )

XSJWG $=$ XSJ*WG $(L)$

C.... CALL PRESSURE SHAPE FUNCTIONS -- . TRUE. BECAUSE PRESSURE

C.... GRADIENT NOT NEEDED, AND WOULD NOT BE CORRECT ANYWAY

C.... BECAUSE NOT ISOPARAMETRIC.

NELP = MINO (NELPC, NEL)

DO $25 I=1$, NELPC

$25 \operatorname{IXP}(I)=\operatorname{IX}(I) * \operatorname{INTERP}(I)$

CALL SHAPE (SG (L) , TG (L) , XL , SHPP , XSJP, NDM, NELP , IXP , . TRUE.)

C.... COMPUTE VELOCITIES, VELOCITY GRADIENTS, PRESSURES $=\mathrm{V}(3)$,

C.... AND FLOW LAW PARAMETER A (ENTERED AS NODAL "TEMPERATURE").

C.... USE ONLY LOWER NODES TO ALLOW VISCOSITY DISCONTINUITY IN DEPTH,

C.... BUT STILL RETAIN CONTINUITY ALONG FLOW DIRECTION.

DO $32 I=1,2$

$V(I)=0$.

DO $31 \mathrm{~K}=1$, NEL

$31 \mathrm{~V}(\mathrm{I})=\mathrm{V}(\mathrm{I})+\operatorname{SHP}(3, \mathrm{~K}) * \mathrm{UL}(\mathrm{I}, \mathrm{K})$

DO $32 \mathrm{~J}=1,2$

$\mathrm{DV}(\mathrm{I}, \mathrm{J})=0.0$

DO $32 \mathrm{~K}=1$, NEL

$32 \operatorname{DV}(I, J)=D V(I, J)+\operatorname{SHP}(J, K) * U L(I, K)$

$\mathrm{V}(3)=0$.

DO $280 \mathrm{~K}=1$, NELP

$280 \mathrm{~V}(3)=\mathrm{V}(3)+\operatorname{SHPP}(3, \mathrm{~K}) * \mathrm{UL}(3, \mathrm{~K})$

$A=0$.

C.... CHECK IF AT BED.

IF (MOD (IX (1) ,NDEEP) .NE. 0) GO TO 283

C.... COMPUTE "A" FLOW LAW COEFFICIENT ALONG BED TO SIMULATE SLIDING. DO $281 \mathrm{~K}=1,3$

281 CALL VALUES (ANODE $(K), M(N 10), 3, \operatorname{IX}(M I D(K)), N D F)$

DO $282 \mathrm{~K}=1$, NEL

$282 A=A+\operatorname{SHP}(3, K) * \operatorname{ANODE}(\operatorname{IANODE}(K))$

$283 A=\operatorname{AMAXI}(D(1), A)$

C.... COMPUTE EFFECTIVE STRAIN RATE EPSEFF

EPSEFF $=0$.

DO $290 \quad I=I, 2$

ELM 043

ELM 044

ELM 045

ELM 046

ELM 047

ELM 048

ELM 049

ELM 050

ELM 051

ELM 052

ELM 053

ELM 054

ELM 055

ELM 056

ELM 057

ELM 058

ELM 059

ELM 060

ELM 061

ELM 062

ELM 063

ELM 064

ELM 065

ELM 066

ELM 067

ELM 068

ELM 069

ELM 070

ELM 071

ELM 072

ELM 073

ELM 074

ELM 075

ELM 076

ELM 077

ELM 078

ELM 079

ELM 080

ELM 081

ELM 082

ELM 083

ELM 084

ELM 085

ELM 086

ELM 087

ELM 088

ELM 089

ELM 090 


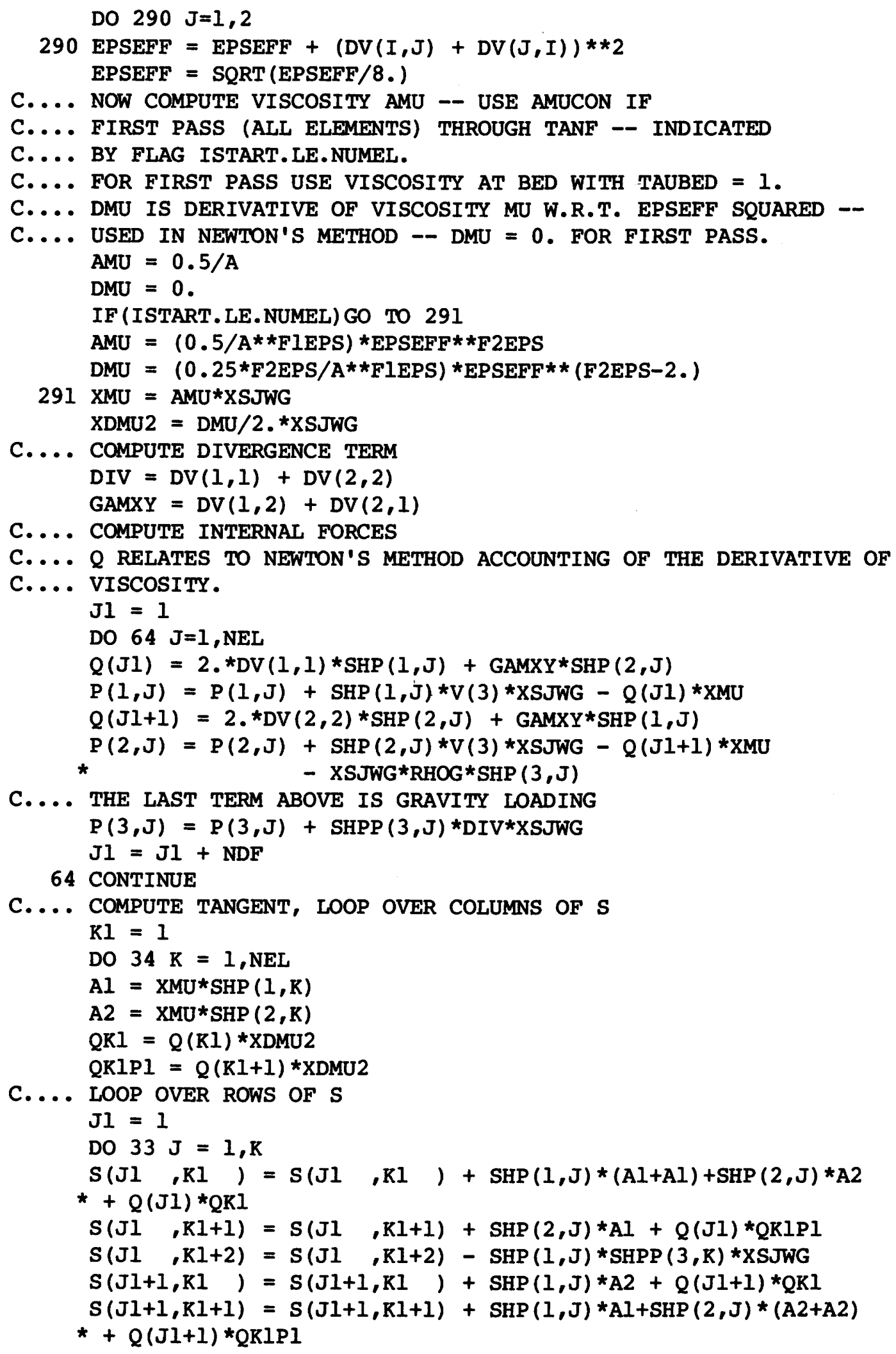

ELM 091

ELM 092

ELM 093

ELM 094

ELM 095

ELM 096

ELM 097

ELM 098

ELM 099

ELM 100

ELM 101

ELM 102

ELM 103

ELM 104

ELM 105

ELM 106

ELM 107

ELM 108

ELM 109

ELM 110

ELM 111

ELM 112

ELM 113

ELM 114

ELM 115

ELM 116

ELM 117

ELM 118

ELM 119

ELM 120

ELM 121

ELM 122

ELM 123

ELM 124

ELM 125

ELM 126

ELM 127

ELM 128

ELM 129

ELM 130

ELM 131

ELM 132

ELM 133

ELM 134

ELM 135

ELM 136

ELM 137

ELM 138

ELM 139

ELM 140 


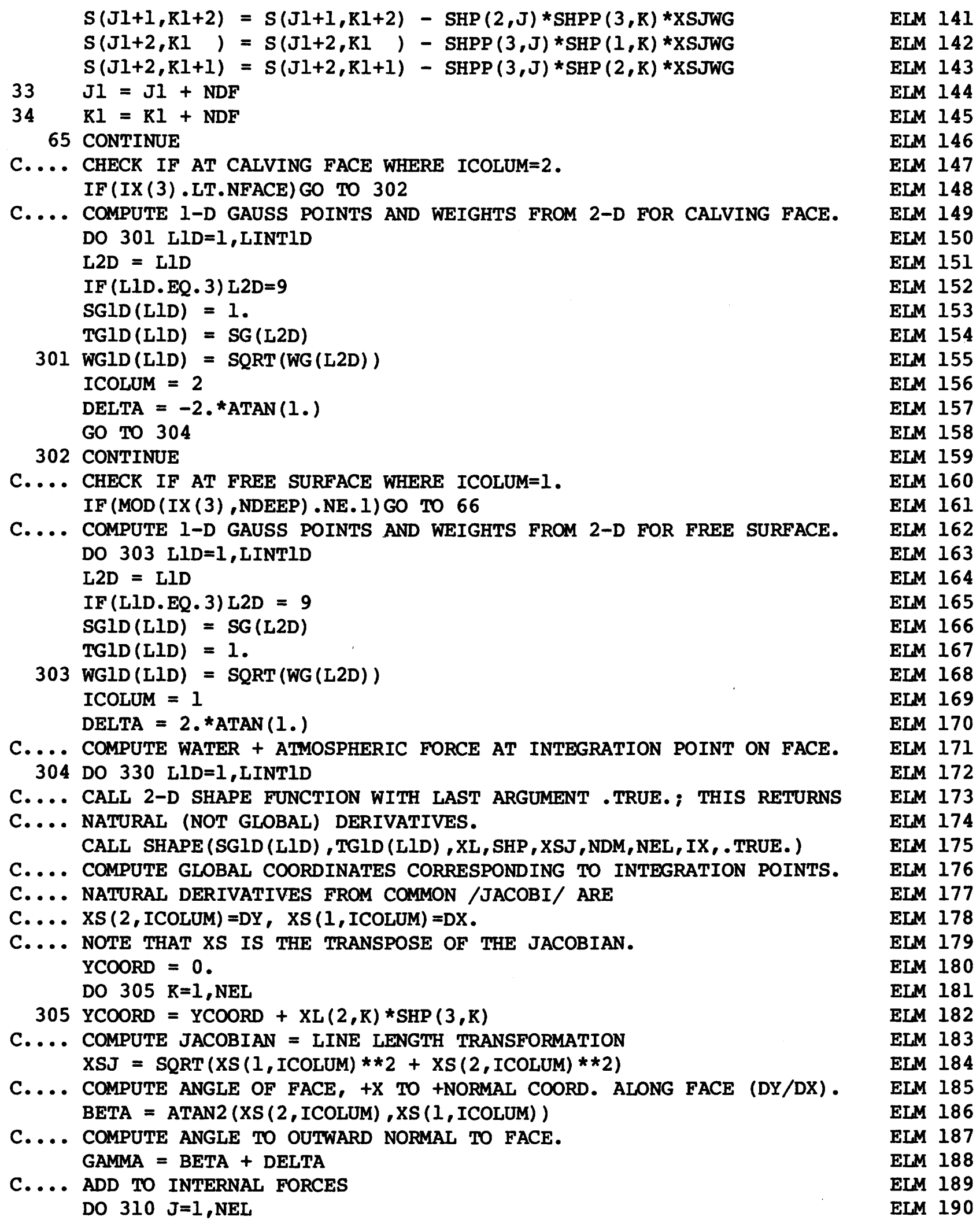

C.... COMPUTE 1-D GAUSS POINTS AND WEIGHTS FROM 2-D FOR FREE SURFACE. DO 303 LID=1,LINTID

C.... COMPUTE WATER + ATMOSPHERIC FORCE AT INTEGRATION POINT ON FACE. 304 DO 330 LID=1, LINTID

C.... CALL 2-D SHAPE FUNCTION WITH LAST ARGUMENT .TRUE.; THIS RETURNS

C.... NATURAL (NOT GLOBAL) DERIVATIVES. CALL SHAPE (SGID (LID) , TGID (LID) ,XL , SHP , XSJ , NDM, NEL , IX , . TRUE. )

C.... COMPUTE GLOBAL COORDINATES CORRESPONDING TO INTEGRATION POINTS.

C.... NATURAL DERIVATIVES FROM COMMON /JACOBI/ ARE

C. ... XS $(2, I C O L U M)=D Y, X S(1, I C O L U M)=D X$.

C.... NOTE THAT XS IS THE TRANSPOSE OF THE JACOBIAN. YCOORD $=0$. DO $305 \mathrm{~K}=1$, NEL 


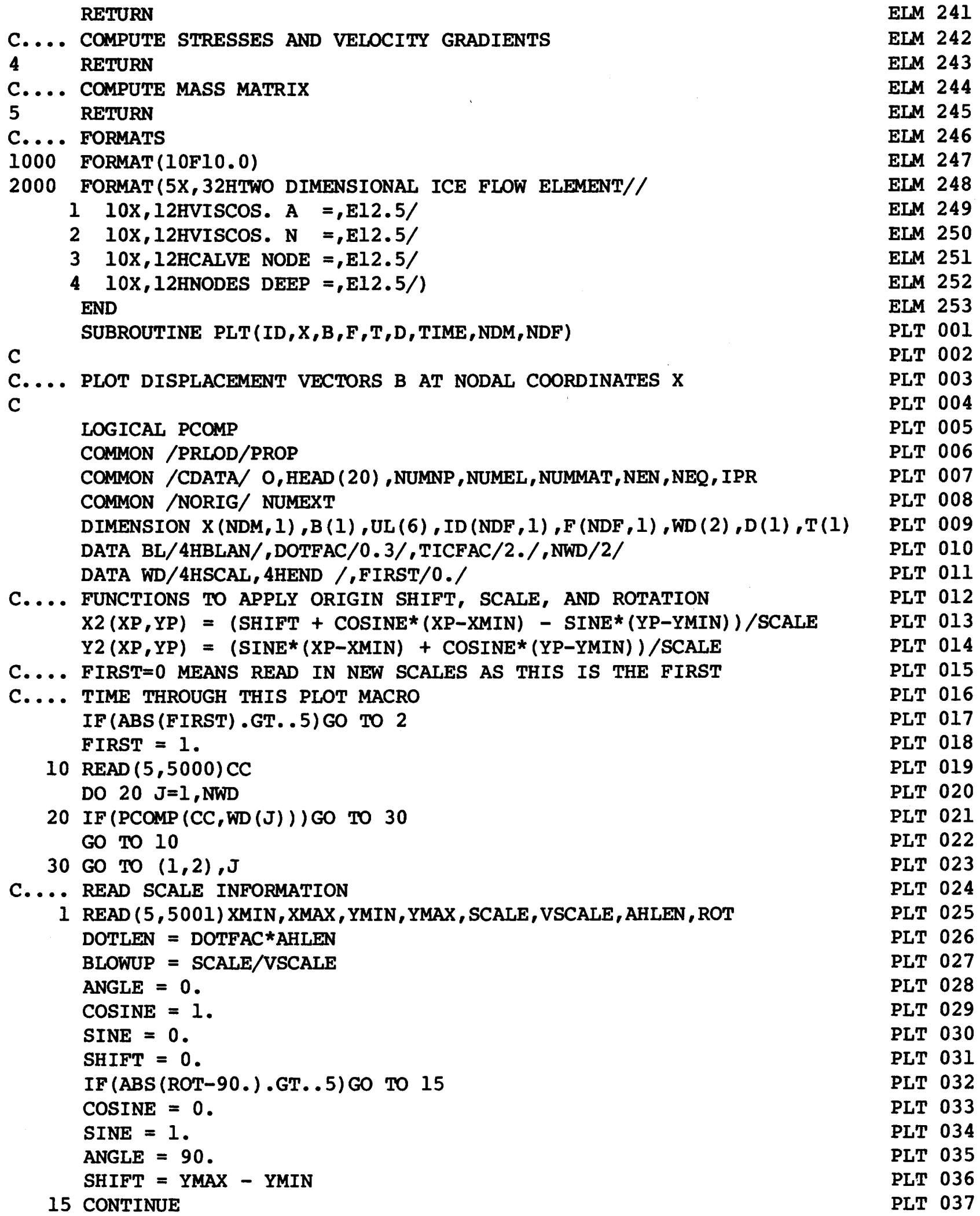




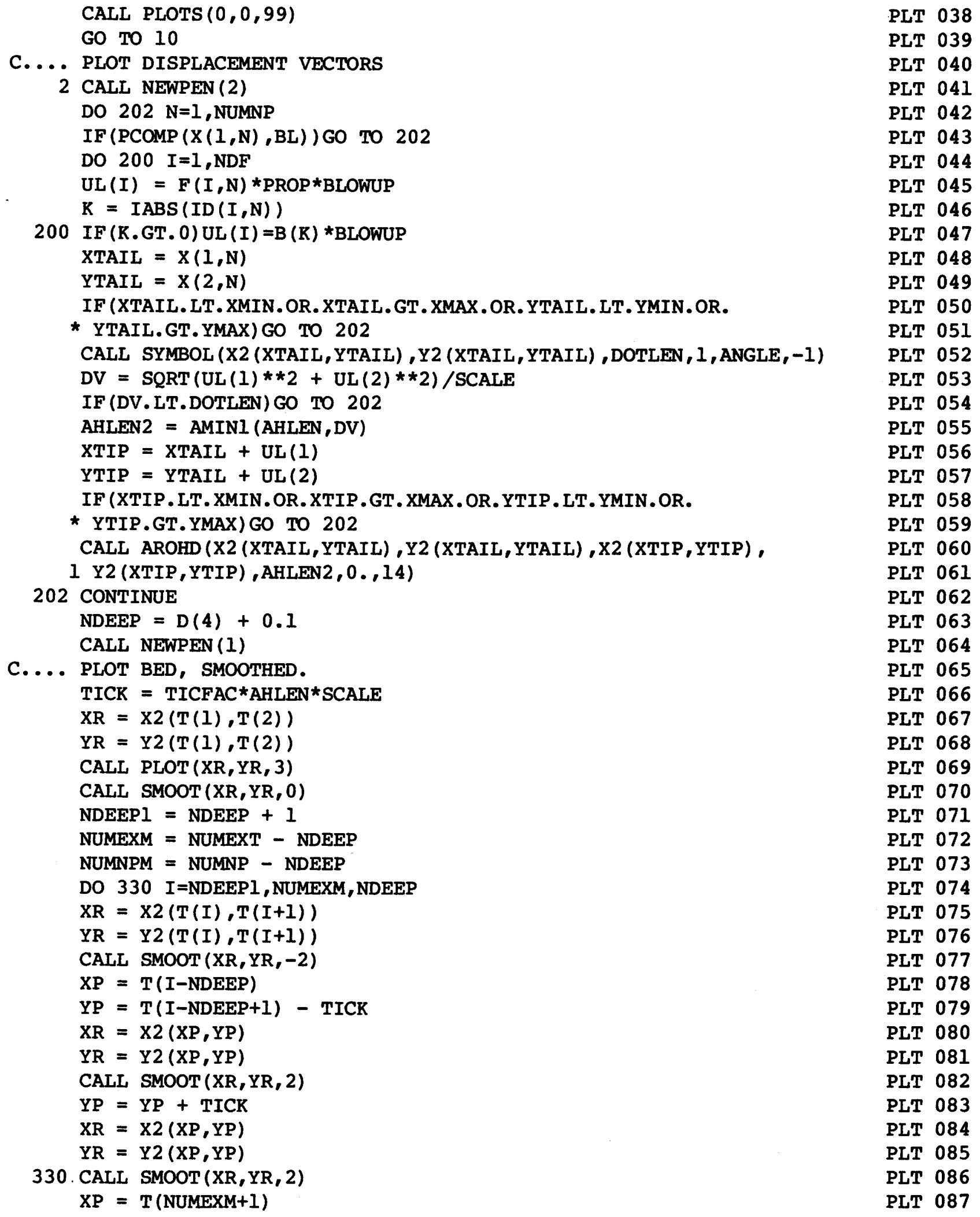




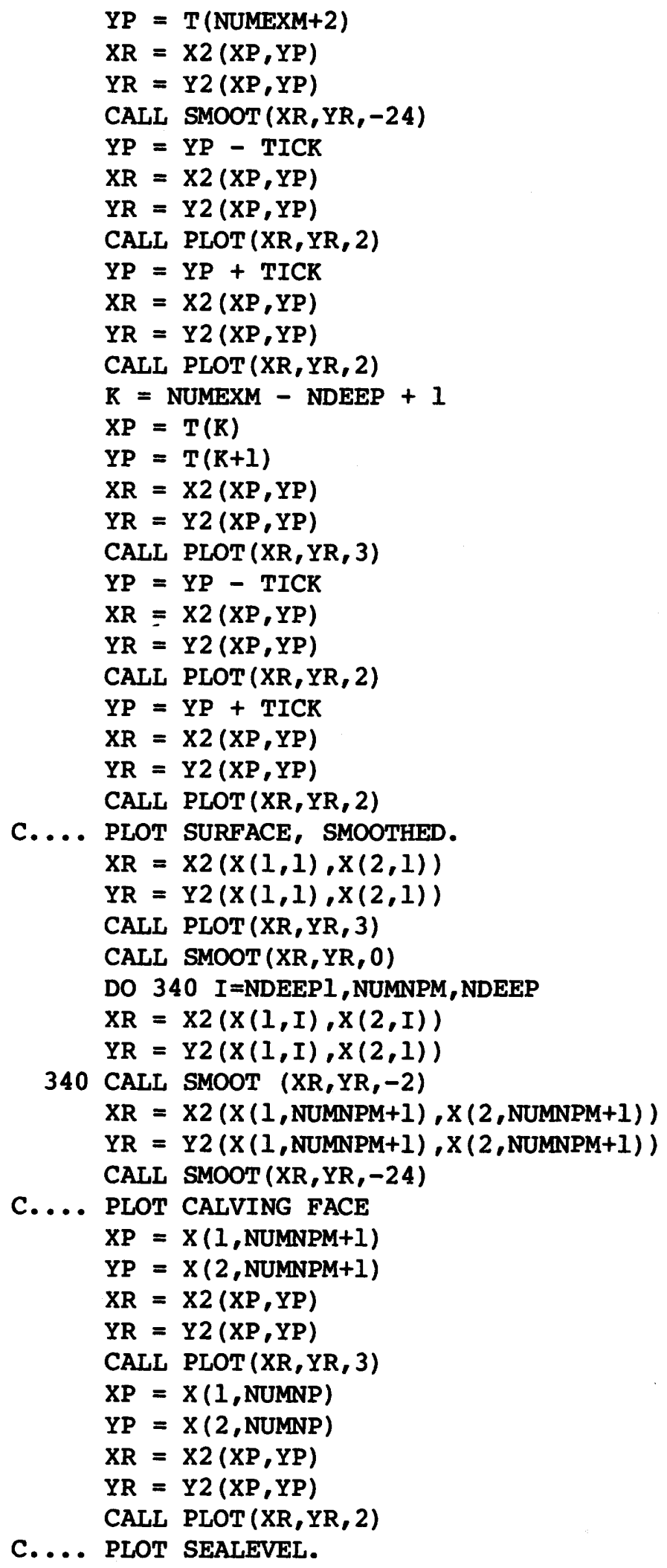

PLT 088

PLT 089

PLT 090

PLT 091

PLT 092

PLT 093

PLT 094

PLT 095

PLT 096

PLT 097

PLT 098

PLT 099

PLT 100

PLT 101

PLT 102

PLT 103

PLT 104

PLT 105

PLT 106

PLT 107

PLT 108

PLT 109

PLT 110

PLT 111

PLT 112

PLT 113

PLT 114

PLT 115

PLT 116

PLT 117

PLT 118

PLT 119

PLT 120

PLT 121

PLT 122

PLT 123

PLT 124

PLT 125

PLT 126

PLT 127

PLT 128

PLT 129

PLT 130

PLT 131

PLT 132

PLT 133

PLT 134

PLT 135

PLT 136

PLT 137 


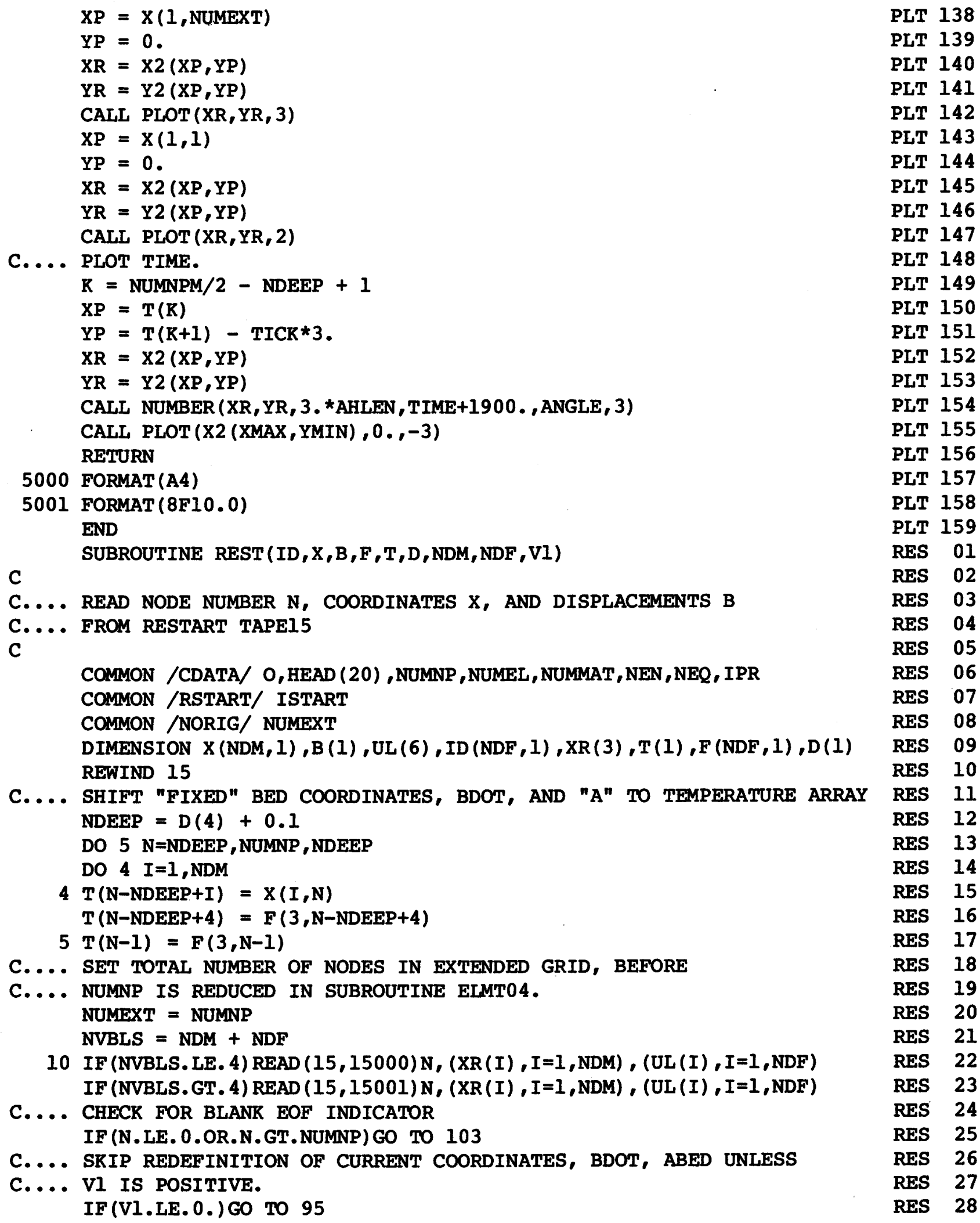

PLT 138

PLT 139

PLT 140

PLT 141

PLT 142

PLT 143

PLT 144

PLT 145

PLT 146

PLT 147

PLT 148

PLT 149

PLT 150

PLT 151

PLT 152

PLT 153

PLT 154

PLT 155

PLT 156

PLT 157

PLT 158

PLT 159

RES 01

RES 02

RES 03

RES 04

RES 05

RES 06

RES 07

RES 08

RES 09

RES 10

RES 11

RES 12

RES 13

RES 14

RES 15

RES 16

RES 17

RES 18

RES 19

RES 20

RES 21

RES 22

RES 23

RES 24

RES 25

RES 26

RES 27

RES 28 


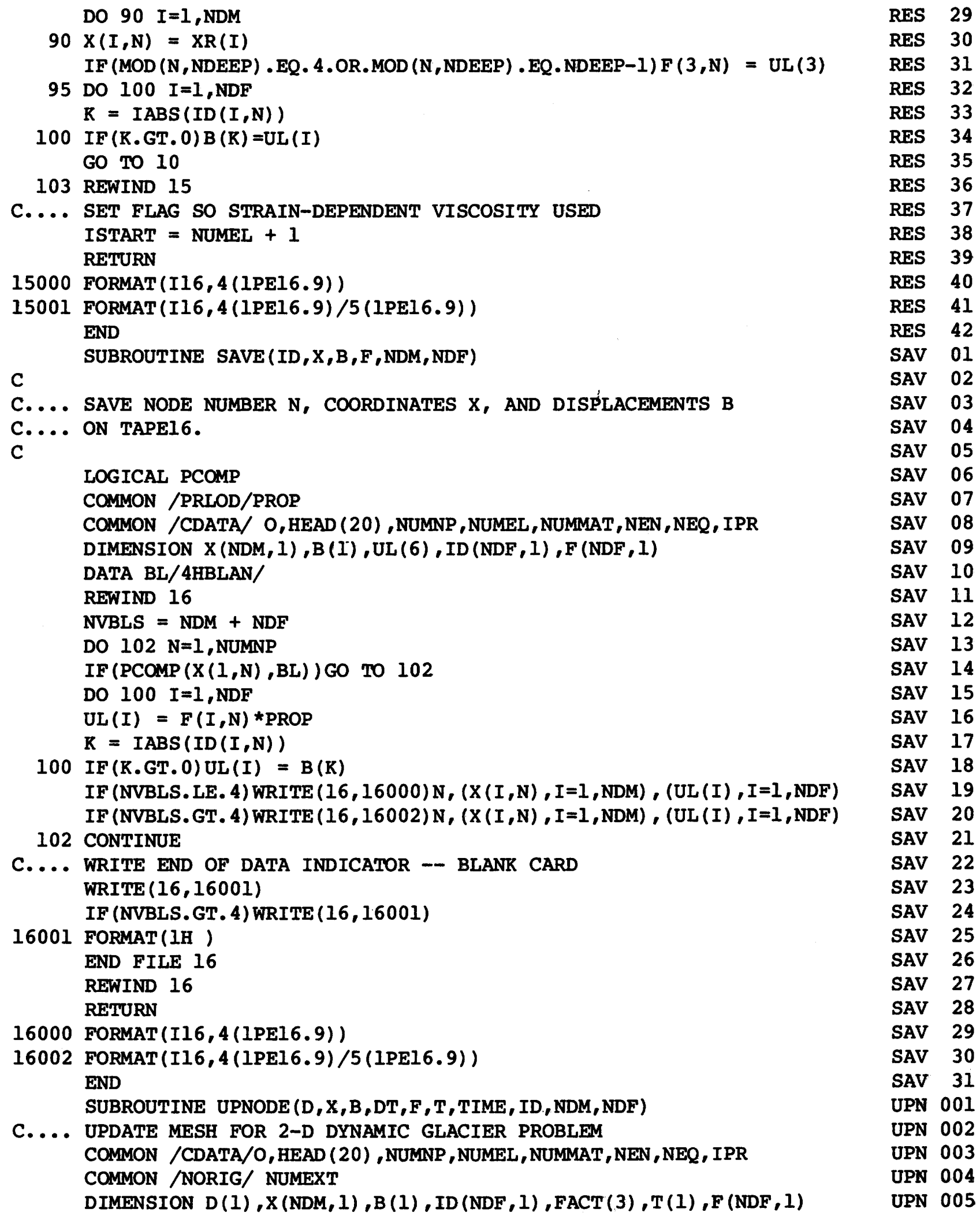




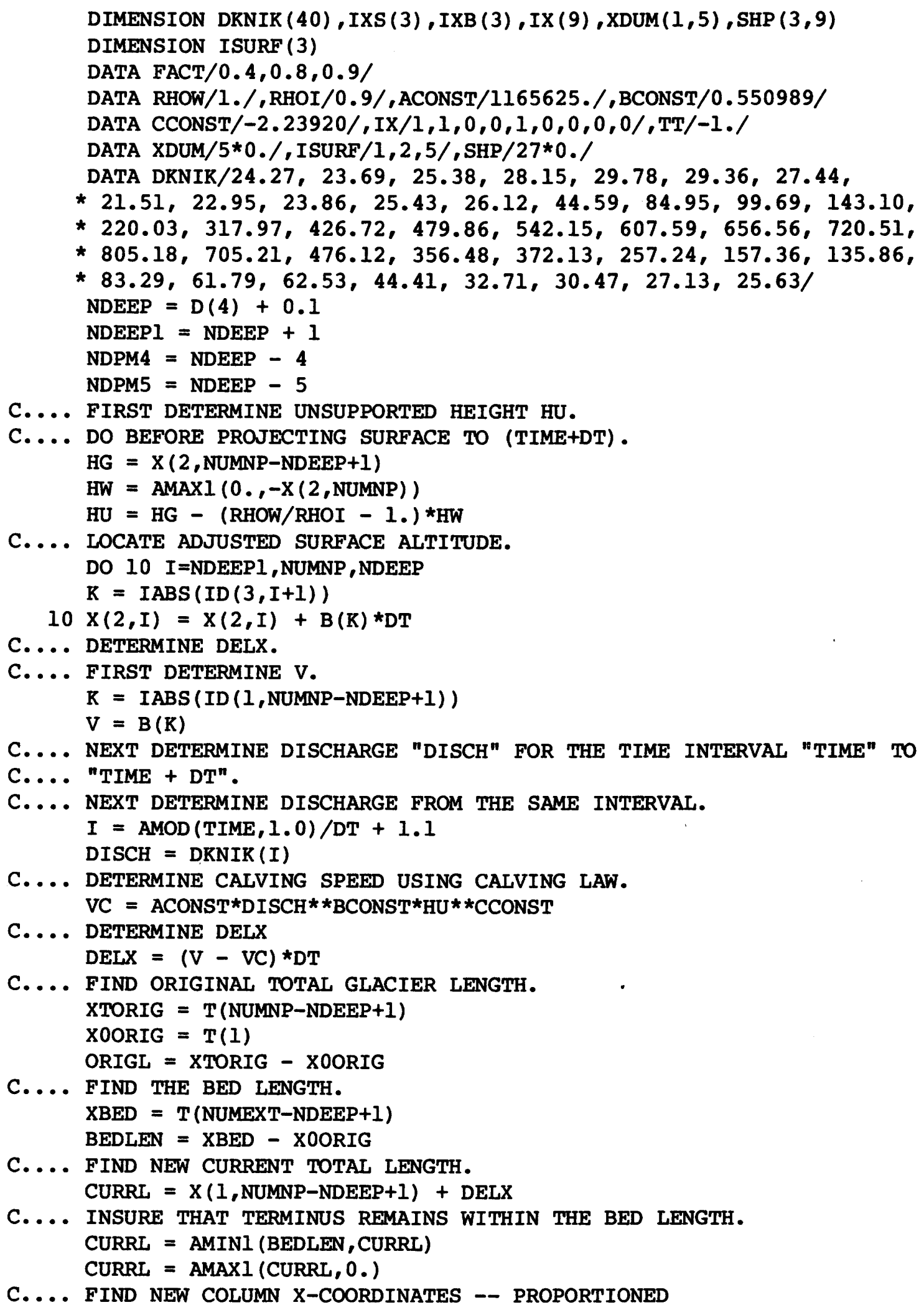

UPN 006

UPN 007

UPN 008

UPN 009

UPN 010

UPN 011

UPN 012

UPN 013

UPN 014

UPN 015

UPN 016

UPN 017

UPN 018

UPN 019

UPN 020

UPN 021

UPN 022

UPN 023

UPN 024

UPN 025

UPN 026

UPN 027

UPN 028

UPN 029

UPN 030

UPN 031

UPN 032

UPN 033

UPN 034

UPN 035

UPN 036

UPN 037

UPN 038

UPN 039

UPN 040

UPN 041

UPN 042

UPN 043

UPN 044

UPN 045

UPN 046

UPN 047

UPN 048

UPN 049

UPN 050

UPN 051

UPN 052

UPN 053

UPN 054

UPN 055 
C.... AS IN ORIGINAL MESH.

UPN 056

C.... THE FIRST COLUMN REMAINS FIXED -- START WITH THE SECOND. $\operatorname{IXS}(1)=1$ $\operatorname{IXS}(3)=1+$ NDEEP

$\operatorname{IXS}(2)=1+2{ }^{*}$ NDEEP

$\operatorname{IXB}(1)=1$.

$\operatorname{IXB}(3)=1+$ NDEEP

$\operatorname{IXB}(2)=1+2 \star N D E E P$

UPN 057

UPN 058

UPN 059 .

UPN 060

UPN 061

UPN 062

DO 300 I=NDEEP I, NUMNP, NDEEP

C.... FIND ORIGINAL X-COORDINATE OF COLUMN. XIORIG $=T(I)$

C.... FIND PROPORTIONATE NEW X-COORDINATE. XSURF $=($ XIORIG - XOORIG) $/$ ORIGL *CURRL + XOORIG

C.... REPLACE X-COORDINATE OF ALL NODES IN THIS COLUMN EXCEPT

C.... THE SURFACE NODE. DO $40 \mathrm{~J}=2$, NDEEP

$40 \times(1, I+J-1)=X S U R F$

C.... DETERMINE CORRECT ELEMENT FOR SURFACE ALTITUDE INTERPOLATION.

50 IF (IXS (2) . GE. NUMNP-NDEEP+1) GO TO 60

IF (XSURF.LE.X $(1$, IXS (2)) ) GO TO 60

DO $55 \mathrm{R}=1,3$

UPN 063

UPN 064

UPN 065

UPN 066

UPN 067

UPN 068

UPN 069

UPN 0.70

UPN 071

UPN 072

UPN 073

UPN 074

UPN 075

UPN 076

UPN 077

UPN 078

GO TO 50

60 CONTINUE

C.... INTERPOLATE SURFACE.

C.... FIRST FIND CORRESPONDING NATURAL COORDINATES.

IF (XSURF.GE.X(1, IXS (3)))

* SS $=(X S U R F-X(1, \operatorname{IXS}(3))) /(X(1, \operatorname{IXS}(2))-X(1, \operatorname{IXS}(3)))$

IF (XSURF. LT.X $(1, \operatorname{IXS}(3)))$

* SS $=($ XSURF $-X(1, \operatorname{IXS}(3))) /(X(1, \operatorname{IXS}(3))-X(1, \operatorname{IXS}(1)))$

CALL SHAPE (SS, TT, XDUM, SHP , XSJ , 1, 5, IX, . TRUE.)

YSURF $=0$.

DO $70 \mathrm{~K}=1,3$

70 YSURF $=$ YSURF $+\operatorname{SHP}(3, \operatorname{ISURF}(\mathrm{K})) * X(2, \operatorname{IXS}(K))$

C.... STORE INTERPOLATED NEW CURRENT Y-COORDINATE OF THE SURFACE NODE

C.... IN PLACE OF THE Y-COORDINATE OF THE SECOND NODE OF THE COLUMN,

C.... TEMPORARILY.

$X(2, I+1)=$ YSURF

C.... DETERMINE CORRECT ELEMENT FOR BED INTERPOLATION.

250 IF (IXB (2) . GE. NUMEXT-NDEEP+1) GO TO 260

IF (XSURF.LE.T(IXB(2))) GO TO 260

DO $255 \mathrm{~K}=1,3$

$255 \operatorname{IXB}(K)=\operatorname{IXB}(K)+$ NDEEP

GO TO 250

260 CONTINUE

C.... INTERPOLATE BED.

C.... FIRST FIND CORRESPONDING NATURAL COORDINATES.

IF (XSURF.GE.T (IXB (3)))

* SS $=($ XSURF $-T(\operatorname{IXB}(3))) /(\operatorname{T}(\operatorname{IXB}(2))-T(\operatorname{IXB}(3)))$

UPN 079

UPN 080

UPN 081

UPN 082

UPN 083

UPN 084

UPN 085

UPN 086

UPN 0.87

UPN 088

UPN 089

UPN 090

UPN 091

UPN 092

UPN 093

UPN 094

UPN 095

UPN 096

UPN 097

UPN 098

UPN 099

UPN 100

UPN 101

UPN 102

UPN 103

UPN 104

IF (XSURF. LT. T (IXB (3)))

UPN 105 


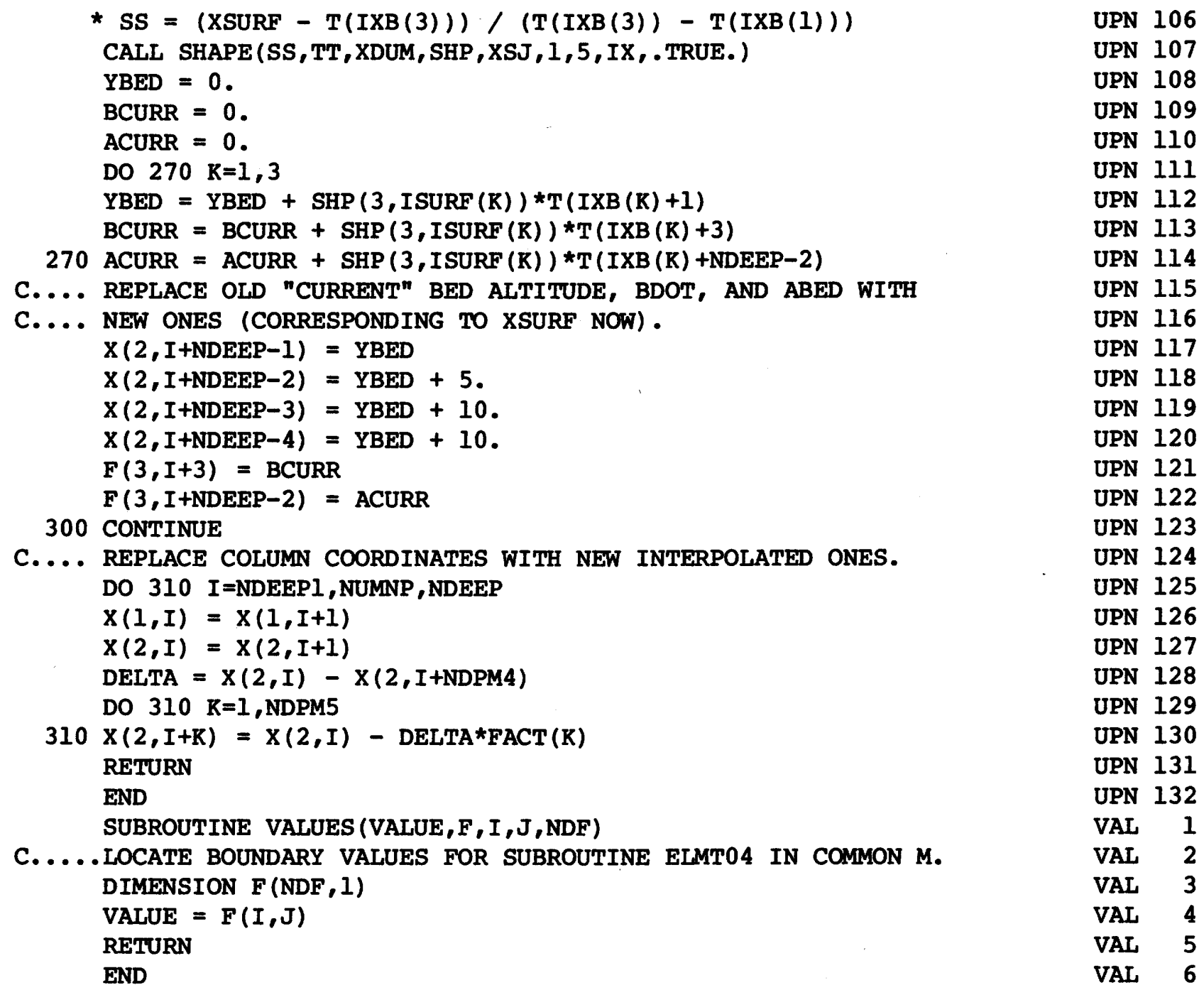




\section{APPENDIX D: MODIFICATIONS OF THE GENERAL PURPOSE FINITE ELEMENT PROGRAM}

Included below are modifications to the general purpose finite element program as it is listed in Zienkiewicz (1977). The subroutine FREEFM is from R. L. Taylor (written commun., 1980), as received from him in the card deck of the general purpose program. It is included here for completeness, so that the reader may refer to the program listed in Zienkiewicz. Some single line modifications listed below are also from Taylor; these are indicated either by explicit statement to that effect or by identification of the form CR $4 / 80 \mathrm{C}$ in columns 73 through 80 of the card. Changes with blanks in these columns are attributable to the author. Enough lines of the general purpose subroutines of Zienkiewicz (1977) are given so that the reader can locate the changes. The inclusion of modifications by Taylor is meant only to specify the exact form of the program used in the modeling. It is strongly recommended that the interested reader obtain the latest version of the program directly from Taylor.

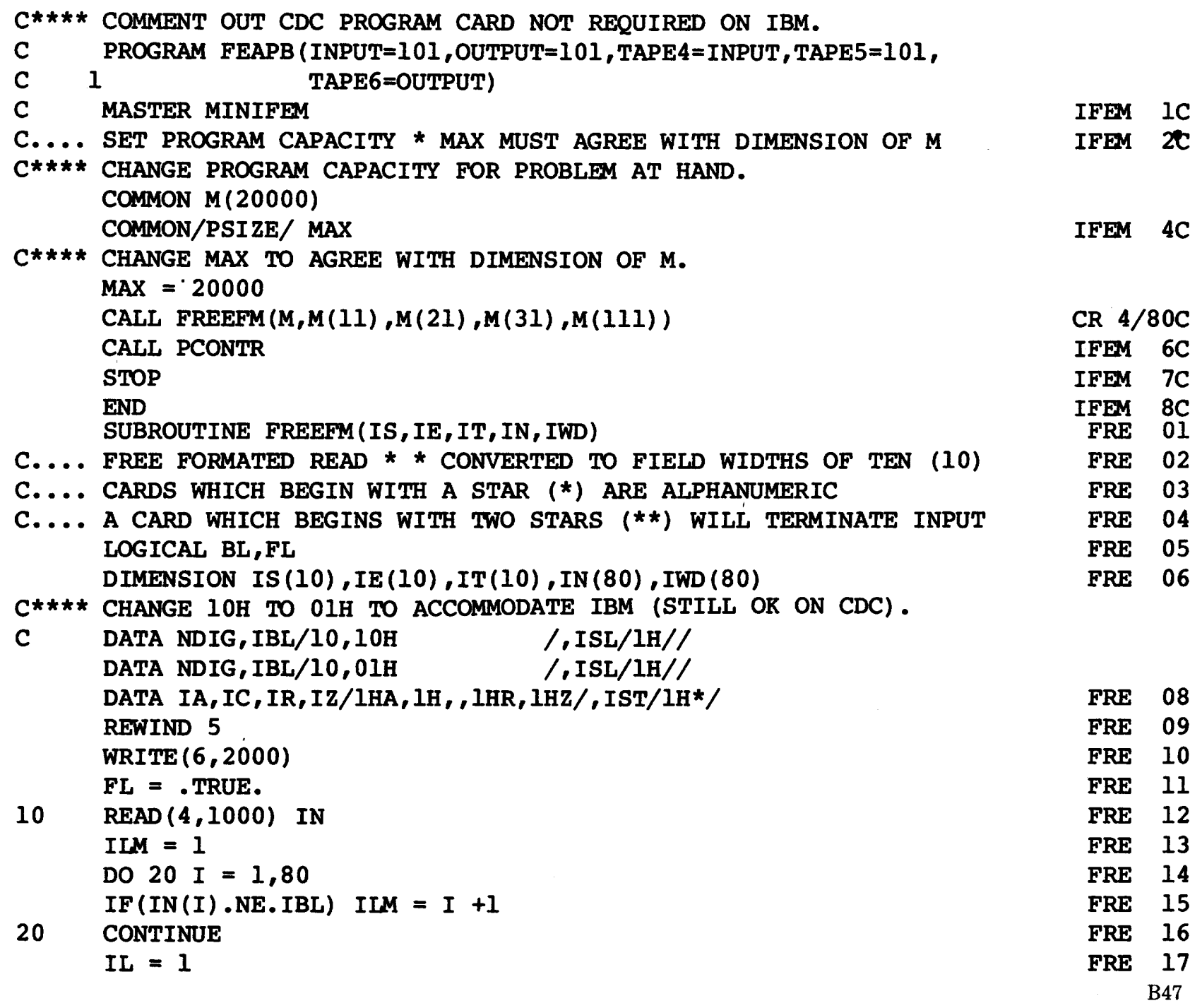




\begin{tabular}{|c|c|c|c|}
\hline 30 & $J L=I L+1$ & FRE & 18 \\
\hline & DO $35 \mathrm{I}=1,80$ & FRE & 19 \\
\hline 35 & $I W D(I)=I B L$ & FRE & 20 \\
\hline & IF(IN(IL).NE.IST) GO TO 50 & FRE & 21 \\
\hline & IF(IN(JL) .EQ.IST) GO TO 160 & FRE & 22 \\
\hline & DO $40 I:=J L, I L M$ & FRE & 23 \\
\hline & $\operatorname{IF}(\operatorname{IN}(I) . E Q . I S L) \quad G O$ TO 45 & FRE & 24 \\
\hline 40 & $\operatorname{IWD}(I-I L)=\operatorname{IN}(I)$ & FRE & 25 \\
\hline & $I L=I L M+1$ & FRE & 26 \\
\hline & GO TO 150 & FRE & 27 \\
\hline 45 & $I L=I+I$ & FRE & 28 \\
\hline & GO TO 150 & FRE & 29 \\
\hline 50 & DO $100 \mathrm{I}=1,10$ & FRE & 30 \\
\hline & $I S(I)=0$ & FRE & 31 \\
\hline 100 & $I T(I)=I R$ & FRE & 32 \\
\hline & $B L=$. TRUE. & FRE & 33 \\
\hline & $k=1$ & FRE & 34 \\
\hline 105 & $J=I N(I L)$ & FRE & 35 \\
\hline & IF (J.EQ.IBL.AND.BL) GO TO 120 & FRE & 36 \\
\hline & IF (J.EQ.IBL.OR.J.EQ.IC.OR.J.EQ.ISL) GO TO 110 & FRE & 37 \\
\hline & IF (.NOT.BL) GO TO 120 & FRE & 38 \\
\hline & $\mathrm{BL}=$. FALSE. & FRE & 39 \\
\hline & $I S(K)=I L$ & FRE & 40 \\
\hline & IF (J.GE.IA.AND.J.IIE.IZ) IT(K) = IA & FRE & 41 \\
\hline & GO TO 120 & FRE & 42 \\
\hline 110 & $\mathrm{BL}=. \mathrm{TRUE}$ & FRE & 43 \\
\hline . & $I E(K)=I L-I$ & FRE & 44 \\
\hline & $K=K+1$ & FRE & 45 \\
\hline 120 & $I L=I L+I$ & FRE & 46 \\
\hline & IF(K.GT.8.OR.J.EQ.ISL) GO TO 125 & FRE & 47 \\
\hline & IF (IL.LE.ILM) GO TO 105 & FRE & 48 \\
\hline 125 & $K=K-1$ & FRE & 49 \\
\hline & IF(K.EQ.0) GO TO 150 & FRE & 50 \\
\hline & $\mathrm{KL}=1$ & FRE & 51 \\
\hline & $\mathrm{KR}=\mathrm{NDIG}$ & FRE & 52 \\
\hline & DO $145 I=1, K$ & FRE & 53 \\
\hline & $\mathrm{JL}=\mathrm{IS}(\mathrm{I})$ & FRE & 54 \\
\hline & IF(JL.EQ.0) GO TO 144 & FRE & 55 \\
\hline & $J R=I E(I)$ & FRE & 56 \\
\hline & IF (JR-JL.GT.9) GO TO 200 & FRE & 57 \\
\hline & $I I=K R-J R$ & FRE & 58 \\
\hline & $I F(I T(I) \cdot E Q \cdot I A) \quad I I=K L-J L$ & FRE & 59 \\
\hline & DO $140 \mathrm{~J}=\mathrm{JL}, \mathrm{JR}$ & FRE & 60 \\
\hline 140 & $\operatorname{IWD}(J+I I)=\operatorname{IN}(J)$ & FRE & 61 \\
\hline 144 & $K L=K R+1$ & FRE & 62 \\
\hline 145 & $\mathrm{KR}=\mathrm{KR}+\mathrm{NDIG}$ & FRE & 63 \\
\hline 150 & WRITE $(6,2001)$ IWD & FRE & 64 \\
\hline & WRITE $(5,1000)$ IWD & FRE & 65 \\
\hline & IF (IL.LE.ILM.OR.IN(IL-1) .EQ.ISL) GO TO 30 & FRE & 66 \\
\hline & GO TO 10 & FRE & 67 \\
\hline 160 & REWIND 5 & FRE & 68 \\
\hline & WRITE $(6,2002)$ & FRE & 69 \\
\hline & IF (FL) RETURN & FRE & 70 \\
\hline & STOP & FRE & 71 \\
\hline
\end{tabular}


200 WRITE $(6,3000)$ IN
FL $=$.FALSE.
GO TO 10
1000 FORMAT $(80 A 1)$
2000 FORMAT $(1 \mathrm{H} 1,54 \mathrm{HFIXED}$ FORMAT FORM OF DATA CARDS FROM FREE FORMAT INP
IUT $\quad / / / 1 \mathrm{X})$

FRE 72

FRE 73

FRE 74

FRE 75

FRE 76

FRE 77

FRE 78

2001 FORMAT $(5 X, 80 \mathrm{Al})$

2002 FORMAT (1H0, 17HEND OF DATA INPUT $/ / / 1 \mathrm{X}$ )

FRE 79

3000 FORMAT (5X, 48HMORE THAN TEN CHARACTERS/DIGITS ON THE DATA CARD//

FRE 80

1 $10 \mathrm{X}, 80 \mathrm{Al})$

FRE 81

FRE 82

END

PCO IC

SUBROUTINE PCONTR

PCO 14C

COMMON $M(1)$

$C \star \star \star \star$ ADD THE FOLLOWING COMMON SO VARIABLES IN M CAN BE FOUND. COMMON /POINTR/ N0,N1,N2,N3, N4, N5, N6, N7, N8, N9, N10,N11,N12, N13,

* N14, NE

DIMENSION TITL (20), WD (3)

PCO 15C

CALL SETMEM(NE)

$59 \mathrm{C}$

CALL PZERO (M(N13), NEQ)

CR10/77C

GO TO 1

PCO $60 \mathrm{C}$

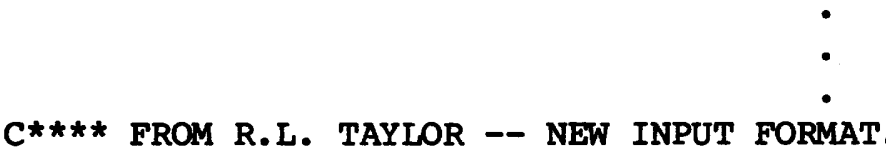

1001 FORMAT (8I10)

PCO 68C

END

PCO 74C

BLOCK DATA

1C

$C * * * *$ SINGLE PRECISION IS SUFFICIENT. DATA $0 / 1 \mathrm{HO} /$, IPR/1/

END

$9 \mathrm{C}$

SUBROUTINE GENVEC (NDM, $\mathrm{X}, \mathrm{CD}, \mathrm{PRT}, \mathrm{ERR}$ )

GEN IC

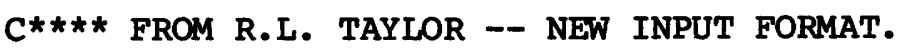

1000 FORMAT (2I10,6F10.0)

GEN 38C

END

GEN 44C 


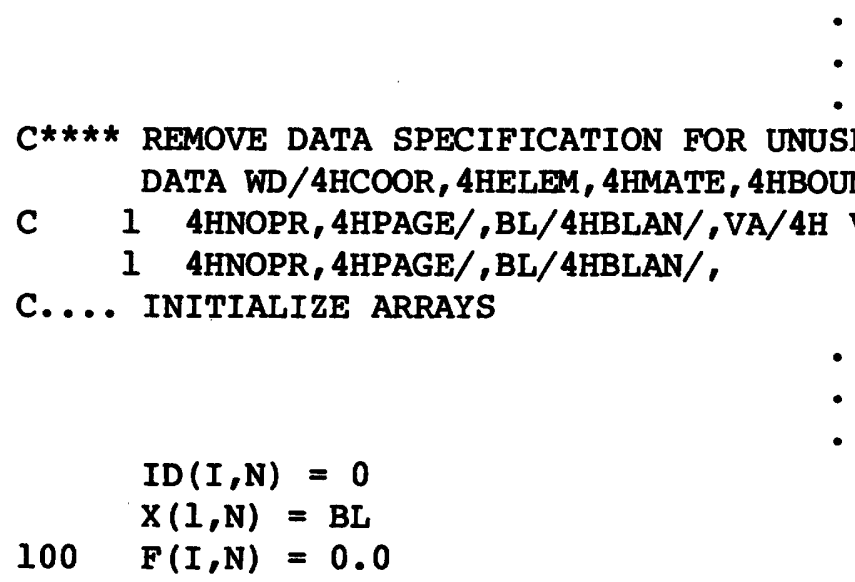

PME 18C

CR 5/79C

PME 19C

C**** FROM R.L. TAYLOR -- OMIT XHED FROM VARIABLES READ. $\operatorname{READ}(5,1002)$ MA, IEL

C**** FROM R.L. TAYLOR -- OMIT XHED FROM VARIABLES WRITTEN. WRITE $(6,2003)$ MA, IEL $\operatorname{IE}(M A)=I E L$

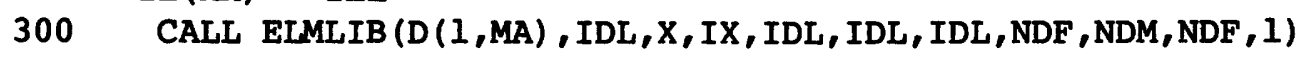

GO TO 10

PME 60C

PME 61C PME 62C CR 8/77C

PME 64C

DO $53 I=1, \mathrm{NDF}$

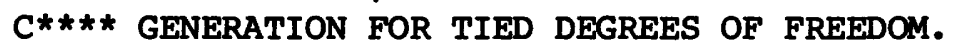
$I F(I D(I, L-L G) . G T .1) I D(I, L)=I D(I, L-L G)+L G$ $53 \operatorname{IF}(I D(I, L-L G) . L T .0) \quad I D(I, L)=-1$

PME 81C

C**** FROM R.L. TAYLOR -- NEW INPUT FORMAT.

1001 FORMAT (8I10)

PME105C

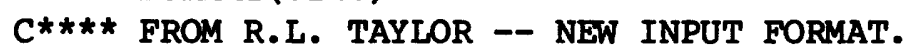

1002 FORMAT (2I10)

PME106C

END

SUBROUTINE PMACR (UL, XL,TL,LD, P,S,IE, D, ID , X, IX, F, T, JDIAG, B, DR, CT $1, \mathrm{NDF}, \mathrm{NDM}, \mathrm{NENI}, \mathrm{NST}, \mathrm{NEND}$ )

PMEII7C

PMA IC

PMA 2C

COMMON /TDATA/ TIME,DT,Cl,C2,C3, 4 ,, $\mathrm{C} 5$

PMA 14C

$C * \star \star *$ INCREASE THE NUMBER OF MACROS.

DIMENSION WD (27), CT $(4,1), \operatorname{CTL}(4), \operatorname{LVS}(9), \operatorname{LVE}(9), \operatorname{JDIAG}(1)$,

$1 \mathrm{UL}(1), X L(1), T L(1), \operatorname{LD}(1), P(1), S(1), \operatorname{IE}(1), D(1), \operatorname{ID}(1), X(1)$,

$2 \quad \mathrm{IX}(1), \mathrm{F}(1), \mathrm{T}(1), \mathrm{B}(1), \mathrm{DR}(1)$

PMA 16C

PMA 17C 


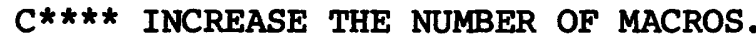

DATA WD/4HTOL , 4HDT , 4HSTRE, 4HDISP, 4HTANG, 4HFORM, 4HLOOP, 4HNEXT,

PMA 18C

1 4HPROP, 4HDATA, 4HTIME , 4HCONV , 4HSOLV, 4HLMAS, 4HCMAS, 4HMESH,

PMA 19C

2 4HEIGE , 4HEXCD, 4HUTAN, 4HREAC , 4HCHEC, 4HSAVE, 4HREST, 4HPLOT,

3 4HUTAF, 4HTANF , 4HUPNO/

DATA NWD/27/,ENDM/4HEND /,NV,NC/1,1/

C.... SET INITIAL VALUES OF PARAMETERS

PMA 22C

IF (L.NE. . . AND. L.NE.LL)

IWRITE $(6,2010) \quad \mathrm{I},(\mathrm{CT}(\mathrm{K}, \mathrm{L}), \mathrm{K}=1,4)$

PMA 85C

PMA 86C

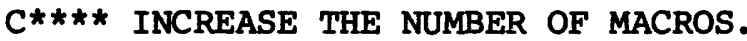

GO TO $(1,2,3,4,5,6,7,8,9,10,11,12,13,14,15,16,17,18,19,20,21$,

* $22,23,24,25,26,27), J$

C.... SET SOLUTION TOLERANCE

PMA 88C

CALL PFORM(UL, XL, TL, LD, P , S, IE, D, ID, X, IX, F , T, JDIAG, DR, DR,DR,

$2 \mathrm{NDF}, \mathrm{NDM}, \mathrm{NEN1}, \mathrm{NST}, 6, \mathrm{~B}, \mathrm{M}(\mathrm{NV})$, . FALSE . . TRUE — , FALSE. , . FALSE.)

PMA121C

PMA122C

C**** ADD STATEMENT NUMBER 60.

60 BFR $=$.TRUE.

$\mathbf{R N}=0$.

PMA124C

21 CALL PFORM (UL, XL, TL, LD, P, S, IE, D, ID, X, IX, F, T, JDIAG, DR, DR, DR,

1 NDF , NDM, NEN1, NST, 2 , B , F , . FALSE. , . FALSE . , . FALSE. , . FALSE.)

PMA229C

C**** ADD MACROS.

GO TO 330

C.... SAVE NODE NUMBER $N$, COORDINATES $X$, AND DISPLACEMENTS B

C.... ON TAPEl6.

22 CALL SAVE (ID, $X, B, F, N D M, N D F)$

GO TO 330

C... READ NODE NUMBER $N$, COORDINATES X $(\operatorname{IF~} \operatorname{CT}(3, L)=1$.$) ,$

C.... AND DISPLACEMENTS B FROM RESTART TAPE15.

C.... IF $C T(3, L)=0$, READ ONLY DISPLACEMENTS.

23 CALL REST(ID,X,B, F, T, D,NDM,NDF, CT $(3, L)$ )

GO TO 330

C.... PLOT

24 CALL PLT(ID, X,B,F,T,D,TIME,NDM,NDF)

GO TO 330

C.... FORM TANGENT STIFFNESS AND OUT OF BALANCE FORCES, ONE CALL

C.... PER ELEMENT.

25 IF (CFL) CALL PSETM (NC, NE, JDIAG (NEQ) *IPR, CFL)

CALL PZERO(M(NC) ,JDIAG (NEQ))

CFR $=$.TRUE.

26 IF (J.EQ. 26) CFR = .FALSE.

IF (GFL) CALL PSETM (NA, NE, JDIAG (NEQ) *IPR, GFL)

IF (NPLD. GT. 0) PROP = PROPLD (TIME, 0)

CALL PZERO (M(NA), JDIAG (NEQ))

CALL PLOAD (ID, F, DR, NNEQ, PROP) 


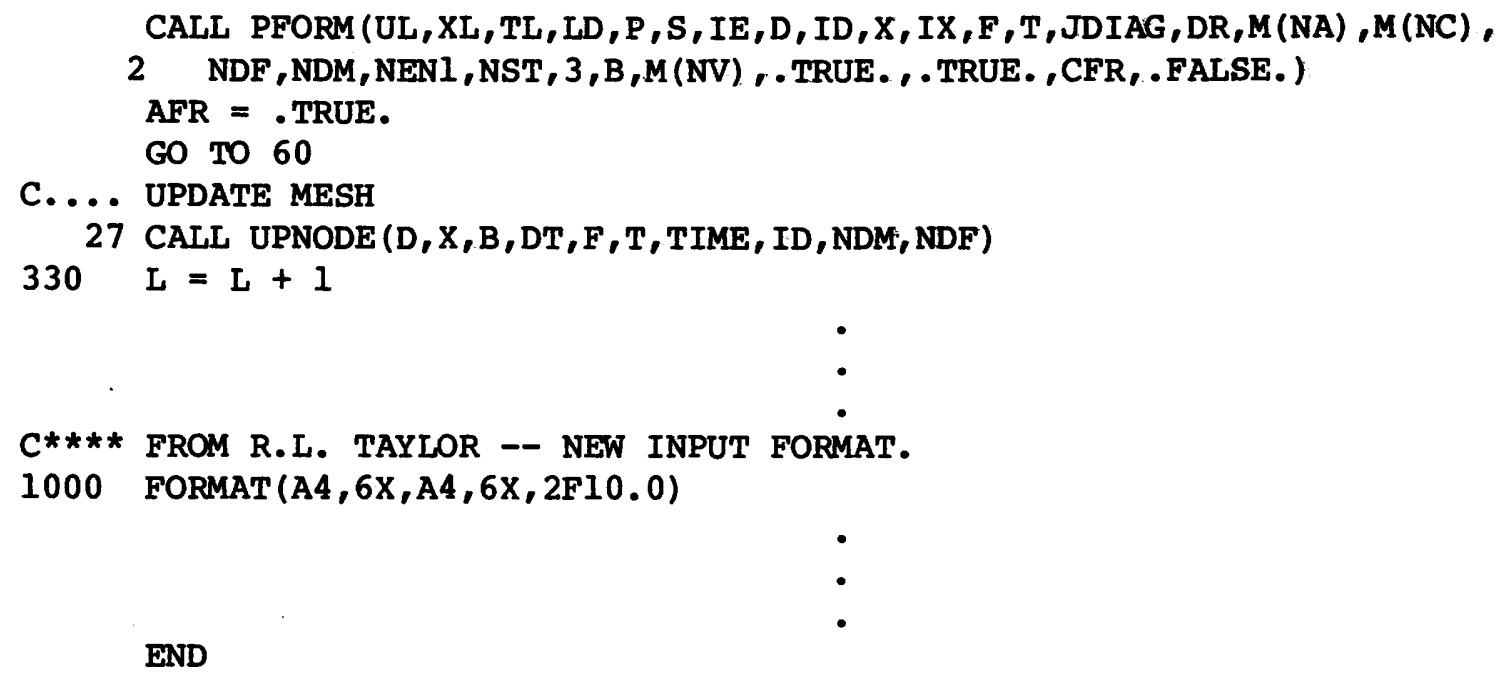


$30 \quad \operatorname{IF}(J . L E . I) I D(I, N)=0$

40 CONTINUE

PRO 18C

END

PRO $49 C$

SUBROUTINE PRTDIS (ID, $X, B, F, N D M, N D F$ )

PRT IC

RETURN

PRT 25C

C**** CHANGE TIME FORMAT FROM El3.5 TO E16.8.

2000 FORMAT (Al, 20A4//5X, 19HNODAL DISPLACEMENTS, 5X, 4HTIME, E16.8//

$16 \mathrm{X}, 4 \mathrm{HNODE}, 9(\mathrm{I} 7, \mathrm{~A} 4, \mathrm{~A} 2))$

END

SUBROUTINE SHAP2 (S, T, SHP, IX, NEL)

PRT 27C

PRT 28C

SHA IC

$T 2=(1 .-T * T) / 2$.

SHA 7C

DO $100 \quad I=5,9$

DO $100 \mathrm{~J}=1,3$

CR 3/78C

SHA $9 \mathrm{C}$

IF(IX (9).EQ.0) GO TO 107

SHA $33 C$

C**** FROM R.L. TAYLOR -- MULTIPLY BY 4.

$\operatorname{SHP}(1,9)=-4 . * \mathrm{~S} * \mathrm{~T} 2$

$\operatorname{SHP}(2,9)=-4 . * T * S 2$

$\operatorname{SHP}(3,9)=4 . * \mathrm{~S} 2 * \mathrm{~T} 2$

SHA $34 C$

SHA $35 \mathrm{C}$

SHA $36 \mathrm{C}$

END

SHA 5lC 


\section{APPENDIX E: SAMPLE RUN}

The following sample run demonstrates input and output associated with going from time 1981.150 to time 1981.275 by using calving law constant $a=1165625$. The corresponding plots can be found in figure 4 . During the actual modeling runs, 3 years were run at a time; the only modification necessary for such a multiple run is to change the macroinstruction LOOP* 1 to LOOP* 24 . The asterisks appearing in some of the macros are merely spacers so that the subroutine FREEFM will place the constants that follow them in the proper card position. The input data contained in data set $\$ \$ \$ \$ \$ \$$.COLDATA is simply the freeform version of the data as listed at the beginning of the output, with single spaces between data items and an appended card with ${ }^{* *}$ in columns 1 and 2 . In addition, the title card has an asterisk in column 1 to indicate alphanumeric data. The general purpose program is contained in subroutine library $\$ \$ \$ \$ \$ \$$.LOADLIB, with the element subroutine ELMT04 for glacier flow in element ICE2 of that library. The data sets $\$ \$ \$ \$ \$ \$ .0 L D S T A R T$ and \$\$\$\$\$\$.RESTART are restart files read by macro REST and written by macro SAVE, respectively. Data set $\$ \$ \$ \$ \$ \$$.COLPLOT is the plot file. SYS1.RS232.DATA100.CALCOMP is a library of Calcomp ${ }^{1}$ software designed to drive a local Calcomp drum plotter. Step COPYPLOT copies the plot file to the appropriate output class $\mathrm{K}$ for local plotting.

1The use of the brand name in this report is for identification purposes only and does not imply endorsement by the U.S. Geological Survey.

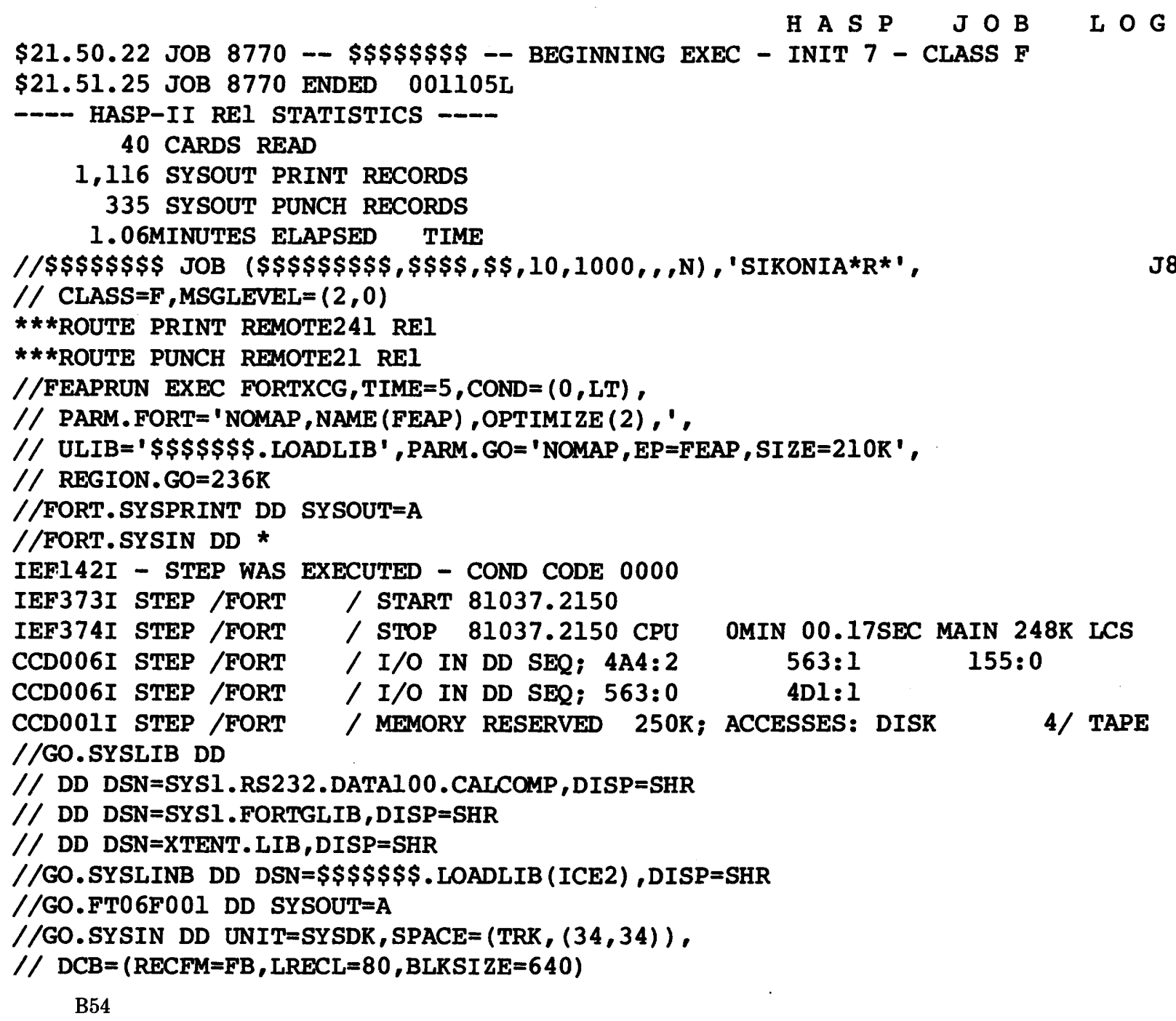


//GO.FT04F001 DD DSN=\$\$\$\$\$ . COLDATA,DISP=SHR

//GO.FT99F001 DD DSN=\$\$\$\$\$.COLPLOT,DISP=OLD

$/ /$ GO.FT15F001 DD DSN=\$\$\$\$\$.OLDSTART,DISP=SHR

//GO.FT16F001 DD DSN=\$\$\$\$\$ .RESTART, DISP= (OLD, KEEP, KEEP)

IEF142I - STEP WAS EXECUTED - COND CODE 0000

IEF373I STEP /GO / START 81037.2150

IEF374I STEP /GO / STOP 81037.2151 CPU

CCD006I STEP /GO

/ I/O IN DD SEQ; 4A3:1

/ I/O IN DD SEQ; 314:0

/ I/O IN DD SEQ; 634:10

/ I/O IN DD SEQ; 4B0:0

/ I/O IN DD SEQ; $740: 42$

/ MEMORY RESERVED 236K; ACCESSES: DISK

CCDO01I STEP /GO

$/ /$ COPYPLOT EXEC PGM=IEBGENER, TIME $=1, \mathrm{COND}=(0, \mathrm{LT}), \mathrm{REGION}=104 \mathrm{~K}$

//SYSPRINT DD SYSOUT=A

//SYSIN DD DUMMY

//SYSUT1 DD DSN=\$\$\$\$\$ . COLPLOT, DISP=SHR

//SYSUT2 DD SYSOUT= $(K$, ,WS81) , DCB $=($ RECFM $=U$, BLKSI ZE $=80)$

IEF142I - STEP WAS EXECUTED - COND CODE 0000

IEF373I STEP /COPYPLOT/ START 81037.2151

IEF374I STEP /COPYPLOT/ STOP 81037.2151 CPU

CCD006I STEP /COPYPLOT/ I/O IN DD SEQ; 4A2:1

CCD006I STEP /COPYPLOT/ I/O IN DD SEQ; 4B0:19

CCD001I STEP /COPYPLOT/ MEMORY RESERVED 104K; ACCESSES: DISK

OMIN 00.22SEC MAIN $34 \mathrm{~K}$ LCS OK $000: 0 \quad 740: 43$

IEF 375I

IEF376I

JOB / $\$ \$ \$ \$ \$ \$ \$ /$ START 81037.2150

JOB /\$\$\$\$\$\$/ STOP 81037.2151 CPU OMIN 12.53SEC

CCD007A

JOB / $\$ \$ \$ \$ \$ \$ /$ BASIC CHRG: FIXED CPU

.41

CCD007D JOB / $\$ \$ \$ \$ \$ \$ /$ LOCAL CHRG: FORMS

2.79

DSK-IO

TPE-IO KBYTE-HR TOTAL

63/ TAPE

0

PRINTING CRDS-RD CRDS-PU TOTAL $.00 \quad .00$

CCD002I JOB / $\$ \$ \$ \$ \$ \$ /$ TOTAL CHARGE RECORDED = $\$ 4.54$

CCD003I JOB / $\$ \$ \$ \$ \$$ US GEOLOGICAL SURVEY REl OS REL $218 \mathrm{TIME}=21.51 .25$ DATE = $02 / 06 / 81$

LEVEL 2.3.0 (JUNE 78) OS/360 FORTRAN H EXTENDED

DATE $81.037 / 21.50 .27$

REQUESTED OPTIONS : NOMAP, NAME (FEAP) , OPTIMIZE (2),

OPTIONS IN EFFECT: NAME (FEAP) OPTIMIZE (2) LINECOUNT (54) SIZE (MAX) AUTODBL (NONE)

SOURCE EBCDIC NOLIST NODECK OBJECT NOMAP NOFORMAT GOSTMT NOXREF NOALC NOANSF NOTERM IBM

C PROGRAM FEAPB (INPUT=101, OUTPUT=101, TAPE4=INPUT, TAPE5=101,

C 1 TAPE6=OUTPUT)

C MASTER MINIFEM

C.... SET PROGRAM CAPACITY * MAX MUST AGREE WITH DIMENSION OF $M$

ISN 0002

ISN 0003 COMMON M(20000)

COMMON/PSIZE/ MAX

$\operatorname{MAX}=20000$

ISN 0004

ISN 0005

ISN 0006

ISN 0007

ISN 0008
CALL FREEFM(M,M(11), M(21), M(31),M(111))

CALL PCONTR

STOP

END
IFEM IC

IFEM 2C

IFEM $4 \mathrm{C}$

IFEM 6C

IFEM 7C

IFEM $8 \mathrm{C}$ 
*OPTIONS IN EFFECT*NAME (FEAP) OPTIMIZE(2) LINECOUNT (54) SIZE (MAX) AUTODBL (NONE)

*OPTIONS IN EFFECT*SOURCE EBCDIC NOLIST NODECR OBJECT NOMAP NOFORMAT GOSTMT NOXREF NOALC NOANSF NOTERM IBM

*STATISTICS* SOURCE STATEMENTS $=\quad 7$, PROGRAM SIZE $=318$, SUBPROGRAM NAME = FEAP

*STATISTICS* NO DIAGNOSTICS GENERATED

$\star \star \star * \star *$ END OF COMPILATION $* \star \star \star \star *$ 58K BYTES OF CORE NOT USED OS/360 LOADER

OPTIONS USED - PRINT, NOMAP, NOLET, CALL , RES, NOTERM , SI ZE $=215040$, NAME $=\star \star G O$ EP=FEAP

TOTAL LENGTH 2EC28

ENTRY ADDRESS 4BA810

FIXED FORMAT FORM OF DATA CARDS FROM FREE FORMAT INPUT FEAP COLUMBIA GLACIER VERTICAL CENTERLINE PROFILE

\begin{tabular}{|c|c|c|c|c|c|}
\hline \multirow{2}{*}{\multicolumn{6}{|c|}{ NOPR }} \\
\hline & & & & & \\
\hline 1 & 1 & 0.0 & 465.00 & & \\
\hline 3 & 1 & 0.0 & -121.40 & & \\
\hline 5 & 0 & 0.0 & -268.00 & & \\
\hline 6 & 1 & 0.0 & -268.00 & & \\
\hline 8 & 0 & 0.0 & -278.00 & & \\
\hline 9 & 1 & 762.50 & 430.00 & & \\
\hline 11 & 1 & 762.50 & -103.60 & & \\
\hline 13 & 0 & 762.50 & -237.00 & & \\
\hline 14 & 1 & 762.50 & -237.00 & & \\
\hline 16 & 0 & 762.50 & -247.00 & & \\
\hline 17 & 1 & 1525.00 & 411.00 & & \\
\hline 19 & 1 & 1525.00 & -119.40 & & \\
\hline 21 & 0 & 1525.00 & -252.00 & & \\
\hline 22 & 1 & 1525.00 & -252.00 & & \\
\hline 24 & 0 & 1525.00 & -262.00 & & \\
\hline 25 & 1 & 2287.50 & 401.00 & & \\
\hline 27 & 1 & 2287.50 & -102.20 & & \\
\hline 29 & 0 & 2287.50 & -228.00 & & \\
\hline 30 & 1 & 2287.50 & -228.00 & & \\
\hline 32 & 0 & 2287.50 & -238.00 & & \\
\hline 33 & 1 & 3050.00 & 370.00 & & \\
\hline 35 & 1 & 3050.00 & -81.20 & & \\
\hline 37 & 0 & 3050.00 & -194.00 & & \\
\hline 38 & 1 & 3050.00 & -194.00 & & \\
\hline 40 & 0 & 3050.00 & -204.00 & & \\
\hline 41 & 1 & 3812.50 & 340.00 & & \\
\hline 43 & 1 & 3812.50 & -76.80 & & \\
\hline 45 & 0 & 3812.50 & -181.00 & & \\
\hline 46 & 1 & 3812.50 & -181.00 & & \\
\hline 48 & 0 & 3812.50 & -191.00 & & \\
\hline 49 & 1 & 4575.00 & 314.00 & & \\
\hline 51 & 1 & 4575.00 & -108.40 & & \\
\hline
\end{tabular}




\begin{tabular}{|c|c|c|c|}
\hline 53 & 0 & 4575.00 & -214.00 \\
\hline 54 & 1 & 4575.00 & -214.00 \\
\hline 56 & 0 & 4575.00 & -224.00 \\
\hline 57 & 1 & 5337.50 & 290.00 \\
\hline 59 & 1 & 5337.50 & -190.00 \\
\hline 61 & 0 & 5337.50 & -310.00 \\
\hline 62 & 1 & 5337.50 & -310.00 \\
\hline 64 & 0 & 5337.50 & -320.00 \\
\hline 65 & 1 & 6100.00 & 275.00 \\
\hline 67 & 1 & 6100.00 & -242.60 \\
\hline 69 & 0 & 6100.00 & -372.00 \\
\hline 70 & 1 & 6100.00 & -372.00 \\
\hline 72 & 0 & 6100.00 & -382.00 \\
\hline 73 & 1 & 6862.50 & 264.00 \\
\hline 75 & 1 & 6862.50 & -255.20 \\
\hline 77 & 0 & 6862.50 & -385.00 \\
\hline 78 & 1 & 6862.50 & -385.00 \\
\hline 80 & 0 & 6862.50 & -395.00 \\
\hline 81 & 1 & 7625.00 & 248.00 \\
\hline 83 & 1 & 7625.00 & -249.60 \\
\hline 85 & 0 & 7625.00 & -374.00 \\
\hline 86 & 1 & 7625.00 & -374.00 \\
\hline 88 & 0 & 7625.00 & -384.00 \\
\hline 89 & 1 & 8387.50 & 226.00 \\
\hline 91 & 1 & 8387.50 & -253.20 \\
\hline 93 & 0 & 8387.50 & -373.00 \\
\hline 94 & 1 & 8387.50 & -373.00 \\
\hline 96 & 0 & 8387.50 & -383.00 \\
\hline 97 & 1 & 9150.00 & 210.00 \\
\hline 99: & 1 & 9150.00 & -271.60 \\
\hline 101 & 0 & 9150.00 & -392.00 \\
\hline 102 & 1 & 9150.00 & -392.00 \\
\hline 104 & 0 & 9150.00 & -402.00 \\
\hline 105 & 1 & 9912.50 & 198.00 \\
\hline 107 & 1 & 9912.50 & -273.20 \\
\hline 109 & 0 & 9912.50 & -391.00 \\
\hline 110 & 1 & 9912.50 & -391.00 \\
\hline 112 & 0 & 9912.50 & $-401: 00$ \\
\hline 113 & 1 & 10675.00 & 178.00 \\
\hline 115 & 1 & 10675.00 & -278.00 \\
\hline 117 & 0 & 10675.00 & -392.00 \\
\hline 118. & 1 & $10675 . ? 0$ & -392.00 \\
\hline 120 & 0 & 10675.00 & -402.00 \\
\hline 121 & 1 & 11056.25 & 167.00 \\
\hline 123 & 1 & 11056.25 & -280.20 \\
\hline 125 & 0 & 11056.25 & -392.00 \\
\hline 126 & 1 & 11056.25 & -392.00 \\
\hline 128 & 0 & 11056.25 & -402.00 \\
\hline 129 & 1 & 11437.50 & 159.00 \\
\hline 131 & 1 & 11437.50 & -265.80 \\
\hline 133 & 0 & 11437.50 & -372.00 \\
\hline 134 & 1 & 11437.50 & -372.00 \\
\hline 136 & 0 & 11437.50 & -382.00 \\
\hline 137 & 1 & 11818.75 & 152.00 \\
\hline
\end{tabular}


B58

$\begin{array}{llrr}139 & 1 & 11818.75 & -245.60 \\ 141 & 0 & 11818.75 & -345.00 \\ 142 & 1 & 11818.75 & -345.00 \\ 144 & 0 & 11818.75 & -355.00 \\ 145 & 1 & 12200.00 & 140.00 \\ 147 & 1 & 12200.00 & -220.00 \\ 149 & 0 & 12200.00 & -310.00 \\ 150 & 1 & 12200.00 & -310.00 \\ 152 & 0 & 12200.00 & -320.00 \\ 153 & 1 & 12581.25 & 129.00 \\ 155 & 1 & 12581.25 & -195.00 \\ 157 & 0 & 12581.25 & -276.00 \\ 158 & 1 & 12581.25 & -276.00 \\ 160 & 0 & 12581.25 & -286.00 \\ 161 & 1 & 12962.50 & 118.00 \\ 163 & 1 & 12962.50 & -176.40 \\ 165 & 0 & 12962.50 & -250.00 \\ 166 & 1 & 12962.50 & -250.00 \\ 168 & 0 & 12962.50 & -260.00 \\ 169 & 1 & 13153.12 & 113.00 \\ 171 & 1 & 13153.12 & -163.00 \\ 173 & 0 & 13153.12 & -232.00 \\ 174 & 1 & 13153.12 & -232.00 \\ 176 & 0 & 13153.12 & -242.00 \\ 177 & 1 & 13343.75 & 108.00 \\ 179 & 1 & 13343.75 & -147.20 \\ 181 & 0 & 13343.75 & -211.00 \\ 182 & 1 & 13343.75 & -211.00 \\ 184 & 0 & 13343.75 & -221.00 \\ 185 & 1 & 13534.37 & 100.00 \\ 187 & 1 & 13534.37 & -128.80 \\ 189 & 0 & 13534.37 & -186.00 \\ 190 & 1 & 13534.37 & -186.00 \\ 192 & 0 & 13534.37 & -196.00 \\ 193 & 1 & 13725.00 & 96.00 \\ 195 & 1 & 13725.00 & -102.40 \\ 197 & 0 & 13725.00 & -152.00 \\ 198 & 1 & 13725.00 & -152.00 \\ 200 & 0 & 13725.00 & -162.00 \\ 201 & 1 & 13915.62 & 96.00 \\ 203 & 1 & 13915.62 & -80.80 \\ 205 & 0 & 13915.62 & -125.00 \\ 206 & 1 & 13915.62 & -125.00 \\ 208 & 0 & 13915.62 & -135.00 \\ 209 & 1 & 14106.25 & 96.00 \\ 211 & 1 & 14106.25 & -57.60 \\ 213 & 0 & 14106.25 & -96.00 \\ 214 & 1 & 14106.25 & -96.00 \\ 216 & 0 & 14106.25 & -106.00 \\ 224 & 1 & 14296.87 & 96.00 \\ 19 & 1 & 14296.87 & -20.80 \\ 19 & 0 & 14296.87 & -50.00 \\ 121 & 0 & 14296.87 & -60.00\end{array}$


APPENDIX E: SAMPLE RUN

B59

$\begin{array}{rrrr}225 & 1 & 14487.50 & 96.00 \\ 227 & 1 & 14487.50 & 19.20 \\ 229 & 0 & 14487.50 & 0.0 \\ 230 & 1 & 14487.50 & 0.0 \\ 232 & 0 & 14487.50 & -10.00\end{array}$

ELEM

\begin{tabular}{|c|c|c|c|c|c|c|c|}
\hline 01 & 1 & 3 & 19 & 17 & 1 & 11 & 18 \\
\hline 9 & 2 & 10 & 2 & & & & \\
\hline 03 & 1 & 8 & 24 & 22 & 6 & 16 & 23 \\
\hline 14 & 7 & 15 & 0 & & & & \\
\hline 04 & 1 & 19 & 35 & 33 & 17 & 27 & 34 \\
\hline 25 & 18 & 26 & 2 & & & & \\
\hline 06 & 1 & 24 & 40 & 38 & 22 & 32 & 39 \\
\hline 30 & 23 & 31 & 0 & & & & \\
\hline 07 & 1 & 35 & 51 & 49 & 33 & 43 & 50 \\
\hline 41 & 34 & 42 & 2 & & & & \\
\hline 09 & 1 & 40 & 56 & 54 & 38 & 48 & 55 \\
\hline 46 & 39 & 47 & 0 & & & & \\
\hline 10 & 1 & 51 & 67 & 65 & 49 & 59 & 66 \\
\hline 57 & 50 & 58 & 2 & & & & \\
\hline 12 & 1 & 56 & 72 & 70 & 54 & 64 & 71 \\
\hline 62 & 55 & 63 & 0 & & & & \\
\hline 13 & 1 & 67 & 83 & 81 & 65 & 75 & 82 \\
\hline 73 & 66 & 74 & 2 & & & & \\
\hline 15 & 1 & 72 & 88 & 86 & 70 & 80 & 87 \\
\hline 78 & 71 & 79 & 0 & & & & \\
\hline 16 & 1 & 83 & 99 & 97 & 81 & 91 & 98 \\
\hline 89 & 82 & 90 & 2 & & & & \\
\hline 18 & 1 & 88 & 104 & 102 & 86 & 96 & 103 \\
\hline 94 & 87 & 95 & 0 & & & & \\
\hline 19 & 1 & 99 & 115 & 113 & 97 & 107 & 114 \\
\hline 105 & 98 & 106 & 2 & & & & \\
\hline 21 & 1 & 104 & 120 & 118 & 102 & 112 & 119 \\
\hline 110 & 103 & 111 & 0 & & & & \\
\hline 22 & 1 & 115 & 131 & 129 & 113 & 123 & 130 \\
\hline 121 & 114 & 122 & 2 & & & & \\
\hline 24 & 1 & 120 & 136 & 134 & 118 & 128 & 135 \\
\hline 126 & 119 & 127 & 0 & & & & \\
\hline 25 & 1 & 131 & 147 & 145 & 129 & 139 & 146 \\
\hline 137 & 130 & 138 & 2 & & & & \\
\hline 27 & 1 & 136 & 152 & 150 & 134 & 144 & 151 \\
\hline 142 & 135 & 143 & 0 & & & & \\
\hline 28 & 1 & 147 & 163 & 161 & 145 & 155 & 162 \\
\hline $\begin{array}{c}153 \\
30\end{array}$ & $\begin{array}{c}146 \\
1\end{array}$ & $\begin{array}{c}154 \\
152\end{array}$ & $\begin{array}{r}2 \\
168\end{array}$ & 166 & 150 & 160 & 167 \\
\hline 158 & 151 & 159 & 0 & & & & \\
\hline 31 & 1 & 163 & 179 & 177 & 161 & 171 & 178 \\
\hline 169 & 162 & 170 & 2 & & & & \\
\hline 33 & 1 & 168 & 184 & 182 & 166 & 176 & 183 \\
\hline 174 & 167 & 175 & 0 & & & & \\
\hline 34 & 1 & 179 & 195 & 193 & 177 & 187 & 194 \\
\hline 185 & 178 & 186 & 2 & & & & \\
\hline 36 & 1 & 184 & 200 & 198 & 182 & 192 & 199 \\
\hline 10 & & 707 & & & & & \\
\hline
\end{tabular}


MATE

\begin{tabular}{|c|c|c|c|c|}
\hline \multirow[b]{3}{*}{ BOUN } & 4 & & & \\
\hline & 3.00 & 193. & 8. & \\
\hline & & & & \\
\hline 8 & 8 & -1 & -1 & \\
\hline 200 & 0 & 1 & 1 & \\
\hline 1 & 0 & 1 & & \\
\hline 2 & 0 & 1 & & \\
\hline 3 & 0 & 1 & & \\
\hline 5 & 0 & 1 & & \\
\hline 6 & 0 & 1 & 5 & \\
\hline 4 & 8 & 1 & 0 & -1 \\
\hline 196 & 0 & 0 & 0 & 1 \\
\hline 7 & 8 & 1 & 0 & -1 \\
\hline 199 & 0 & 0 & 0 & 1 \\
\hline 14 & 8 & 13 & 13 & \\
\hline 198 & 0 & 197 & 197 & \\
\hline 201 & 1 & -1 & -1 & -1 \\
\hline 232 & 0 & 1 & 1 & 1 \\
\hline
\end{tabular}

FORC

$\begin{array}{rrr}950.00 & & \\ 943.56 & & \\ 846.88 & & \\ 784.83 & 0 & -2.67 \\ 698.25 & & \\ 698.25 & & \\ 349.13 & 0 & 40 \\ 0 & 0 & -3.42 \\ 0 & 0 & -3.98 \\ 0 & 0 & -4.45 \\ 0 & 0 & -4.90 \\ 0 & 0 & -5.41 \\ 0 & 0 & -5.98 \\ 0 & 0 & -6.30 \\ 0 & 0 & -6.32 \\ 0 & 0 & -6.29 \\ 0 & 0 & -6.26 \\ 0 & 0 & -6.27 \\ 0 & 0 & -6.36 \\ 0 & 0 & -6.53 \\ 0 & 0 & -6.68 \\ 0 & 0 & -6.76 \\ 0 & 0 & -6.91 \\ 0 & 0 & -7.09 \\ 0 & 0 & -7.21 \\ 0 & 0 & -7.38 \\ 0 & 0 & -7.63 \\ 0 & 0 & -7.77 \\ 0 & 0 & -7.87 \\ 0 & 0 & -7.93 \\ 0 & 0 & -7.94 \\ 0 & 0 & -7.94 \\ 0 & 0 & -7.94 \\ 0 & 0 & -7.94 \\ & 0 & \end{array}$




$\begin{array}{rr}228 & 0 \\ 15 & 0 \\ 23 & 0 \\ 31 & 0 \\ 39 & 0 \\ 47 & 0 \\ 55 & 0 \\ 63 & 0 \\ 71 & 0 \\ 79 & 0 \\ 87 & 0 \\ 95 & 0 \\ 103 & 0 \\ 111 & 0 \\ 119 & 0 \\ 127 & 0 \\ 135 & 0 \\ 143 & 0 \\ 151 & 0 \\ 159 & 0 \\ 167 & 0 \\ 175 & 0 \\ 183 & 0 \\ 191 & 0 \\ 199 & 0 \\ 207 & 0 \\ 215 & 0 \\ 223 & 0 \\ 231 & 0\end{array}$

$-7.94$

37.

25.14

8.99

8.38

6.91

8.63

11.24

7.51

7.36

15.91

21.35

22.58

18.01

20.84

28.

33.

37.76

40.25

40.25

40.25

40.25

40.25

40.25

40.25

40.25

40.25

40.25

40.25

TEMP

$\begin{array}{lll}6 & 0 & 950\end{array}$

14

22

30

38

46

54

62

70

78

86

94

102

110

118

126

134

142

150

1030

960

922

935

930

900

839

808

812

866

904

$\begin{array}{rr}0 & 933 \\ 0 & 1012\end{array}$

$0 \quad 1102$

$0 \quad 1150$

$0 \quad 1210$

$0 \quad 1320$

END

MACR

TOL

DT

$* \quad 1 . E-2$
$* \quad 81.15$

TIME 


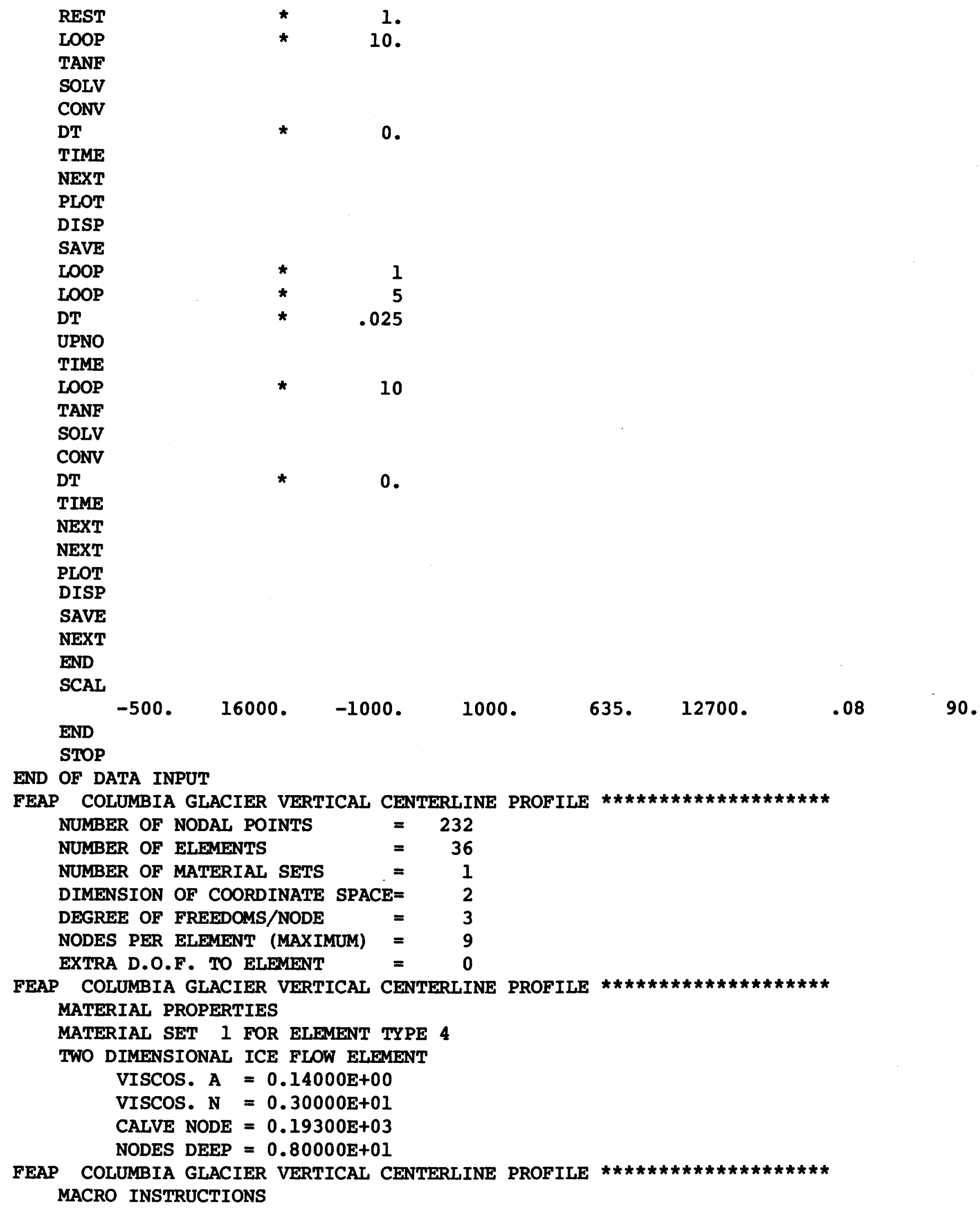


MACRO STATEMENT

TOL

DT

TIME

REST

LOOP

TANF

SOLV

CONV

DT

TIME

NEXT

PLOT

DISP

SAVE

LOOP

LOOP

DT

UPNO

TIME

LOOP

TANF

SOLV

CONV

DT

TIME

NEXT

NEXT

PLOT

DISP

SAVE

NEXT

END

**MACRO INSTRUCTION

**MACRO INSTRUCTION

* *MACRO INSTRUCTION

**MACRO INSTRUCTION

* *MACRO INSTRUCTION

* *MACRO INSTRUCTION

FORCE CONVERGENCE
VARIABLE 1 .10000E-01

81.150

.0

1.0000

10.000

.0

.0

.0

.0

.0

.0

.0

.0

.0

1.0000

5.0000 .

$.25000 \mathrm{E}-01$

.0

.0

10.000

.0

.0

.0

.0

.0

.0

.0

.0

.0

.0

.0

.0

1 EXECUTED**

2 EXECUTED**

3 EXECUTED**

4 EXCCUTE* $* *$ TIM

5 EXECUTE* REST

6 EXECUTED** TANF

TEST

.39112

7 EXECUTED** RN

* MACRO INSTRUCTION
**MACRO INSTRUCTION

DISPLACEMENT CONV

8 EXECUTED** CONV

$$
\text { UNMAX = }
$$

ERGENCE TEST

* *MACRO INSTRUCTION

**MACRO INSTRUCTION

$\star *$ MACRO INSTRUCTION

13151 .

9 EXECUTED** DT

10 EXECUTED** TIME

11 EXECUTED * * NEXT

**MACRO INSTRUCTION 12 EXECUTED** PLOT

**MACRO INSTRUCTION 13 EXECUTED** DISP
VARIABLE 2
.0
.0
.0
.0
.0
.0
.0
.0
.0
.0
.0
.0
.0
.0
.0
.0
.0
.0
.0
.0
.0
.0
.0
.0
.0
.0
.0

.0

.0

.0

.0

.0

.0

.0

.0

.0

.0

.0

.0

.0

.0

.0

.0

.0

.0

.0

.0

.0

.0

.0

.0

.0

.0

.0

TOL

T

ME

\section{$T$}

TANF

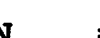

39112

$\mathrm{VI}=$

$\mathrm{V} 1=$

$.26771 \mathrm{E}-01$

$\mathrm{Vl}=$

$\mathrm{Vl}=$

$\mathrm{Vl}=$

81.15

.0

1.000

10.00

.0

$\mathrm{V} 1=\quad .0$

$\mathrm{Vl}=$

.0
.0

.0

.0

.0

12.00

$\mathrm{V} 2=12$
$\mathrm{~V} 2=0$

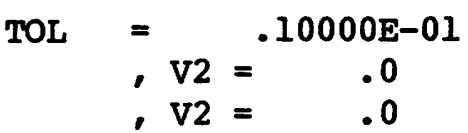

TOL $=.10000 \mathrm{E}-01$

, $\mathrm{V} 2=\quad .0$

, $\mathrm{V} 2=.0$

, $\mathrm{V} 2=6.000$

, $\mathrm{V} 2=.0$

, $\mathrm{V} 2=\quad .0$ 


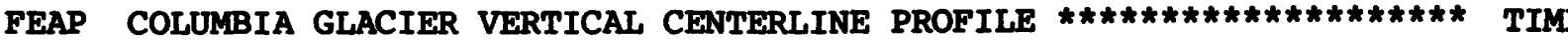
PROPORTIONAL LOAD 1.0000

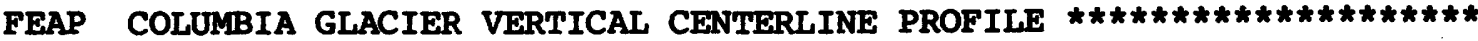
NODAL DISPLACEMENTS TIME 0.81149994E+02

\begin{tabular}{|c|c|c|c|c|c|}
\hline DE & 1 COORD & 2 COORD & 1 DISPL & 2 DISPL & $\begin{array}{r}3 \text { DISF } \\
0,1454 E+C\end{array}$ \\
\hline 1 & 0.0 & 465.0000 & $0.9500 \mathrm{E}+03$ & $0.2658 \mathrm{E}+02$ & $0.1454 E+0]$ \\
\hline 2 & 0.0 & 171.8000 & $0.9436 E+03$ & $0.3344 \mathrm{E}+02$ & $0.1315 \mathrm{E}+$ \\
\hline 3 & 0.0 & -121.4000 & $0.8469 \mathrm{E}+03$ & $0.4342 \mathrm{E}+02$ & $0.5157 \mathrm{E}+$ \\
\hline 4 & 0.0 & -194.7000 & $0.7848 E+03$ & $0.4757 \mathrm{E}+02$ & $-0.2670 \mathrm{E}+$ \\
\hline 5 & 0.0 & -268.0000 & $0.6982 \mathrm{E}+03$ & $0.6042 E+02$ & $0.6282 \mathrm{E}+$ \\
\hline 6 & 0.0 & -268.0000 & $0.6982 \mathrm{E}+03$ & $0.6042 \mathrm{E}+02$ & $0.6363 \mathrm{E}+$ \\
\hline 7 & 0.0 & -273.0000 & $0.3491 E+03$ & $0.3069 \mathrm{E}+02$ & $0.4000 \mathrm{E}+$ \\
\hline 8 & 0.0 & -278.0000 & 0.0 & 0.0 & $0.6445 \mathrm{E}+$ \\
\hline 9 & 768.9395 & 456.6458 & $0.9785 E+03$ & $-0.2287 \mathrm{E}+02$ & $0.3865 \mathrm{E}+$ \\
\hline 10 & 768.9395 & 179.2141 & $0.9582 \mathrm{E}+03$ & $-0.1728 E+02$ & $0.8934 \mathrm{E}+$ \\
\hline 11 & 768.9395 & -98.2178 & $0.9041 E+03$ & $-0.7195 E+01$ & $0.4951 \mathrm{E}+$ \\
\hline 12 & 768.9395 & -167.5757 & $0.8807 E+03$ & $-0.2426 E+01$ & $-0.3426 \mathrm{E}+$ \\
\hline 13 & 768.9395 & -236.9341 & $0.8561 E+03$ & $0.3056 \mathrm{E}+01$ & $0.6186 \mathrm{E}+$ \\
\hline 14 & 768.9395 & -236.9341 & $0.8561 E+03$ & $0.3056 \mathrm{E}+01$ & $0.6235 \mathrm{E} t$ \\
\hline 15 & 768.9395 & -241.9341 & $0.4316 \mathrm{E}+03$ & $0.1645 \mathrm{E}+01$ & $0.3694 \mathrm{E} t$ \\
\hline 16 & 768.9395 & -246.9341 & 0.0 & 0.0 & $0.6325 \mathrm{E}+$ \\
\hline 17 & 1537.8792 & 429.7080 & $0.9810 \mathrm{E}+03$ & $-0.1349 \mathrm{E}+02$ & $0.6445 \mathrm{E}+$ \\
\hline 18 & 1537.8792 & 157.0576 & $0.9806 E+03$ & $-0.6178 \mathrm{E}+01$ & $0.4564 \mathrm{E}+$ \\
\hline 19 & 1537.8792 & -115.5928 & $0.9235 E+03$ & $-0.7839 \mathrm{E}+00$ & $0.4921 \mathrm{E}+$ \\
\hline 20 & 1537.8792 & -183.7554 & $0.8882 E+03$ & $-0.3930 \mathrm{E}+01$ & $-0.3989 \mathrm{E}+$ \\
\hline 21 & 1537.8792 & -251.9182 & $0.8384 \mathrm{E}+03$ & $-0.1038 E+02$ & $0.6127 \mathrm{E}+$ \\
\hline 22 & 1537.8792 & -251.9182 & $0.8384 \mathrm{E}+03$ & $-0.1038 E+02$ & $0.6072 \mathrm{E}+$ \\
\hline 23 & 1537.8792 & -256.9182 & $0.4251 \mathrm{E}+03$ & $-0.5466 \mathrm{E}+01$ & $0.2490 \mathrm{E} t$ \\
\hline 24 & 1537.8792 & -261.9182 & 0.0 & 0.0 & $0.6156 \mathrm{E} t$ \\
\hline 25 & 2306.8184 & 422.9641 & $0.1045 E+04$ & $-0.1377 \mathrm{E}+02$ & $-0.6725 \mathrm{E}-$ \\
\hline 26 & 2306.8184 & 162.8738 & $0.1024 \mathrm{E}+04$ & $0.1247 E+02$ & $0.2698 \mathrm{E}+$ \\
\hline 27 & 2306.8184 & -97.2166 & $0.9461 E+03$ & $0.3053 E+02$ & $0.4666 \mathrm{E}+$ \\
\hline 28 & 2306.8184 & -162.2393 & $0.8948 \mathrm{E}+03$ & $0.3436 E+02$ & $-0.4462 \mathrm{E}+$ \\
\hline 29 & 2306.8184 & -227.2621 & $0.8223 E+03$ & $0.3676 E+02$ & $0.5836 \mathrm{E} t$ \\
\hline 30 & 2306.8184 & -227.2621 & $0.8223 E+03$ & $0.3676 E+02$ & $0.5858 \mathrm{E}+$ \\
\hline 31 & 2306.8184 & -232.2621 & $0.4134 E+03$ & $0.1864 E+02$ & $0.8783 \mathrm{E}+$ \\
\hline 32 & 2306.8184 & -237.2621 & 0.0 & 0.0 & $0.5948 \mathrm{E}+$ \\
\hline $\begin{array}{l}33 \\
34\end{array}$ & $\begin{array}{l}3075.7583 \\
3075.7583\end{array}$ & $\begin{array}{l}397.1182 \\
160.9837\end{array}$ & $\begin{array}{l}0.1138 \mathrm{E}+04 \\
0.1114 \mathrm{E}+04\end{array}$ & $\begin{array}{l}-0.326 \\
-0.391\end{array}$ & \\
\hline 35 & 3075.7583 & -75.1506 & $0.1025 E+04$ & $0.2363 E+02$ & $0.4208 \mathrm{E}+$ \\
\hline 36 & 3075.75 & -134.1843 & $0.9871 E+03$ & $0.2973 E+02$ & $-0.4916 \mathrm{E}+$ \\
\hline 37 & 307 & -193.2181 & $0.9433 E+03$ & $0.3318 E+02$ & $0.5281 \mathrm{E}+$ \\
\hline 38 & 3075 & -193.2181 & $0.9433 E+03$ & $0.3318 E+02$ & $0.5299 \mathrm{E}+$ \\
\hline 39 & 3075 & -198.21 & $0.4804 E+03$ & $0.1690 \mathrm{E}+02$ & $0.8344 \mathrm{E}+$ \\
\hline 40 & 3075.75 & -203.21 & 0.0 & 0.0 & $0.5386 \mathrm{E}+$ \\
\hline 41 & 3844.69 & 369.8826 & $0.1206 \mathrm{E}+04$ & $-0.5064 \mathrm{E}+02$ & $0.2668 \mathrm{E} t$ \\
\hline 42 & 3844.69 & 149.3443 & $0.1182 \mathrm{E}+04$ & $-0.3620 \mathrm{E}+02$ & $0.2964 \mathrm{E}+$ \\
\hline 43 & 3844.6975 & -71.1938 & $0.1100 \mathrm{E}+04$ & $-0.1966 \mathrm{E}+02$ & $0.3966 \mathrm{E}+$ \\
\hline 44 & 3844.6975 & -126.3284 & $0.1039 E+04$ & $-0.1402 \mathrm{E}+02$ & $-0.5433 \mathrm{E}+$ \\
\hline 45 & 3844.6975 & -181.4632 & $0.9477 E+03$ & $-0.9526 \mathrm{E}+01$ & $0.4966 \mathrm{E}+$ \\
\hline 46 & 3844.6975 & -181.4632 & $0.9477 \mathrm{E}+03$ & $-0.9526 E+01$ & $0.4974 \mathrm{E}+$ \\
\hline 47 & 3844.6975 & -186.4632 & $0.4826 \mathrm{E}+03$ & $-0.4756 \mathrm{E}+01$ & $0.6918 \mathrm{E}+$ \\
\hline 48 & 3844.6975 & -191.4632 & 0.0 & 0.0 & $0.5063 \mathrm{E}+$ \\
\hline 49 & 4613.6367 & 319.5710 & $0.1219 \mathrm{E}+04$ & $-0.8927 E+02$ & $0.2130 \mathrm{E}+$ \\
\hline 50 & 4613.6367 & 104.8030 & $0.1196 \mathrm{E}+04$ & $-0.1060 \mathrm{E}+03$ & $-0.3566 \mathrm{E}+$ \\
\hline
\end{tabular}

3 Explanation

pressure

hdot

pressure

bdot

pressure

pressure

Abed

pressure 


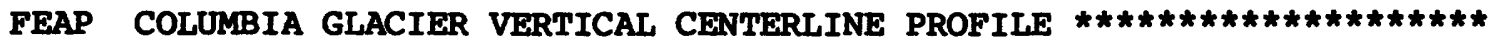
NODAL DISPLACEMENTS TIME $0.81149994 \mathrm{E}+02$

\begin{tabular}{|c|c|c|c|c|c|}
\hline NODE & 1 COORD & 2 COORD & 1 DISPL & 2 DISPL & 3 DISPL \\
\hline 51 & 4613.6367 & -109.9651 & $0.1124 E+04$ & $-0.1178 E+03$ & $0.3881 \mathrm{E}+02$ \\
\hline 52 & 4613.6367 & -163.6570 & $0.1078 E+04$ & $-0.1176 E+03$ & $-0.6002 \mathrm{E}+01$ \\
\hline 53 & 4613.6367 & -217.3492 & $0.1009 \mathrm{E}+04$ & $-0.1131 E+03$ & $0.4791 \mathrm{E}+02$ \\
\hline 54 & 4613.6367 & -217.3492 & $0.1009 E+04$ & $-0.1131 \mathrm{E}+03$ & $0.4783 \mathrm{E}+02$ \\
\hline 55 & 4613.6367 & -222.3492 & $0.5209 E+03$ & $-0.5836 E+02$ & $0.8741 \mathrm{E}+01$ \\
\hline 56 & 4613.6367 & -227.3492 & 0.0 & 0.0 & $0.4870 \mathrm{E}+02$ \\
\hline 57 & 5382.5742 & 281.2563 & $0.1089 \mathrm{E}+04$ & $-0.1921 E+02$ & $0.2112 \mathrm{E}+01$ \\
\hline 58 & 5382.5742 & 42.9097 & $0.1076 \mathrm{E}+04$ & $-0.5648 E+02$ & $0.6542 \mathrm{E}+01$ \\
\hline 59 & 5382.5742 & -195.4370 & $0.9849 E+03$ & $-0.8647 E+02$ & $0.4367 \mathrm{E}+02$ \\
\hline 60 & 5382.5742 & -255.0234 & $0.9346 E+03$ & $-0.9266 E+02$ & $-0.6310 \mathrm{E}+01$ \\
\hline 61 & 5382.5742 & -314.6104 & $0.8710 \mathrm{E}+03$ & $-0.9498 E+02$ & $0.5376 \mathrm{E}+02$ \\
\hline 62 & 5382.5742 & -314.6104 & $0.8710 \mathrm{E}+03$ & $-0.9498 E+02$ & $0.5342 \mathrm{E}+02$ \\
\hline 63 & 5382.5742 & -319.6104 & $0.4392 E+03$ & $-0.4815 E+02$ & $0.1120 \mathrm{E}+02$ \\
\hline 64 & 5382.5742 & -324.6104 & 0.0 & 0.0 & $0.5429 \mathrm{E}+02$ \\
\hline 65 & 6151.5156 & 270.0581 & $0.1001 E+04$ & $0.3958 E+01$ & $0.2001 E+01$ \\
\hline 66 & 6151.5156 & 12.2664 & $0.9778 E+03$ & $-0.8922 \mathrm{E}+01$ & $0.5873 E+01$ \\
\hline 67 & 6151.5156 & -245.5256 & $0.8962 E+03$ & $-0.2281 E+02$ & $0.4647 \mathrm{E}+02$ \\
\hline $\begin{array}{l}68 \\
69\end{array}$ & $\begin{array}{l}6151.5156 \\
6151.5156\end{array}$ & $\begin{array}{l}-309.9736 \\
-374.4216\end{array}$ & $\begin{array}{l}0.8555 E+03 \\
0.8090 E+03\end{array}$ & $\begin{array}{l}-0.2435 E+02 \\
-0.2707 E+02\end{array}$ & $\begin{array}{r}-0.6320 \mathrm{E}+01 \\
0.5796 \mathrm{E}+02\end{array}$ \\
\hline 70 & 6151.5156 & -374.4216 & $0.8090 \mathrm{E}+03$ & $-0.2707 E+02$ & $0.5769 \mathrm{E}+02$ \\
\hline 71 & 6151.5156 & -379.4216 & $0.4065 E+03$ & $-0.1364 \mathrm{E}+02$ & $0.7387 \mathrm{E}+01$ \\
\hline 72 & 6151.5156 & -384.4216 & 0.0 & 0.0 & $0.5858 \mathrm{E}+02$ \\
\hline 73 & 6920.4570 & 256.9724 & $0.9923 E+03$ & $-0.7751 E+01$ & $0.6951 \mathrm{~L}+00$ \\
\hline 74 & 6920.4570 & 0.1812 & $0.9711 E+03$ & $-0.5736 \mathrm{E}+01$ & $0.6039 \mathrm{E}+01$ \\
\hline 75 & 6920.4570 & -256.6106 & $0.8839 E+03$ & $-0.1563 E+00$ & $0.4632 E+02$ \\
\hline 76 & 6920.4570 & -320.8083 & $0.8274 E+03$ & $0.8642 \mathrm{E}+00$ & $-0.6288 \mathrm{E}+01$ \\
\hline 77 & 6920.4570 & -385.0063 & $0.7512 \mathrm{E}+03$ & $0.1675 E+01$ & $0.5767 \mathrm{E}+02$ \\
\hline 78 & 6920.4570 & -385.0063 & $0.7512 \mathrm{E}+03$ & $0.1675 E+01$ & $0.5769 \mathrm{E}+02$ \\
\hline 79 & 6920.4570 & -390.0063 & $0.3774 E+03$ & $0.8385 \mathrm{E}+00$ & $0.7704 E+01$ \\
\hline 80 & 6920.4570 & -395.0063 & 0.0 & 0.0 & $0.5857 \mathrm{E}+02$ \\
\hline 81 & 7689.3945 & 239.8603 & $0.1001 E+04$ & $-0.1462 \mathrm{E}+02$ & $0.7923 \mathrm{E}+00$ \\
\hline 82 & 7689.3945 & -5.4953 & $0.9865 E+03$ & $-0.1085 E+02$ & $0.5455 \mathrm{E}+01$ \\
\hline 83 & 7689.3945 & -250.8506 & $0.9322 E+03$ & $0.1088 E+01$ & $0.4402 \mathrm{E}+02$ \\
\hline 84 & 7689.3945 & -312.1895 & $0.8920 \mathrm{E}+03$ & $0.8432 E+01$ & $-0.6259 \mathrm{E}+01$ \\
\hline 85 & 7689.3945 & -373.5288 & $0.8343 E+03$ & $0.1788 E+02$ & $0.5492 \mathrm{E}+02$ \\
\hline 86 & 7689.3945 & -373.5288 & $0.8343 E+03$ & $0.1788 \mathrm{E}+02$ & $0.5547 \mathrm{E}+02$ \\
\hline 87 & 7689.3945 & -378.5288 & $0.4222 \mathrm{E}+03$ & $0.9346 \mathrm{E}+01$ & $0.1649 \mathrm{E}+02$ \\
\hline 88 & 7689.3945 & -383.5288 & 0.0 & 0.0 & $0.5638 \mathrm{E}+02$ \\
\hline 89 & 8458.3359 & 216.2448 & $0.1006 \mathrm{E}+04$ & $-0.2367 E+02$ & $0.7183 \mathrm{E}+00$ \\
\hline 90 & 8458.3359 & -19.8220 & $0.9992 E+03$ & $-0.2227 E+02$ & $0.1431 \mathrm{E}+01$ \\
\hline 91 & 8458.3359 & -255.8888 & $0.9684 \mathrm{E}+03$ & $-0.1869 E+02$ & $0.4247 \mathrm{E}+02$ \\
\hline 92 & 8458.3359 & -314.9053 & $0.9475 E+03$ & $-0.1722 E+02$ & $-0.6275 \mathrm{E}+01$ \\
\hline 93 & 8458.3359 & -373.9224 & $0.9187 E+03$ & $-0.1509 E+02$ & $0.5284 \mathrm{E}+02$ \\
\hline 94 & 8458.3359 & -373.9224 & $0.9187 \mathrm{E}+03$ & $-0.1509 E+02$ & $0.5299 E+02$ \\
\hline 95 & 8458.3359 & -378.9224 & $0.4685 E+03$ & $-0.7634 \mathrm{E}+01$ & $0.2164 \mathrm{E}+02$ \\
\hline 96 & 8458.3359 & -383.9224 & 0.0 & 0.0 & $0.5387 \mathrm{E}+02$ \\
\hline 97 & 9227.2734 & 193.8667 & $0.1005 E+04$ & $-0.1446 \mathrm{E}+02$ & $0.8011 \mathrm{E}+00$ \\
\hline 98 & 9227.2734 & -40.8036 & $0.1001 E+04$ & $-0.1389 \mathrm{E}+02$ & $0.2497 \mathrm{E}+01$ \\
\hline 99 & 9227.2734 & -275.4739 & $0.9639 E+03$ & $-0.1330 \mathrm{E}+02$ & $0.4242 \mathrm{E}+02$ \\
\hline 100 & 9227.2734 & -334.1414 & $0.9376 \mathrm{E}+03$ & $-0.1393 E+02$ & $-0.6374 E+01$ \\
\hline
\end{tabular}




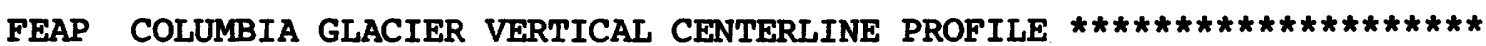
NODAL DISPLACEMENTS

NODE

101

102

103

104

105

106

107

108

109

110

111

112

113

114

115

116

117

118

119

120

121

122

123

124

125

126

127

128

129

130

131

132

133

134

135

136

137

138

139

140

141

142

143

144

145

146

147

148

149

150
1 COORD

9227.2734

9227.2734

9227.2734

9227.2734

9996.2148

9996.2148

9996.2148

9996.2148

9996.2148

9996.2148

9996.2148

9996.2148

10765.1523

10765.1523

10765.1523

10765.1523

10765.1523

10765.1523

10765.1523

10765.1523

11149.6211

11149.6211

11149.6211

11149.6211

11149.6211

11149.6211

11149.6211

11149.6211

11534.0937

11534.0937

11534.0937

11534.0937

11534.0937

11534.0937

11534.0937

11534.0937

11918.5625

11918.5625

11918.5625

11918.5625

11918.5625

11918.5625

11918.5625

11918.5625

12303.0312

12303.0312

12303.0312

12303.0312

12303.0312

12303.0312
TIME $0.81149994 \mathrm{E}+02$

2 COORD 1 DISPL

$-392.8093$

$-392.8093$

$-397.8093$

$-402.8093$

177.0835

$-50.1546$

$-277.3923$

$-334.2019$

$-391.0117$

$-391.0117$

$-396.0117$

$-401.0117$

156.6192

$-62.8644$

$-282.3479$

$-337.2187$

$-392.0901$

$-392.0901$

$-397.0901$

$-402.0901$

149.5192

$-65.8687$

$-281.2566$

$-335.1035$

$-388.9509$

$-388.9509$

$-393.9509$

$-398.9509$

148.0525

$-57.4969$

$-263.0461$

$-314.4336$

$-365.8213$

$-365.8213$

$-370.8213$

$-375.8213$

140.1805

$-50.5356$

$-241.2516$

$-288.9304$

$-336.6099$

$-336.6099$

$-341.6099$

$-346.6099$

131.3288

$-41.4878$

$-214.3042$

$-257.5083$

$-300.7129$

$-300.7129$
$0.9023 \mathrm{E}+03$

$0.9023 E+03$

$0.4529 \mathrm{E}+03$

0.0

$0.1014 \mathrm{E}+04$

$0.1008 \mathrm{E}+04$

$0.9791 E+03$

$0.9559 \mathrm{E}+03$

$0.9225 E+03$

$0.9225 E+03$

0.0

$0.1020 E+04$

$0.1015 E+04$

$0.9908 E+03$

$0.9737 E+03$

$0.9501 E+03$

$0.9501 E+03$

$0.4841 \mathrm{E}+03$

0.0

$0.1024 E+04$

$0.1026 E+04$

$0.9940 \mathrm{E}+03$

$0.9772 E+03$

$0.9582 E+03$

$0.9582 E+03$

$0.4736 \mathrm{E}+03$

0.0

$0.1061 E+04$

$0.1056 \mathrm{E}+04$

$0.1029 E+04$

$0.1013 E+04$

$0.9896 \mathrm{E}+03$

$0.9896 E+03$

$0.5074 E+03$

0.0

$0.1124 \mathrm{E}+04$

$0.1108 \mathrm{E}+04$

$0.1066 \mathrm{E}+04$

$0.1050 \mathrm{E}+04$

$0.1030 \mathrm{E}+04$

$0.1030 E+04$

$0.5193 E+03$

0.0

$0.1210 \mathrm{E}+04$

$0.1192 \mathrm{E}+04$

$0.1136 \mathrm{E}+04$

$0.1114 \mathrm{E}+04$

$0.1088 \mathrm{E}+04$

$0.1088 E+04$
$0.4677 \mathrm{E}+03$
2 DISPL
$-0.1475 E+02$
$-0.1475 E+02$
$-0.7455 E+01$
0.0
$-0.6122 E+01$
$-0.3719 E+01$
$0.1995 E+00$
$0.1658 E+01$
$0.3707 E+01$
$0.3707 E+01$
$0.1906 E+01$
0.0

$-0.1305 E+02$

$-0.1277 \mathrm{E}+02$

$-0.1292 \mathrm{E}+02$

$-0.1291 E+02$

$-0.1263 E+02$

$-0.1263 E+02$

$-0.6267 \mathrm{E}+01$

0.0

$0.6732 E+01$

$0.1787 E+02$

$0.2880 \mathrm{E}+02$

$0.3101 E+02$

$0.3309 E+02$

$0.3309 \mathrm{E}+02$

$0.1643 E+02$

0.0

$0.2465 \mathrm{E}+02$

$0.4870 \mathrm{E}+02$

$0.6691 E+02$

$0.7144 \mathrm{E}+02$

$0.7523 E+02$

$0.7523 E+02$

$0.3856 \mathrm{E}+02$

0.0

$0.1301 E+02$

$0.4891 E+02$

$0.7625 E+02$

$0.8179 \mathrm{E}+02$

$0.8593 E+02$

$0.8593 E+02$

$0.4347 \mathrm{E}+02$

0.0

$0.6849 \mathrm{E}+01$

$0.5015 E+02$

$0.9043 E+02$

$0.9956 \mathrm{E}+02$

$0.1066 \mathrm{E}+03$

$0.1066 \mathrm{E}+03$

3 DISPL

$0.5275 E+02$

$0.5262 E+02$

$0.2238 \mathrm{E}+02$

$0.5350 \mathrm{E}+02$

$0.6530 \mathrm{E}+00$

$0.1126 \mathrm{E}+02$

$0.4115 \mathrm{E}+02$

$-0.6547 E+01$

$0.5117 \mathrm{E}+02$

$0.5135 E+02$

$0.1796 \mathrm{E}+02$

$0.5223 E+02$

$0.7924 \mathrm{E}+00$

$0.1112 \mathrm{E}+02$

$0.3919 \mathrm{E}+02$

$-0.6705 E+01$

$0.4880 \mathrm{E}+02$

$0.4882 E+02$

$0.2214 E+02$

$0.4971 E+02$

$0.3306 \mathrm{E}+00$

$0.9019 E+01$

$0.3899 \mathrm{E}+02$

$-0.6790 \mathrm{E}+01$

$0.4855 \mathrm{E}+02$

$0.4881 E+02$

$0.2942 \mathrm{E}+02$

$0.4968 \mathrm{E}+02$

$-0.7999 \mathrm{E}-01$

$0.2809 E+02$

$0.3699 E+02$

$-0.6953 E+01$

$0.4636 E+02$

$0.4682 \mathrm{E}+02$

$0.3423 \mathrm{E}+02$

$0.4772 \mathrm{E}+02$

$-0.1882 E+00$

$0.3065 \mathrm{E}+02$

$0.3374 \mathrm{E}+02$

$-0.7127 \mathrm{E}+01$ 
FEAP COLUMBIA GLACIER VERTICAL CENTERLINE PROFILE $* * * * * * * * * * * * * * * * * * * *$ NODAL DISPLACEMENTS TIME 0.81149994E+02

\begin{tabular}{|c|c|c|c|c|c|}
\hline NODE & 1 COORD & 2 COORD & 1 DISPL & 2 DISPL & 3 DISPL \\
\hline 151 & 12303.0312 & -305.7129 & $0.5562 \mathrm{E}+03$ & $0.5478 E+02$ & $0.4050 \mathrm{E}+02$ \\
\hline 152 & 12303.0312 & -310.7129 & 0.0 & 0.0 & $0.4061 E+02$ \\
\hline 153 & 12687.5039 & 116.6096 & $0.1298 E+04$ & $-0.1562 \mathrm{E}+01$ & $-0.2111 \mathrm{E}+00$ \\
\hline 154 & 12687.5039 & -37.2140 & $0.1287 \mathrm{E}+04$ & $0.3523 E+02$ & $0.4183 \mathrm{E}+02$ \\
\hline 155 & 12687.5039 & -191.0374 & $0.1237 \mathrm{E}+04$ & $0.7301 \mathrm{E}+02$ & $0.2695 \mathrm{E}+02$ \\
\hline 156 & 12687.5039 & -229.4932 & $0.1215 E+04$ & $0.8263 \mathrm{E}+02$ & $-0.7442 \mathrm{E}+01$ \\
\hline 157 & 12687.5039 & -267.9495 & $0.1189 \mathrm{E}+04$ & $0.9161 \mathrm{E}+02$ & $0.3394 \mathrm{E}+02$ \\
\hline 158 & 12687.5039 & -267.9495 & $0.1189 \mathrm{E}+04$ & $0.9161 \mathrm{E}+02$ & $0.3488 \mathrm{E}+02$ \\
\hline 159 & 12687.5039 & -272.9495 & $0.6078 \mathrm{E}+03$ & $0.4715 \mathrm{E}+02$ & $0.4025 \mathrm{E}+02$ \\
\hline 160 & 12687.5039 & -277.9495 & 0.0 & 0.0 & $0.3576 \mathrm{E}+02$ \\
\hline 161 & 13071.9727 & 101.4698 & $0.139 I E+04$ & $0.1581 E+02$ & $-0.3078 E+00$ \\
\hline 162 & 13071.9727 & -34.5920 & $0.1386 \mathrm{E}+04$ & $0.5316 \mathrm{E}+02$ & $0.6919 \mathrm{E}+02$ \\
\hline 163 & 13071.9727 & -170.6537 & $0.1342 \mathrm{E}+04$ & $0.8741 E+02$ & $0.2428 \mathrm{E}+02$ \\
\hline 164 & 13071.9727 & -204.6691 & $0.1325 E+04$ & $0.9566 \mathrm{E}+02$ & $-0.7724 E+01$ \\
\hline 165 & 13071.9727 & -238.6848 & $0.1304 \mathrm{E}+04$ & $0.1033 E+03$ & $0.3045 \mathrm{E}+02$ \\
\hline 166 & 13071.9727 & -238.6848 & $0.1304 \mathrm{E}+04$ & $0.1033 E+03$ & $0.3135 E+02$ \\
\hline 167 & 13071.9727 & -243.6848 & $0.6799 E+03$ & $0.5462 \mathrm{E}+02$ & $0.4025 E+02$ \\
\hline 168 & 13071.9727 & -248.6848 & 0.0 & 0.0 & $0.3225 \mathrm{E}+02$ \\
\hline 169 & 13264.2031 & 94.3128 & $0.1473 E+04$ & $0.9351 E+01$ & $-0.5730 \mathrm{E}+00$ \\
\hline 170 & 13264.2031 & -31.4634 & $0.1454 \mathrm{E}+04$ & $0.7239 \mathrm{E}+02$ & $0.3975 \mathrm{E}+02$ \\
\hline 171 & 13264.2031 & -157.2396 & $0.1403 E+04$ & $0.1234 \mathrm{E}+03$ & $0.2189 \mathrm{E}+02$ \\
\hline 172 & 13264.2031 & -188.6836 & $0.1385 E+04$ & $0.1339 E+03$ & $-0.7833 E+01$ \\
\hline 173 & 13264.2031 & -220.1277 & $0.1363 \mathrm{E}+04$ & $0.1437 \mathrm{E}+03$ & $0.2756 \mathrm{E}+02$ \\
\hline 174 & 13264.2031 & -220.1277 & $0.1363 \mathrm{E}+04$ & $0.1437 \mathrm{E}+03$ & $0.2865 \mathrm{E}+02$ \\
\hline 175 & 13264.2031 & -225.1277 & $0.6702 \mathrm{E}+03$ & $0.7095 \mathrm{E}+02$ & $0.4025 E+02$ \\
\hline $\begin{array}{l}176 \\
177\end{array}$ & $\begin{array}{l}13264.2031 \\
13456.4414\end{array}$ & $\begin{array}{r}-230.1277 \\
89.8647\end{array}$ & $\begin{array}{l}0.0 \\
0.1602 \mathrm{E}+04\end{array}$ & $\begin{array}{l}0.0 \\
-0.7009 E+01\end{array}$ & $\begin{array}{r}0.2952 E+02 \\
-0.1291 E+01\end{array}$ \\
\hline 178 & 13456.4414 & -24.7626 & $0.1576 \mathrm{E}+04$ & $0.1070 \mathrm{E}+03$ & $0.6118 \mathrm{E}+02$ \\
\hline 179 & 13456.4414 & -139.3900 & $0.1492 \mathrm{E}+04$ & $0.1856 \mathrm{E}+03$ & $0.2025 \mathrm{E}+02$ \\
\hline 180 & 13456.4414 & -168.0467 & $0.1469 \mathrm{E}+04$ & $0.2002 \mathrm{E}+03$ & $-0.7910 \mathrm{E}+01$ \\
\hline 181 & 13456.4414 & -196.7039 & $0.1450 \mathrm{E}+04$ & $0.2093 E+03$ & $0.2610 \mathrm{E}+02$ \\
\hline 182 & 13456.4414 & -196.7039 & $0.1450 E+04$ & $0.2093 E+03$ & $0.2713 E+02$ \\
\hline 183 & 13456.4414 & -201.7039 & $0.8329 E+03$ & $0.1207 E+03$ & $0.4025 E+02$ \\
\hline 184 & 13456.4414 & -206.7039 & 0.0 & 0.0 & $0.2811 \mathrm{E}+02$ \\
\hline 185 & 13648.6719 & 76.2207 & $0.1824 \mathrm{E}+04$ & $-0.4276 \mathrm{E}+02$ & $-0.8349 E+00$ \\
\hline 186 & 13648.6719 & -20.9452 & $0.1795 E+04$ & $0.6911 \mathrm{E}+02$ & $0.6717 \mathrm{E}+02$ \\
\hline 187 & 13648.6719 & -118.1111 & $0.1689 E+04$ & $0.1934 E+03$ & $0.1660 \mathrm{E}+02$ \\
\hline 188 & 13648.6719 & -142.4025 & $0.1643 E+04$ & $0.2221 E+03$ & $-0.7942 E+01$ \\
\hline 189 & 13648.6719 & -166.6940 & $0.1591 E+04$ & $0.2464 \mathrm{E}+03$ & $0.2117 \mathrm{E}+02$ \\
\hline 190 & 13648.6719 & -166.6940 & $0.1591 \mathrm{E}+04$ & $0.2464 \mathrm{E}+03$ & $0.2295 E+02$ \\
\hline 191 & 13648.6719 & -171.6940 & $0.7263 E+03$ & $0.1141 E+03$ & $0.4025 E+02$ \\
\hline 192 & 13648.6719 & -176.6940 & 0.0 & 0.0 & $0.2379 E+02$ \\
\hline 193 & 13840.9141 & 66.9960 & $0.1955 E+04$ & $-0.2757 E+02$ & $-0.1211 E+01$ \\
\hline 194 & 13840.9141 & -13.7014 & $0.2063 E+04$ & $0.4808 \mathrm{E}+02$ & $0.1659 E+02$ \\
\hline 195 & 13840.9141 & -94.3988 & $0.2034 E+04$ & $0.1827 E+03$ & $0.1231 E+02$ \\
\hline 196 & 13840.9141 & -114.5732 & $0.2000 \mathrm{E}+04$ & $0.2339 E+03$ & $-0.7941 E+01$ \\
\hline 197 & 13840.9141 & -134.7476 & $0.1959 E+04$ & $0.2749 E+03$ & $0.1806 \mathrm{E}+02$ \\
\hline 198 & 13840.9141 & -134.7476 & $0.1959 E+04$ & $0.2749 \mathrm{E}+03$ & $0.2018 \mathrm{E}+02$ \\
\hline 199 & 13840.9141 & -139.7476 & $0.1570 E+04$ & $0.2394 E+03$ & $0.4025 E+02$ \\
\hline 200 & 13840.9141 & -144.7476 & 0.0 & 0.0 & $0.2173 E+02$ \\
\hline
\end{tabular}




\begin{tabular}{|c|c|c|c|c|c|c|c|c|}
\hline * *MACRO & INSTRUCTION & 14 EXECUTED** & SAVE & & v1 $=$ & .0 & , V2 & .0 \\
\hline **MACRO & INSTRUCTION & 15 EXECUTED** & LOOP & & $\mathrm{v1}=$ & 1.000 & $\mathrm{~V} 2$ & 32.00 \\
\hline * *MACRO & INSTRUCTION & 16 EXECUTED** & LOOP & & $\mathrm{vl}=$ & 5.000 & $\mathrm{~V} 2$ & 28.00 \\
\hline * *MACRO & INSTRUCTION & 17 EXECUTEDD** & DT & & $\mathrm{V} 1=$ & $.2500 \mathrm{E}-01$ & , v2 & .0 \\
\hline * *MACRO & INSTRUCTION & 18 EXECUTED** & UPNO & & $\mathrm{vl}=$ & .0 & $\mathrm{~V} 2$ & .0 \\
\hline **MACRO & INSTRUCTION & 19 EXECUTED** & TIME & & $\mathrm{vl}=$ & .0 & V2 & .0 \\
\hline **MACRO & INSTRUCTION & 20 EXECUTED** & LOOP & & $\mathrm{vl}=$ & 10.00 & . V2 & 27.00 \\
\hline * *MACRO & INSTRUCTION & 21 EXECUTED** & TANF & & $\mathrm{v} 1=$ & .0 & . V2 & .0 \\
\hline \multicolumn{9}{|c|}{ FORCE CONVERGENCE TEST } \\
\hline & $\operatorname{RNMAX}=$ & 1985.6 & RN & $=$ & 1985.6 & TOL & $=$ & $.10000 \mathrm{E}-01$ \\
\hline **MACRO & INSTRUCTION & 22 EXECUTED** & soLv & & $\mathrm{Vl}=$ & .0 & . V2 & $=.0$ \\
\hline **MACRO & INSTRUCTION & 23 EXECUTED** & CONV & & VI $=$ & .0 & , V2 & .0 \\
\hline \multicolumn{9}{|c|}{ DISPLACEMENT CONVERGENCE TEST } \\
\hline **MACRO & $\begin{array}{l}\text { UNMAX = } \\
\text { INSTRUCTION }\end{array}$ & $\begin{array}{l}13008 \text {. } \\
24 \text { EXECUTED** }\end{array}$ & $\begin{array}{l}\text { UN } \\
\text { DT }\end{array}$ & $=$ & $\begin{array}{r}166.76 \\
\mathrm{Vl}=\end{array}$ & TOL & & $=\begin{array}{c}.10000 \mathrm{E}-01 \\
.0\end{array}$ \\
\hline **MACRO & INSTRUCTION & 25 EXECUTED** & TIME & & $\mathrm{Vl}=$ & .0 & , v2 & .0 \\
\hline **MACRO & INSTRUCTION & 26 EXECUTED** & NEXT & & $\mathrm{vl}=$ & 1.000 & V2 & 21.00 \\
\hline **MACRO & INSTRUCTION & 21 EXECUTED** & TANF & & $\mathrm{Vl}=$ & .0 & V2 & .0 \\
\hline \multicolumn{9}{|c|}{ FORCE CONVERGENCE TEST } \\
\hline & $\operatorname{RNMAX}=$ & 15.457 & RN & $=$ & 15.457 & TOL & $=$ & $.10000 \mathrm{E}-01$ \\
\hline **MACRO & INSTRUCTION & 22 EXECUTED** & SOLV & & $\mathrm{vl}=$ & .0 & , v2 & $=\quad .0$ \\
\hline **MACRO & INSTRUCTION & 23 EXECUTED** & CONV & & $\mathrm{Vl}=$ & .0 & V2 & .0 \\
\hline \multicolumn{9}{|c|}{ DISPLACEMENT CONVERGENCE TEST } \\
\hline & UNMAX $=$ & 13010 & UN & $=$ & 2.4093 & TOL & $=$ & $.10000 \mathrm{E}-01$ \\
\hline * *MACRO & INSTRUCTION & 24 EXECUTED** & DT & & $\mathrm{Vl}=$ & .0 & , V2 & .0 \\
\hline **MACRO & INSTRUCTION & 25 EXECUTED** & TIME & & $\mathrm{vl}=$ & .0 & 72 & .0 \\
\hline * *MACRO & INSTRUCTION & 26 EXECUTED** & NEXT & & $\mathrm{vl}=$ & 10.00 & 12 & 21.00 \\
\hline * *MACRO & INSTRUCTION & 27 EXECUTED** & NEXT & & $\mathrm{VI}=$ & 1.000 & $\mathbf{v 2}$ & 17.00 \\
\hline **MACRO & INSTRUCTION & 17 EXECUTED** & DT & & $\mathrm{v1}=$ & $.2500 \mathrm{E}-01$ & , V2 & .0 \\
\hline * *MACRO & INSTRUCTION & 18 EXECUTED** & UPNO & & $\mathrm{Vl}=$ & .0 & V2 & .0 \\
\hline * *MACRO & INSTRUCTION & 19 EXECUTED** & TIME & & $\mathrm{VI}=$ & .0 & V2 & .0 \\
\hline * *MACRO & INSTRUCTION & 20 EXECUTED** & LOOP & & $\mathrm{v} \mathbf{1}=$ & 10.00 & v2 & 27.00 \\
\hline * *MACRO & INSTRUCTION & 21 EXECUTED** & TANF & & $\mathrm{vl}=$ & .0 & , & .0 \\
\hline \multicolumn{9}{|c|}{ FORCE CONVERGENCE TEST } \\
\hline & RNMAX = & 2440.2 & RN & $=$ & 2440.2 & TOL & $=$ & $.10000 \mathrm{E}-01$ \\
\hline **MACRO & INSTRUCTION & 22 EXECUTED** & SOLV & & $\mathbf{v} \mathbf{l}=$ & .0 & , V2 & .0 \\
\hline **MACRO & INSTRUCTION & 23 EXECUTED** & CONV & & $\mathrm{Vl}=$ & .0 & , & .0 \\
\hline \multicolumn{9}{|c|}{ DISPLACEMENT CONVERGENCE TEST } \\
\hline & UNMAX = & 12846 & UN & $=$ & 195.34 & TOL & $=$ & $.10000 \mathrm{E}-01$ \\
\hline **MACRO & INSTRUCTION & 24 EXECUTED** & DT & & $\mathrm{V} 1=$ & .0 & 12 & .0 \\
\hline **MACRO & INSTRUCTION & 25 EXECUTED** & TIME & & $\mathrm{vl}=$ & .0 & 12 & .0 \\
\hline **MACRO & INSTRUCTION & 26 EXECUTED** & NEXT & & $\mathrm{vl}=$ & 1.000 & 2 & 21.00 \\
\hline * *MACRO & INSTRUCTION & 21 EXECUTED** & TANF & & $\mathrm{v} 1=$ & .0 & , & .0 \\
\hline \multicolumn{9}{|c|}{ FORCE CONVERGENCE TEST } \\
\hline & RNMAX $=$ & 19.483 & RN & $=$ & 19.483 & TOL & $=$ & $.10000 \mathrm{E}-01$ \\
\hline **MACRO & INSTRUCTION & 22 EXECUTED** & SOLV & & Vl $=$ & .0 & 12 & .0 \\
\hline * *MACRO & INSTRUCTION & 23 EXECUTED** & CONV & & $\mathrm{vl}=$ & .0 & , & .0 \\
\hline \multicolumn{9}{|c|}{ DISPLACEMENT CONVERGENCE TEST } \\
\hline & UNMAX = & 12848. & UN & $=$ & 3.0509 & TOL & $=$ & $.10000 \mathrm{E}-01$ \\
\hline **MACRO & INSTRUCTION & 24 EXECUTED** & DT & & $\mathrm{V} 1=$ & .0 & , & .0 \\
\hline **MACRO & INSTRUCTION & 25 EXECUTED** & TIME & & $\mathrm{vl}=$ & .0 & $\sqrt{2}$ & .0 \\
\hline * *MACRO & INSTRUCTION & 26 EXECUTED** & NEXT & & $\mathrm{v} 1=$ & 10.00 & 12 & 21.00 \\
\hline
\end{tabular}




\begin{tabular}{|c|c|c|c|c|c|c|c|c|c|}
\hline 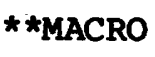 & INSTRUCTION & 27 EXECUTED** & NEXT & & $\mathbf{v} 1=$ & 2.000 & , v2 & $=$ & 17.00 \\
\hline **MACRO & INSTRUCTION & 17 EXECUTED** & DT & & $\mathrm{v} \mathbf{l}=$ & $.2500 \mathrm{E}-01$ & , v2 & $=$ & .0 \\
\hline **MACRO & INSTRUCTION & 18 EXECUTED** & UPNO & & $\mathbf{v l}=$ & .0 & , v2 & $=$ & .0 \\
\hline **MACRO & INSTRUCTION & 19 EXECUTED** & TIME & & $\mathrm{vl}=$ & .0 & , v2 & $=$ & .0 \\
\hline * * MACRO & INSTRUCTION & 20 EXECUTED** & LOOP & & $\mathrm{V} \mathbf{l}=$ & 10.00 & , v2 & $=$ & 27.00 \\
\hline * *MACRO & INSTRUCTION & 21 EXECUTED** & TANF & & $\mathrm{V} \mathbf{1}=$ & .0 & , v2 & $=$ & .0 \\
\hline \multicolumn{10}{|c|}{ FORCE CONVERGENCE TEST } \\
\hline & RNMAX = & 2394.2 & RN & $=$ & 2394.2 & TOL & $=$ & & $00 \mathrm{E}-01$ \\
\hline **MACRO & INSTRUCTION & 22 EXECUTED** & SOLV & & $\mathrm{vl}=$ & .0 & , v2 & $=$ & .0 \\
\hline **MACRO & INSTRUCTION & 23 EXECUTED** * & CONV & & $\mathrm{VI}=$ & .0 & , v2 & $=$ & .0 \\
\hline \multicolumn{10}{|c|}{ DISPLACEMENT CONVERGENCE TEST } \\
\hline & UNMAX $=$ & 12704 & UN & $=$ & 175.48 & TOL & $=$ & & $00 \mathrm{E}-01$ \\
\hline * *MACRO & INSTRUCTION & 24 EXECUTED** & DT & & $\mathrm{vl}=$ & .0 &, $\mathrm{v} 2$ & $=$ & .0 \\
\hline * *MACRO & INSTRUCTION & 25 EXECUTED** & TIME & & $\mathrm{vl}=$ & .0 & , v2 & $=$ & .0 \\
\hline * *MACRO & INSTRUCTION & 26 EXECUTED** & NEXT & & $\mathbf{v l}=$ & 1.000 & , v2 & $=$ & 21.00 \\
\hline * *MACRO & INSTRUCTION & 21 EXECUTED** & TANF & & $\mathrm{V} \mathbf{l}=$ & .0 & v2 & $=$ & .0 \\
\hline \multicolumn{10}{|c|}{ FORCE CONVERGENCE TEST } \\
\hline & RNMAX $=$ & 27.012 & RN & $=$ & 27.012 & TOL & $=$ & & $00 E-01$ \\
\hline **MACRO & INSTRUCTION & 22 EXECUTED** & SOLV & & $\mathrm{vl}=$ & .0 & , v2 & $=$ & .0 \\
\hline * *MACRO & INSTRUCTION & 23 EXECUTED** & CONV & & $\mathrm{Vl}=$ & .0 & , v2 & $=$ & .0 \\
\hline \multicolumn{10}{|c|}{ DISPLACEMENT CONVERGENCE TEST } \\
\hline & UNMAX $=$ & 12706. & UN & $=$ & 2.7596 & TOL & $=$ & & $00 E-01$ \\
\hline **MACRO & INSTRUCTION & 24 EXECUTED** & DT & & $\mathrm{vl}=$ & .0 & , v2 & $=$ & .0 \\
\hline **MACRO & INSTRUCTION & 25 EXECUTED** & TIME & & $\mathrm{V} \mathbf{l}=$ & .0 & , v2 & $=$ & .0 \\
\hline **MACRO & INSTRUCTION & 26 EXECUTED** & NEXT & & $\mathrm{vl}=$ & 10.00 & , v2 & $=$ & 21.00 \\
\hline **MACRO & INSTRUCTION & 27 EXECUTED** & NEXT & & $\mathbf{v} \mathbf{l}=$ & 3.000 & , v2 & $=$ & 17.00 \\
\hline * *MACRO & INSTRUCTION & 17 EXECUTED** & DT & & $\mathrm{vl}=$ & $.2500 \mathrm{E}-01$ & . v2 & $=$ & .0 \\
\hline **MACRO & INSTRUCTION & 18 EXECUTED ** & UPNO & & $\mathrm{vl}=$ & .0 & , v2 & $=$ & .0 \\
\hline **MACRO & INSTRUCTION & 19 EXECUTED** & TIME & & $\mathrm{vl}=$ & .0 & , v2 & $=$ & .0 \\
\hline **MACRO & INSTRUCTION & 20 EXECUTED ** & LOOP & & $\mathrm{v} \mathbf{1}=$ & 10.00 & , v2 & $=$ & 27.00 \\
\hline * *MACRO & INSTRUCTION & 21 EXECUTED** & TANF & & $\mathrm{vl}=$ & .0 & . v2 & $=$ & .0 \\
\hline \multicolumn{10}{|c|}{ FORCE CONVERGENCE TEST } \\
\hline & $\operatorname{RNMAX}=$ & 1750.1 & $\mathbf{R N}$ & $=$ & 1750.1 & TOL & $=$ & & $000 \mathrm{E}-01$ \\
\hline **MACRO & INSTRUCTION & 22 EXECUTED** & soLV & & $\mathrm{vl}=$ & .0 & , v2 & $=$ & .0 \\
\hline **MACRO & INSTRUCTION & 23 EXECUTED ** & CONV & & $\mathrm{V} \mathbf{l}=$ & .0 & . v2 & $=$ & .0 \\
\hline \multicolumn{10}{|c|}{ DISPLACEMENT CONVERGENCE TEST } \\
\hline & UNMAX $=$ & 12572. & UN & $=$ & 152.09 & TOL & $=$ & & $000 \mathrm{E}-01$ \\
\hline * *MACRO & INSTRUCTION & 24 EXECUTED** & DT & & $\mathrm{VI}=$ & .0 & . v2 & $=$ & .0 \\
\hline **MACRO & INSTRUCTION & 25 EXECUTED ** & TIME & & $\mathrm{vl}=$ & .0 & , v2 & $=$ & .0 \\
\hline **MACRO & INSTRUCTION & 26 EXECUTED** & NEXT & & $\mathrm{vl}=$ & 1.000 & , v2 & $=$ & 21.00 \\
\hline$\star \star$ MACRO & INSTRUCTION & 21 EXECUTED ** & TANF & & $\mathrm{vl}=$ & .0 & v2 & $=$ & .0 \\
\hline \multicolumn{10}{|c|}{ FORCE CONVERGENCE TEST } \\
\hline & RNMAX $=$ & 127.53 & $\mathrm{RN}$ & $=$ & 127.53 & TOL & $=$ & & $00 \mathrm{E}-01$ \\
\hline **MACRO & INSTRUCTION & 22 EXECUTED** & SOLV & & $\mathrm{vl}=$ & .0 & , v2 & $=$ & .0 \\
\hline **MACRO & INSTRUCTION & 23 EXECUTED ** & CONV & & $\mathrm{Vl}=$ & .0 & . v2 & $=$ & .0 \\
\hline \multicolumn{10}{|c|}{ DISPLACEMENT CONVERGENCE TEST } \\
\hline & UNMAX $=$ & 12574 & UN & $=$ & 2.6256 & TOL & $=$ & & $00 \mathrm{E}-01$ \\
\hline * *MACRO & INSTRUCTION & 24 EXECUTED** & DT & & $\mathrm{v} 1=$ & .0 & , v2 & $=$ & .0 \\
\hline **MACRO & INSTRUCTION & 25 EXECUTED ** & TIME & & $\mathrm{vl}=$ & .0 & , v2 & $=$ & .0 \\
\hline **MACRO & INSTRUCTION & 26 EXECUTED ** & NEXT & & $\mathrm{V} 1=$ & 10.00 & , v2 & $=$ & 21.00 \\
\hline **MACRO & INSTRUCTION & 27 EXECUTED** & NEXT & & $\mathrm{Vl}=$ & 4.000 & , v2 & $=$ & 17.00 \\
\hline **MACRO & INSTRUCTION & 17 EXECUTED** & DT & & $\mathrm{v} \mathbf{l}=$ & $.2500 \mathrm{E}-01$ & , v2 & $=$ & .0 \\
\hline
\end{tabular}




\begin{tabular}{|c|c|c|c|c|c|c|c|c|c|}
\hline **MACRO & INSTRUCTION & 18 EXECUTED** & UPNO & & $\mathrm{Vl}=$ & .0 & , v2 & $=$ & .0 \\
\hline * *MACRO & INSTRUCTION & 19 EXECUTED** & TIME & & $\mathrm{Vl}=$ & .0 & , v2 & $=$ & .0 \\
\hline **MACRO & INSTRUCTION & 20 EXECUTED** & LOOP & & $\mathrm{v} 1=$ & 10.00 & v2 & $=$ & 27.00 \\
\hline **MACRO & INSTRUCTION & 21 EXECUTED** & TANF & & $\mathrm{V} 1=$ & .0 & , v2 & $=$ & .0 \\
\hline \multicolumn{10}{|c|}{ FORCE CONVERGENCE TEST } \\
\hline & $\operatorname{RNMAX}=$ & 1291.0 & RN & $=$ & 1291.0 & TOL & $=$ & & $00 \mathrm{E}-01$ \\
\hline **MACRO & INSTRUCTION & 22 EXECUTED** & SOLV & & $\mathrm{Vl}=$ & .0 & , v2 & $=$ & .0 \\
\hline * *MACRO & INSTRUCTION & 23 EXECUTED** & CONV & & $\mathrm{V} 1=$ & .0 & , v2 & $=$ & .0 \\
\hline \multicolumn{10}{|c|}{ DISPLACEMENT CONVERGENCE TEST } \\
\hline & UNMAX $=$ & $1246^{\prime} 6$ & UN & $=$ & 123.86 & TOL & $=$ & & $00 \mathrm{E}-01$ \\
\hline * *MACRO & INSTRUCTION & 24 EXECUTED** & DT & & $\mathrm{V} 1=$ & .0 &, $\mathrm{v} 2$ & $=$ & .0 \\
\hline * *MACRO & INSTRUCTION & 25 EXECUTED** & TIME & & $\mathrm{VI}=$ & .0 &, $\mathrm{v} 2$ & $=$ & .0 \\
\hline * *MACRO & INSTRUCTION & 26 EXECUTED** & NEXT & & $\mathrm{V} 1=$ & 10.00 & V2 & $=$ & 21.00 \\
\hline * *MACRO & INSTRUCTION & 27 EXECUTED** * & NEXT & & $\mathrm{Vl}=$ & 5.000 & v2 & $=$ & 17.00 \\
\hline * *MACRO & INSTRUCTION & 28 EXECUTED** & PLOT & & $\mathrm{Vl}=$ & .0 & v2 & $=$ & .0 \\
\hline * *MACRO & INSTRUCTION & 29 EXECUTED** & DISP & & $\mathrm{Vl}=$ & .0 & V2 & $=$ & .0 \\
\hline
\end{tabular}

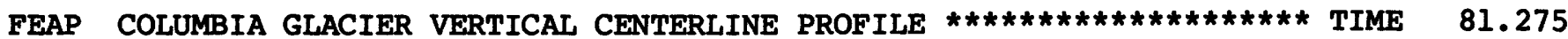
PROPORTIONAL LOAD 1.0000

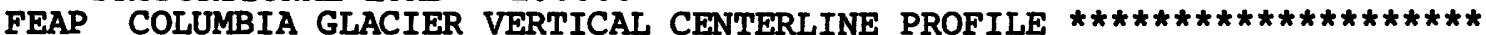

\begin{tabular}{rc} 
NODAL & DISPLACEMENT \\
NODE & 1 COORD \\
1 & 0.0 \\
2 & 0.0 \\
3 & 0.0 \\
4 & 0.0 \\
5 & 0.0 \\
6 & 0.0 \\
7 & 0.0 \\
8 & 0.0 \\
9 & 774.9919 \\
10 & 774.9919 \\
11 & 774.9919 \\
12 & 774.9919 \\
13 & 774.9919 \\
14 & 774.9919 \\
15 & 774.9919 \\
16 & 774.9919 \\
17 & 1549.9841 \\
18 & 1549.9841 \\
19 & 1549.9841 \\
20 & 1549.9841 \\
21 & 1549.9841 \\
22 & 1549.9841 \\
23 & 1549.9841 \\
24 & 1549.9841 \\
25 & 2324.9758 \\
26 & 2324.9758 \\
27 & 2324.9758 \\
28 & 2324.9758 \\
29 & 2324.9758 \\
30 & 2324.9758 \\
31 & 2324.9758 \\
32 & 2324.9758 \\
33 & 3099.9685 \\
& \\
\hline
\end{tabular}

TIME $0.81274963 \mathrm{E}+02$

2 COORD 1 DISPL

$465.0000 \quad 0.9500 \mathrm{E}+03$

$171.8000 \quad 0.9436 \mathrm{E}+03$

$-121.4000$

$-194.7000$

$-268.0000$

$-268.0000$

$-273.0000$

$-278.0000$

456.7146

179.2788

$-98.1570$

$-167.5159$

$-236.8751$

$-236.8751$

$-241.8751$

$-246.8751$

429.6428

157.0532

$-115.5364$

$-183.6838$

$-251.8313$

$-251.8313$

$-256.8313$

$-261.8313$

423.0266

163.1912

$-96.6445$

$-161.6035$

$-226.5626$

$-226.5626$

$-231.5626$

$-236.5626$

396.8281
$0.8469 \mathrm{E}+03$

$0.7848 \mathrm{E}+03$

$0.6982 E+03$

$0.6982 E+03$

$0.3491 E+03$

0.0

$0.9753 E+03$

$0.9557 \mathrm{E}+03$

$0.9024 \mathrm{E}+03$

$0.8791 E+03$

$0.8548 \mathrm{E}+03$

$0.8548 \mathrm{E}+03$

$0.4309 E+03$

0.0

$0.9762 E+03$

$0.9760 \mathrm{E}+03$

$0.9192 E+03$

$0.8838 \mathrm{E}+03$

$0.8338 \mathrm{E}+03$

$0.8338 \mathrm{E}+03$

$0.4227 \mathrm{E}+03$

0.0

$0.1037 E+04$

$0.1017 \mathrm{E}+04$

$0.9395 E+03$

$0.8878 \mathrm{E}+03$

$0.8145 \mathrm{E}+03$

$0.8145 E+03$

$0.4095 E+03$

0.0

$0.1126 E+04$
2 DISPL

$0.2882 \mathrm{E}+02$

$0.3435 E+02$

$0.4353 \mathrm{E}+02$

$0.4749 \mathrm{E}+02$

$0.6017 \mathrm{E}+02$

$0.6017 \mathrm{E}+02$

$0.3056 \mathrm{E}+02$

0.0

$-0.2072 E+02$

$-0.1599 E+02$

$-0.6765 E+01$

$-0.2233 E+01$

$0.3018 \mathrm{E}+01$

$0.3018 \mathrm{E}+01$

$0.1622 \mathrm{E}+01$

0.0

$-0.1030 \mathrm{E}+02$

$-0.3824 E+01$

$0.5947 \mathrm{E}+00$

$-0.2891 E+01$

$-0.9678 \mathrm{E}+01$

$-0.9678 \mathrm{E}+01$

$-0.5113 E+01$

0.0

$-0.1124 E+02$

$0.1365 \mathrm{E}+02$

$0.3074 \mathrm{E}+02$

$0.3431 \mathrm{E}+02$

$0.3651 \mathrm{E}+02$

$0.3651 \mathrm{E}+02$

$0.1851 \mathrm{E}+02$

0.0

$-0.2900 E+02$

3 DISPL
$0.1535 E+01$
$0.1517 E+02$
$0.5159 E+02$
$-0.2670 E+01$
$0.6284 E+02$
$0.6365 E+02$
$0.4000 E+02$
$0.6447 E+02$
$0.4242 E+00$
$0.2853 E+01$
$0.4952 E+02$
$-0.3431 E+01$
$0.6187 E+02$
$0.6234 E+02$
$0.3688 E+02$
$0.6324 E+02$
$0.6830 E+00$
$0.3248 E+01$
$0.4924 E+02$
$-0.3997 E+01$
$0.6130 E+02$
$0.6073 E+02$
$0.2468 E+02$
$0.6157 E+02$
$-0.5320 E-01$
$0.5053 E+01$
$0.4662 E+02$
$-0.4473 E+01$
$0.5830 E+02$
$0.5852 E+02$
$0.8597 E+01$
$0.5942 E+02$
$0.1372 E+00$
0




$\begin{array}{rrrlrr}34 & 3099.9685 & 161.0949 & 0.1103 \mathrm{E}+04 & -0.2955 \mathrm{E}+01 & 0.6358 \mathrm{E}+01 \\ 35 & 3099.9685 & -74.6382 & 0.1017 \mathrm{E}+04 & 0.2284 \mathrm{E}+02 & 0.4203 \mathrm{E}+02 \\ 36 & 3099.9685 & -133.5715 & 0.9795 \mathrm{E}+03 & 0.2885 \mathrm{E}+02 & -0.4932 \mathrm{E}+01 \\ 37 & 3099.9685 & -192.5051 & 0.9362 \mathrm{E}+03 & 0.3245 \mathrm{E}+02 & 0.5274 \mathrm{E}+02 \\ 38 & 3099.9685 & -192.5051 & 0.9362 \mathrm{E}+03 & 0.3245 \mathrm{E}+02 & 0.5293 \mathrm{E}+02 \\ 39 & 3099.9685 & -197.5051 & 0.4769 \mathrm{E}+03 & 0.1656 \mathrm{E}+02 & 0.8310 \mathrm{E}+01 \\ 40 & 3099.9685 & -202.5051 & 0.0 & 0.0 & 0.5380 \mathrm{E}+02 \\ 41 & 3874.9602 & 368.8999 & 0.1185 \mathrm{E}+04 & -0.4704 \mathrm{E}+02 & 0.3037 \mathrm{E}+00 \\ 42 & 3874.9602 & 148.5506 & 0.1162 \mathrm{E}+04 & -0.3464 \mathrm{E}+02 & 0.6679 \mathrm{E}+01 \\ 43 & 3874.9602 & -71.7986 & 0.1084 \mathrm{E}+04 & -0.2039 \mathrm{E}+02 & 0.3967 \mathrm{E}+02 \\ 44 & 3874.9602 & -126.8860 & 0.1026 \mathrm{E}+04 & -0.1568 \mathrm{E}+02 & -0.5454 \mathrm{E}+01 \\ 45 & 3874.9602 & -181.9735 & 0.9358 \mathrm{E}+03 & -0.1186 \mathrm{E}+02 & 0.4961 \mathrm{E}+02 \\ 46 & 3874.9602 & -181.9735 & 0.9358 \mathrm{E}+03 & -0.1186 \mathrm{E}+02 & 0.4968 \mathrm{E}+02 \\ 47 & 3874.9602 & -186.9735 & 0.4768 \mathrm{E}+03 & -0.5977 \mathrm{E}+01 & 0.6931 \mathrm{E}+01 \\ 48 & 3874.9602 & -191.9735 & 0.0 & 0.0 & 0.5056 \mathrm{E}+02 \\ 49 & 4649.9492 & 317.6731 & 0.1192 \mathrm{E}+04 & -0.8114 \mathrm{E}+02 & 0.2195 \mathrm{E}+01 \\ 50 & 4649.9492 & 102.3462 & 0.1170 \mathrm{E}+04 & -0.1003 \mathrm{E}+03 & 0.3837 \mathrm{E}+01\end{array}$

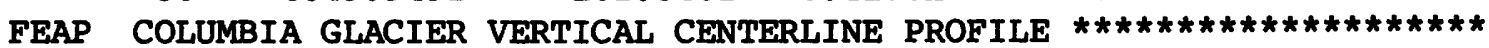

\begin{tabular}{|c|c|c|c|c|c|}
\hline & SPLACEMENTS & TIME & $274963 E+02$ & & \\
\hline NODE & 1 COORD & 2 COORD & 1 DISPL & 2 DISPL & 3 DISPL \\
\hline 51 & 4649.9492 & -112.9807 & $0.1094 \mathrm{E}+04$ & $-0.1151 E+03$ & $0.3902 \mathrm{E}+02$ \\
\hline 52 & 4649.9492 & -166.8125 & $0.1048 \mathrm{E}+04$ & $-0.1162 E+03$ & $-0.6023 E+01$ \\
\hline 53 & 4649.9492 & -220.6443 & $0.9791 E+03$ & $-0.1126 \mathrm{E}+03$ & $0.4809 E+02$ \\
\hline 54 & 4649.9492 & -220.6443 & $0.9791 E+03$ & $-0.1126 E+03$ & $0.4797 \mathrm{E}+02$ \\
\hline 55 & 4649.9492 & -225.6443 & $0.5050 \mathrm{E}+03$ & $-0.5810 \mathrm{E}+02$ & $0.8847 \mathrm{E}+01$ \\
\hline 56 & 4649.9492 & -230.6443 & 0.0 & 0.0 & $0.4884 \mathrm{E}+02$ \\
\hline 57 & 5424.9414 & 281.0791 & $0.1054 \mathrm{E}+04$ & $-0.9754 \mathrm{E}+01$ & $0.2136 \mathrm{E}+01$ \\
\hline 58 & 5424.9414 & 41.1132 & $0.1039 \mathrm{E}+04$ & $-0.4953 E+02$ & $0.1298 \mathrm{E}+02$ \\
\hline 59 & 5424.9414 & -198.8525 & $0.9476 \mathrm{E}+03$ & $-0.8097 \mathrm{E}+02$ & $0.4398 \mathrm{E}+02$ \\
\hline 60 & 5424.9414 & -258.8440 & $0.8986 \mathrm{E}+03$ & $-0.8734 \mathrm{E}+02$ & $-0.6318 \mathrm{E}+01$ \\
\hline 61 & 5424.9414 & -318.8357 & $0.8368 \mathrm{E}+03$ & $-0.8974 \mathrm{E}+02$ & $0.5414 \mathrm{E}+02$ \\
\hline 62 & 5424.9414 & -318.8357 & $0.8368 \mathrm{E}+03$ & $-0.8974 \mathrm{E}+02$ & $0.5380 \mathrm{E}+02$ \\
\hline 63 & 5424.9414 & -323.8357 & $0.4217 \mathrm{E}+03$ & $-0.4547 E+02$ & $0.1113 E+02$ \\
\hline 64 & 5424.9414 & -328.8357 & 0.0 & 0.0 & $0.5467 \mathrm{E}+02$ \\
\hline 65 & 6199.9336 & 270.1453 & $0.9592 E+03$ & $0.5920 \mathrm{E}+01$ & $0.2010 \mathrm{E}+01$ \\
\hline 66 & 6199.9336 & 11.4897 & $0.9382 \mathrm{E}+03$ & $-0.6883 E+01$ & $0.8312 \mathrm{E}+01$ \\
\hline 67 & 6199.9336 & -247.1658 & $0.8640 \mathrm{E}+03$ & $-0.1952 \mathrm{E}+02$ & $0.4661 E+02$ \\
\hline 68 & 6199.9336 & -311.8296 & $0.8260 \mathrm{E}+03$ & $-0.2080 \mathrm{E}+02$ & $-0.6319 E+01$ \\
\hline 69 & 6199.9336 & -376.4937 & $0.7824 \mathrm{E}+03$ & $-0.2302 \mathrm{E}+02$ & $0.5812 \mathrm{E}+02$ \\
\hline $\begin{array}{l}70 \\
71\end{array}$ & $\begin{array}{l}6199.9336 \\
6199.9336\end{array}$ & $\begin{array}{l}-376.4937 \\
-381.4937\end{array}$ & $\begin{array}{l}0.7824 \mathrm{E}+03 \\
0.3934 \mathrm{E}+03\end{array}$ & $\begin{array}{l}-0.2302 \mathrm{E}+02 \\
-0.1161 \mathrm{E}+02\end{array}$ & $\begin{array}{l}0.5789 \mathrm{E}+02 \\
0.7286 \mathrm{E}+01\end{array}$ \\
\hline 72 & 6199.9336 & -386.4937 & 0.0 & 0.0 & $0.5878 \mathrm{E}+02$ \\
\hline 73 & .9297 & 256.8132 & $0.9498 \mathrm{E}+03$ & $-0.3999 \mathrm{E}+01$ & $0.8032 \mathrm{E}+00$ \\
\hline 74 & 6974.9297 & 0.1335 & $0.9307 E+03$ & $-0.2694 \mathrm{E}+01$ & $0.9165 \mathrm{E}+01$ \\
\hline 75 & .9297 & -256.5461 & $0.8516 E+03$ & $0.1483 E+01$ & $0.4629 \mathrm{E}+02$ \\
\hline 76 & 6974.9297 & -320.7161 & $0.7993 E+03$ & $0.2469 \mathrm{E}+01$ & $-0.6286 \mathrm{E}+0 \mathrm{l}$ \\
\hline 77 & 6974.9297 & -384.8862 & $0.7284 E+03$ & $0.2891 \mathrm{E}+01$ & $0.5766 \mathrm{E}+02$ \\
\hline 78 & 6974.9297 & -384.8862 & $0.7284 E+03$ & $0.2891 \mathrm{E}+01$ & $0.5767 E+02$ \\
\hline 79 & 6974.9297 & -389.8862 & $0.3661 E+03$ & $0.1450 \mathrm{E}+01$ & $0.8074 \mathrm{E}+01$ \\
\hline 80 & 6974.9297 & -394.8862 & 0.0 & 0.0 & $0.5855 E+02$ \\
\hline 81 & 7749.9180 & 239.0933 & $0.9555 E+03$ & $-0.1150 E+02$ & $0.1017 \mathrm{E}+01$ \\
\hline 82 & 7749.9180 & -5.8043 & $0.9420 \mathrm{E}+03$ & $-0.9521 E+01$ & $0.8511 E+01$ \\
\hline 83 & 7749.9180 & -250.7019 & $0.8951 E+03$ & $0.1285 \mathrm{E}+00$ & $0.4395 \mathrm{E}+02$ \\
\hline & & & $0.8576 E+03$ & $0.7086 E+01$ & $-0.6259 \mathrm{E}+01$ \\
\hline
\end{tabular}


B72

STUDIES OF COLUMBIA GLACIER, ALASKA

$\begin{array}{rrrllr}85 & 7749.9180 & -373.1509 & 0.8030 \mathrm{E}+03 & 0.1561 \mathrm{E}+02 & 0.5488 \mathrm{E}+02 \\ 86 & 7749.9180 & -373.1509 & 0.8030 \mathrm{E}+03 & 0.1561 \mathrm{E}+02 & 0.5538 \mathrm{E}+02 \\ 87 & 7749.9180 & -378.1509 & 0.4069 \mathrm{E}+03 & 0.8168 \mathrm{E}+01 & 0.1701 \mathrm{E}+02 \\ 88 & 7749.9180 & -383.1509 & 0.0 & 0.0 & 0.5629 \mathrm{E}+02 \\ 89 & 8524.9102 & 214.6174 & 0.9552 \mathrm{E}+03 & -0.1915 \mathrm{E}+02 & 0.9557 \mathrm{E}+00 \\ 90 & 8524.9102 & -21.2081 & 0.9497 \mathrm{E}+03 & -0.1881 \mathrm{E}+02 & 0.4678 \mathrm{E}+01 \\ 91 & 8524.9102 & -257.0334 & 0.9224 \mathrm{E}+03 & -0.1738 \mathrm{E}+02 & 0.4242 \mathrm{E}+02 \\ 92 & 8524.9102 & -315.9897 & 0.9030 \mathrm{E}+03 & -0.1636 \mathrm{E}+02 & -0.6280 \mathrm{E}+01 \\ 93 & 8524.9102 & -374.9465 & 0.8762 \mathrm{E}+03 & -0.1495 \mathrm{E}+02 & 0.5280 \mathrm{E}+02 \\ 94 & 8524.9102 & -374.9465 & 0.8762 \mathrm{E}+03 & -0.1495 \mathrm{E}+02 & 0.5290 \mathrm{E}+02 \\ 95 & 8524.9102 & -379.9465 & 0.4469 \mathrm{E}+03 & -0.7574 \mathrm{E}+01 & 0.2188 \mathrm{E}+02 \\ 96 & 8524.9102 & -384.9465 & 0.0 & 0.0 & 0.5378 \mathrm{E}+02 \\ 97 & 9299.9023 & 192.5049 & 0.9525 \mathrm{E}+03 & -0.8651 \mathrm{E}+01 & 0.1247 \mathrm{E}+01 \\ 98 & 9299.9023 & -41.8501 & 0.9479 \mathrm{E}+03 & -0.9233 \mathrm{E}+01 & 0.4868 \mathrm{E}+01 \\ 99 & 9299.9023 & -276.2048 & 0.9116 \mathrm{E}+03 & -0.1030 \mathrm{E}+02 & 0.4240 \mathrm{E}+02 \\ 100 & 9299.9023 & -334.7937 & 0.8873 \mathrm{E}+03 & -0.1063 \mathrm{E}+02 & -0.6387 \mathrm{E}+01\end{array}$

FEAP COLUMBIA GLACIER VERTICAL CENTERLINE PROFILE NODAL DISPLACEMENTS

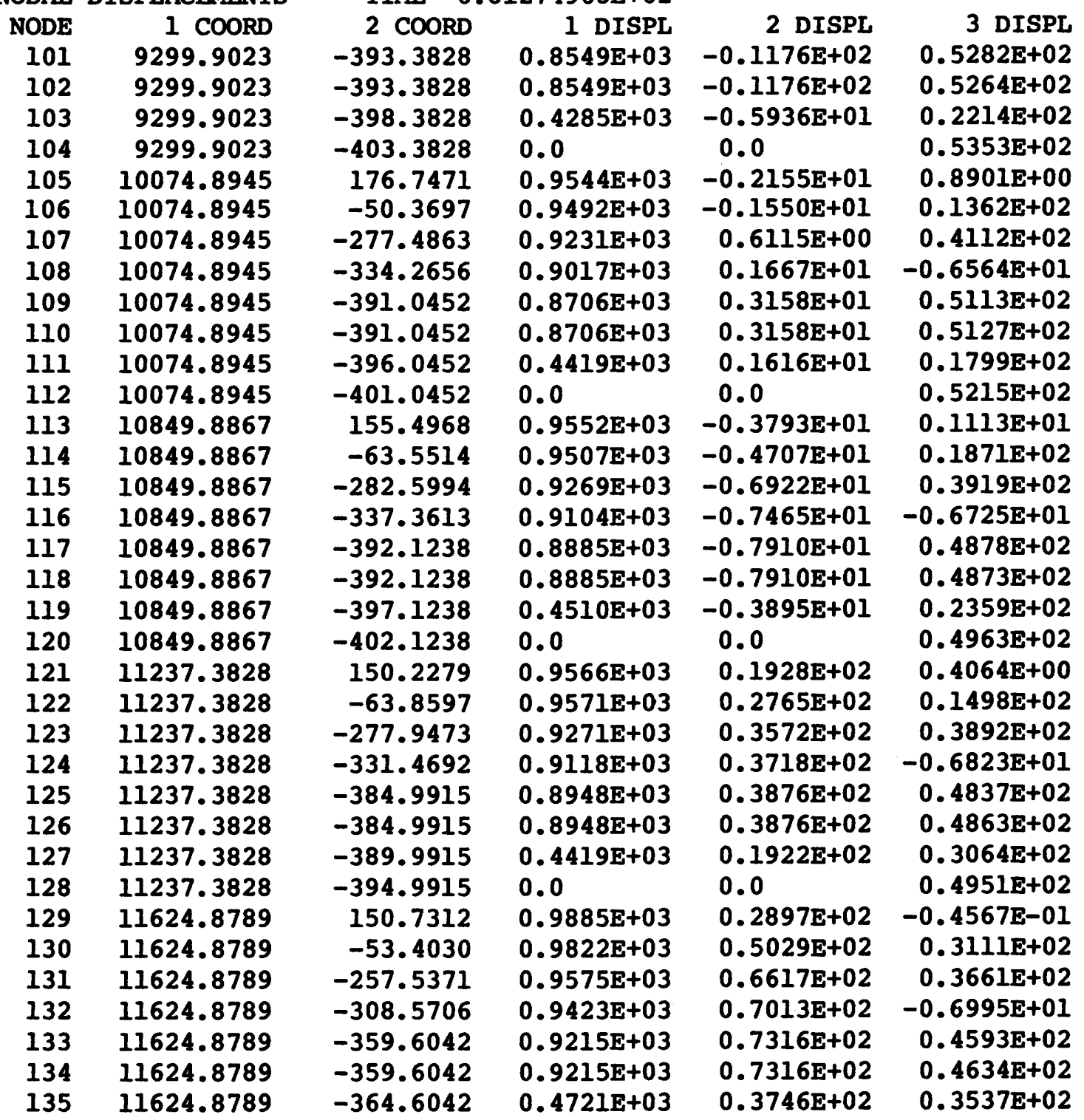


APPENDIX E: SAMPLE RUN

$\begin{array}{rlrllr}136 & 11624.8789 & -369.6042 & 0.0 & 0.0 & 0.4724 \mathrm{E}+02 \\ 137 & 12012.3750 & 142.2204 & 0.1045 \mathrm{E}+04 & 0.1843 \mathrm{E}+02 & -0.1379 \mathrm{E}+00 \\ 138 & 12012.3750 & -45.9574 & 0.1031 \mathrm{E}+04 & 0.4992 \mathrm{E}+02 & 0.3542 \mathrm{E}+02 \\ 139 & 12012.3750 & -234.1351 & 0.9915 \mathrm{E}+03 & 0.7445 \mathrm{E}+02 & 0.3338 \mathrm{E}+02 \\ 140 & 12012.3750 & -281.1792 & 0.9765 \mathrm{E}+03 & 0.7946 \mathrm{E}+02 & -0.7158 \mathrm{E}+01 \\ 141 & 12012.3750 & -328.2241 & 0.9587 \mathrm{E}+03 & 0.8321 \mathrm{E}+02 & 0.4200 \mathrm{E}+02 \\ 142 & 12012.3750 & -328.2241 & 0.9587 \mathrm{E}+03 & 0.8321 \mathrm{E}+02 & 0.4252 \mathrm{E}+02 \\ 143 & 12012.3750 & -333.2241 & 0.4834 \mathrm{E}+03 & 0.4212 \mathrm{E}+02 & 0.3931 \mathrm{E}+02 \\ 144 & 12012.3750 & -338.2241 & 0.0 & 0.0 & 0.4341 \mathrm{E}+02 \\ 145 & 12399.8711 & 133.1550 & 0.1119 \mathrm{E}+04 & 0.1276 \mathrm{E}+02 & -0.1695 \mathrm{E}+00 \\ 146 & 12399.8711 & -36.9271 & 0.1104 \mathrm{E}+04 & 0.4695 \mathrm{E}+02 & 0.4065 \mathrm{E}+02 \\ 147 & 12399.8711 & -207.0090 & 0.1056 \mathrm{E}+04 & 0.7955 \mathrm{E}+02 & 0.3036 \mathrm{E}+02 \\ 148 & 12399.8711 & -249.5296 & 0.1036 \mathrm{E}+04 & 0.8724 \mathrm{E}+02 & -0.7293 \mathrm{E}+01 \\ 149 & 12399.8711 & -292.0505 & 0.1012 \mathrm{E}+04 & 0.9337 \mathrm{E}+02 & 0.3825 \mathrm{E}+02 \\ 150 & 12399.8711 & -292.0505 & 0.1012 \mathrm{E}+04 & 0.9337 \mathrm{E}+02 & 0.3897 \mathrm{E}+02\end{array}$

FEAP COLUMBIA GLACIER VERTICAL CENTERLINE PROFILE

NODAL DISPLACEMENTS

NODE

151

12399.8711

$153 \quad 12787.3672$

$154 \quad 12787.3672$

$155 \quad 12787.3672$

$156 \quad 12787.3672$

$157 \quad 12787.3672$

$158 \quad 12787.3672$

$159 \quad 12787.3672$

$\begin{array}{ll}160 & 12787.3672\end{array}$

$161 \quad 13174.8633$

$162 \quad 13174.8633$

$163 \quad 13174.8633$

$164 \quad 13174.8633$

$165 \quad 13174.8633$

$166 \quad 13174.8633$

$167 \quad 13174.8633$

$168 \quad 13174.8633$

$169 \quad 13368.6094$

$170 \quad 13368.6094$

$171 \quad 13368.6094$

$172 \quad 13368.6094$

$173 \quad 13368.6094$

$174 \quad 13368.6094$

$175 \quad 13368.6094$

$176 \quad 13368.6094$

$177 \quad 13562.3594$

$178 \quad 13562.3594$

$179 \quad 13562.3594$

$180 \quad 13562.3594$

$181 \quad 13562.3594$

$182 \quad 13562.3594$

$183 \quad 13562.3594$

$184 \quad 13562.3594$

$185 \quad 13756.1055$

$186 \quad 13756.1055$
TIME $0.81274963 E+02$

2 COORD 1 DISPL

$-297.0505$

$-302.0505$

118.2029

$-33.4582$

$-185.1193$

$-223.0344$

$-260.9500$

$-260.9500$

$-265.9500$

$-270.9500$

104.6301

$-29.1245$

$-162.8789$

$-196.3176$

$-229.7564$

$-229.7564$

$-234.7564$

$-239.7564$

97.0733

$-24.9426$

$-146.9585$

$-177.4623$

$-207.9665$

$-207.9665$

$-212.9665$

$-217.9665$

92.0420

$-17.4035$

$-126.8490$

$-154.2104$

$-181.5718$

$-181.5718$

$-186.5718$

$-191.5718$

78.2083

$-11.9215$
$0.5201 \mathrm{E}+03$

0.0

$0.1189 \mathrm{E}+04$

$0.1181 E+04$

$0.1139 E+04$

$0.1121 E+04$

$0.1099 E+04$

$0.1099 E+04$

$0.5602 E+03$

0.0

$0.1271 \mathrm{E}+04$

$0.1270 \mathrm{E}+04$

$0.1233 E+04$

$0.1218 \mathrm{E}+04$

$0.1199 E+04$

$0.1199 E+04$

$0.6223 E+03$

0.0

$0.1357 E+04$

$0.1339 E+04$

$0.1291 E+04$

$0.1274 E+04$

$0.1257 \mathrm{E}+04$

$0.1257 \mathrm{E}+04$

$0.6225 E+03$

0.0

$0.1496 \mathrm{E}+04$

$0.1464 \mathrm{E}+04$

$0.1375 E+04$

$0.1351 E+04$

$0.1331 E+04$

$0.1331 E+04$

$0.7400 \mathrm{E}+03$

0.0

$0.1743 E+04$

$0.1707 E+04$
2 DISPL

$0.4817 E+02$

0.0

$0.6555 \mathrm{E}+01$

$0.3665 E+02$

$0.6797 \mathrm{E}+02$

$0.7596 \mathrm{E}+02$

$0.8338 \mathrm{E}+02$

$0.8338 \mathrm{E}+02$

$0.4281 E+02$

0.0

$0.2728 \mathrm{E}+02$

$0.6326 \mathrm{E}+02$

$0.9604 \mathrm{E}+02$

$0.1039 \mathrm{E}+03$

$0.1111 \mathrm{E}+03$

$0.1111 \mathrm{E}+03$

$0.580 \mathrm{lE}+02$

0.0

$0.2381 E+02$

$0.8648 \mathrm{E}+02$

$0.1334 E+03$

$0.1423 E+03$

$0.1504 \mathrm{E}+03$

$0.1504 \mathrm{E}+03$

$0.7506 E+02$

0.0

$-0.5806 \mathrm{E}-01$

$0.1197 \mathrm{E}+03$

$0.2031 E+03$

$0.2184 \mathrm{E}+03$

$0.2276 E+03$

$0.2276 E+03$

$0.1243 E+03$

0.0

$-0.4757 \mathrm{E}+02$

$0.6358 \mathrm{E}+02$
3 DISPL

$0.4056 \mathrm{E}+02$

$0.3987 E+02$

$-0.1346 \mathrm{E}+00$

$0.4326 \mathrm{E}+02$

$0.2667 E+02$

$-0.7505 E+01$

$0.3354 E+02$

$0.3440 \mathrm{E}+02$

$0.4025 \mathrm{E}+02$

$0.3529 E+02$

$-0.3111 E+00$

$0.6827 \mathrm{E}+02$

$0.2384 \mathrm{E}+02$

$-0.7783 \mathrm{E}+01$

$0.2995 E+02$

$0.3087 E+02$

$0.4025 \mathrm{E}+02$

$0.3177 E+02$

$-0.5945 E+00$

$0.5714 E+02$

$0.2130 \mathrm{E}+02$

$-0.7880 \mathrm{E}+01$

$0.2677 \mathrm{E}+02$

$0.2781 E+02$

$0.4025 E+02$

$0.2869 \mathrm{E}+02$

$-0.1345 \mathrm{E}+01$

$0.5321 \mathrm{E}+02$

$0.1920 E+02$

$-0.7935 E+01$

$0.2491 E+02$

$0.2601 E+02$

$0.4025 E+02$

$0.2697 E+02$

$-0.9306 \mathrm{E}+00$

$0.8268 \mathrm{E}+02$ 


$\begin{array}{rlr}187 & 13756.1055 & -102.0513 \\ 188 & 13756.1055 & -124.5837 \\ 189 & 13756.1055 & -147.1162 \\ 190 & 13756.1055 & -147.1162 \\ 191 & 13756.1055 & -152.1162 \\ 192 & 13756.1055 & -157.1162 \\ 193 & 13949.8594 & 62.7661 \\ 194 & 13949.8594 & -10.3158 \\ 195 & 13949.8594 & -83.3978 \\ 196 & 13949.8594 & -101.6682 \\ 197 & 13949.8594 & -119.9387 \\ 198 & 13949.8594 & -119.9387 \\ 199 & 13949.8594 & -124.9387 \\ 200 & 13949.8594 & -129.9387 \\ \text { **MACRO INSTRUCTION 30 EXECUTED** } \\ \text { **MACRO INSTRUCTION 31 EXECUTED** } \\ \text { DATA SET UTIIITY - GENERATE } \\ \text { PROCESSING ENDED AT EOD }\end{array}$

PROCESSING ENDED AT EOD
$0.1595 E+04$
$0.1548 \mathrm{E}+04$
$0.1495 E+04$
$0.1495 E+04$
$0.7126 \mathrm{E}+03$
0.0
$0.1895 E+04$
$0.1965 E+04$
$0.1922 \mathrm{E}+04$
$0.1889 \mathrm{E}+04$
$0.1850 \mathrm{E}+04$
$0.1850 \mathrm{E}+04$
$0.1454 \mathrm{E}+04$
0.0

SAVE

NEXT
$0.1812 \mathrm{E}+03$

$0.2081 E+03$

$0.2310 \mathrm{E}+03$

$0.2310 \mathrm{E}+03$

$0.1115 \mathrm{E}+03$

0.0

$-0.7402 E+02$

$-0.1467 \mathrm{E}+02$

$0.9215 E+02$

$0.1333 E+03$

$0.1682 E+03$

$0.1682 E+03$

$0.1565 E+03$

0.0

$\mathrm{vl}=.0$

$\mathrm{V} 1=1.000$
$0.1544 E+02$

$-0.7941 E+01$

$0.1974 E+02$

$0.2155 E+02$

$0.4025 E+02$

$0.2240 \mathrm{E}+02$

$-0.1078 E+01$

$0.6399 E+02$

$0.1077 E+02$

$-0.7940 E+01$

$0.1576 \mathrm{E}+02$

$0.1780 \mathrm{E}+02$

$0.4025 \mathrm{E}+02$

$0.1928 \mathrm{E}+02$ 


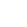


